\title{
Clasificación de los bosques mesófilos de montaña de México: afinidades de la flora
}

\section{Classification of the Mexican cloud forests: floristic affinities}

\author{
Carlos Alberto Ruiz-Jiménez ${ }^{1,3 凶}$, Oswaldo Téllez-Valdés ${ }^{2}$ e Isolda Luna-Vega ${ }^{1}$ \\ ${ }^{\prime}$ Laboratorio de Biogeografia y Sistemática,Departamento de Biología Evolutiva, Facultad de Ciencias, Universidad Nacional Autónoma de México. \\ Apartado postal 70-399, 04510 México, D. F., México \\ ${ }^{2}$ Laboratorio de Recursos Naturales, Unidad de Biología, Tecnología y Prototipos, Facultad de Estudios Superiores Iztacala, Universidad Nacional \\ Autónoma de México. Apartado postal 314, Av. De los Barrios 1, Los Reyes Iztacala, 54090 Tlalnepantla, Estado de México. \\ ${ }^{3}$ Posgrado en Ciencias Biológicas, Facultad de Ciencias, Universidad Nacional Autónoma de México. Apartado postal 70-399, 04510 México, D. F. \\ México. \\ 凶ruiz.jimenez.carlos@gmail.com
}

\begin{abstract}
Resumen. Se realizó un análisis de clasificación numérica para comparar las semejanzas florístico-geográficasbioclimáticas de los bosques mesófilos de montaña (BMM) de México. Con base en publicaciones de carácter florístico, de vegetación y sinecológico se obtuvo una base de datos de la flora vascular del BMM que contiene 6 453 especies, 1426 géneros y 213 familias. La matriz de presencia-ausencia consta de 2856 especies (180 familias, 897 géneros) distribuidas en 83 localidades; la clasificación se realizó mediante un análisis de conglomerados, utilizando índices de similitud; se agrupó con el método UPGMA y se construyeron dendrogramas. Con BIOCLIM se obtuvo el perfil bioclimático de cada grupo y con el promedio de las variables se generó una matriz que se clasificó como la anterior. La importancia de las variables bioclimáticas fue evaluada mediante un análisis de ordenación por componentes principales. Los grupos florísticamente similares se ajustan a las provincias florísticas de México y los perfiles bioclimáticos respaldan dichas agrupaciones. Por sus características bioclimáticas, los BMM se agrupan en 3 conjuntos de localidades. Se sustenta que las localidades geográficamente más cercanas presentan mayor similitud florística. Conforme se genera más información sobre el BMM de México se refuerzan las hipótesis de relación entre las provincias florísticas.
\end{abstract}

Palabras clave: análisis multivariado, análisis de ordenación, bioclim, dendrograma, índice de similitud, provincias florísticas.

\begin{abstract}
A numerical classification analysis was made to compare the floristic-geographic-bioclimatic resemblance among Mexico's cloud forest (MCF). A MCF vascular flora database was made based on floristics, vegetation and sinecological published work; which contains 6453 species, 1426 genera and 213 families. The presence-absence matrix consists of 2856 species ( 180 families and 897 genera) scattered through 83 localities; this was rated by means of a conglomerate analysis using the similarity indexes this was put together using the UPGMA method; dendrograms were also made. The bioclimatic profile of each group was obtained using BIOCLIM, the variable average was used to generate a matrix which was rated like the previous one. Based on the order analysis the importance of bioclimatic variables was evaluated through its main component. The floristical similar groups match Mexico's floristic provinces and bioclimatic profiles which back up such groupings. Based on their bioclimatic features the MCF are rated on three groups of localities. It has been noticed that the closer localities are geographically they exhibit greater floristic similarities. Based on the research of the MCF relationships among floristic provinces we reach stronger hypothesis.
\end{abstract}

Key words: multivariate analysis, ordination analysis, bioclim, dendrogram, similarity index, floristic provinces.

\section{Introducción}

En México, el bosque mesófilo de montaña (BMM) es el tipo de vegetación con mayor riqueza florística por unidad de área. Se estima que es hábitat de más de 6790 especies de plantas vasculares y cerca del $34.8 \%$ son

Recibido: 11 enero 2012; aceptado: 03 mayo 2012 endémicas (Villaseñor, 2010). Se calcula que el área que cubre el BMM no sobrepasa el 1\% del territorio nacional (Rzedowski, 1978, 1991; Palacio-Prieto et al., 2000). Su distribución fragmentaria se limita a zonas montañosas con topografía de pendientes pronunciadas, en particular cañadas y zonas protegidas de radiación solar y vientos fuertes (Rzedowski, 1978). Las zonas donde se distribuye presentan variaciones altitudinales, edáficas y climáticas, 
que interactúan a su vez con características locales, como la orientación, la pendiente, la altitud, la latitud, la nubosidad, y la humedad del aire y del suelo; tales factores actúan sobre la vegetación provocando variabilidad florística, fisonómica y estructural, de tal modo que la información obtenida de esta comunidad es difícil de interpretar y de someter a generalizaciones (Rzedowski, 1978, 1991; RuizJiménez et al., 2000).

La composición florística, estructura y fisonomía de los BMM mexicanos varía dependiendo de la región donde se encuentra y considerando que la velocidad a la que se ha deteriorado esta comunidad vegetal en los últimos años, ha sido excesiva, por lo anterior, es urgente que se realicen estudios detallados, sobre todo en áreas poco conocidas. Estas investigaciones deberán enfocarse hacia el conocimiento de la composición florística, el inventario de las asociaciones del bosque, la distribución de especies exclusivas/o diagnósticas; y en enfatizar la importancia de la dinámica, la estructura y las variables que le proporcionan sus peculiares rasgos fisonómicos.

Por lo anterior, y con la finalidad de contribuir al conocimiento del BMM, en este estudio se plantea el objetivo de analizar algunas localidades de BMM de México utilizando métodos de clasificación mediante las semejanzas florísticas y de las variables ambientales (bioclimáticas).

\section{Materiales y métodos}

Se construyó una base de datos de la flora vascular del BMM de México (Fig. 1 y Apéndice), que incluye angiospermas, gimnospermas y helechos y está compuesta por 213 familias, 1426 géneros y 6453 especies. Esta base fue depurada para evitar sinonimias y suprimir especies introducidas. Asimismo, se eliminaron las especies presentes en una sola localidad y los taxa no identificados hasta especie porque la información que proporcionan sobre su distribución no es precisa. Se generó, así, una matriz de presencia-ausencia compuesta por 83 localidades. La matriz final incluye 2856 especies, pertenecientes a 180 familias y 897 géneros.

La base de datos se elaboró a partir de la información que se obtuvo de los estudios florísticos, estructurales y ecológicos de Carlson (1954), Gómez-Pompa (1966), Rzedowski (1966), Rzedowski y McVaugh (1966), Rzedowski (1969), Chiang (1970), Álvarez del Castillo (1977), Rzedowski y Palacios-Chávez (1977), Vargas (1982), Ibarra (1983), Puig et al. (1983), Reyes y Breceda (1985), Ballesteros (1986), Puig y Bracho (1987), García et al. (1988), Ishiki (1988), Luna-Vega et al. (1988), Martínez (1988), Luna-Vega et al. (1989), Machuca (1989), Puig (1989), Fragoso (1990), Madrigal (1990), Madrigal y Guridi (inédito [1990]), Briones (1991), Long y Heath
(1991), Torres (1991), Williams-Linera (1991), Croda (1992), Díaz-Barriga y Palacios-Ríos (1992), Durán (1992), Meave et al. (1992), Muñoz (1992), Santiago (1992), Zamora (1992), Zamudio et al. (1992), Campos (1993), Jiménez et al. (1993), Medina y Rodríguez (1993), Miranda y González (1993), Santiago y Jardel (1993), Tolomé (1993), Ahumada (1994), Arriaga (1994), Blanco (1994), Cuevas (1994), Luna-Vega et al. (1994), Campos-Villanueva y Villaseñor (1995), Labat (1995), López (1995), Orozco (1995),

Ruiz-Jiménez (1995), Smith (1995), Téllez-Valdez (1995), Vázquez et al. (1995), Alcántara (1996), Boyle (1996), Castillo (1996), Pérez-Calix (1996), WilliamsLinera et al. (1996), Alcántara y Luna-Vega (1997), Fernández y Colmenero (1997), López (1997), Luna (1997), García et al. (1998), Mayorga et al. (1998), Ramírez-Marcial et al. (1998), Ramírez (1999), RamírezMarcial et al. (inédito [1999]), Vázquez-García et al. (1999), Arellanes (2000), Mascarúa (2000), Medina et al. (2000), Ruiz-Jiménez et al. (2000), Vázquez (2000), Zarco (2000), Alcántara y Luna-Vega (2001), Blanco (2001), Diego-Pérez et al. (2001), Fonseca et al. (2001), Hernández (2001), Sánchez (2001), Acosta (2002), Cartujano et al. (2002), Cuevas (2002), Sánchez-Rodríguez (2002), Cornejo-Tenorio et al. (2003), Lozada et al. (2003), Mejía (2003), Osorio (2003), Reyes (2003), Sánchez-Rodríguez et al. (2003), Valdez et al. (2003), Ávila (2004), Catalán (2004), Escutia (2004), Martínez et al. (2004), Peterson et al. (2004), Quintos et al. (2004), Reynoso (2004), Sahagún (2004), Lorea (2005), Mendoza et al. (2005), Ruiz-Jiménez et al. (2005), Vargas (2005), Ávila (2006), Montalvo (2006), Ponce-Vargas et al. (2006), Santiago (2006), Vázquez et al. (2006), Rincón (2007), Ávila et al. (2008), Gallardo et al. (2008), García-Franco et al. (2008), García-Franco y Toledo (2008), Juárez (2008), Martínez-Meléndez et al. (2008), Padilla et al. (2008), Mehltreter (2008), Williams-Linera y López-Gómez (2008), Castillo-Campos y Luna (2009), y Saavedra-Millán (2009).

Cada localidad con BMM se consideró como 1 unidad geográfica operativa (UGO; Crovello, 1981); en el caso de localidades que contaran con 2 o más estudios, las especies se agruparon formando 1 sola UGO. En total, las UGO que se consideraron fueron 83 .

Mediante técnicas de análisis multivariado (análisis de conglomerados) se establecieron las semejanzas florísticas entre las 83 UGO con ayuda del programa PC-ORD versión 5 (McCune y Mefford, 2006). Para tal análisis de agrupamiento se emplearon los índices de similitud de Sorensen (Bray-Curtis) y el de Jaccard, por la solidez de ambos. El índice de Sorensen (Bray-Curtis) considera el desequilibrio entre 0 y 1 (siempre con más 0 que 1); el de Jaccard es reco- 


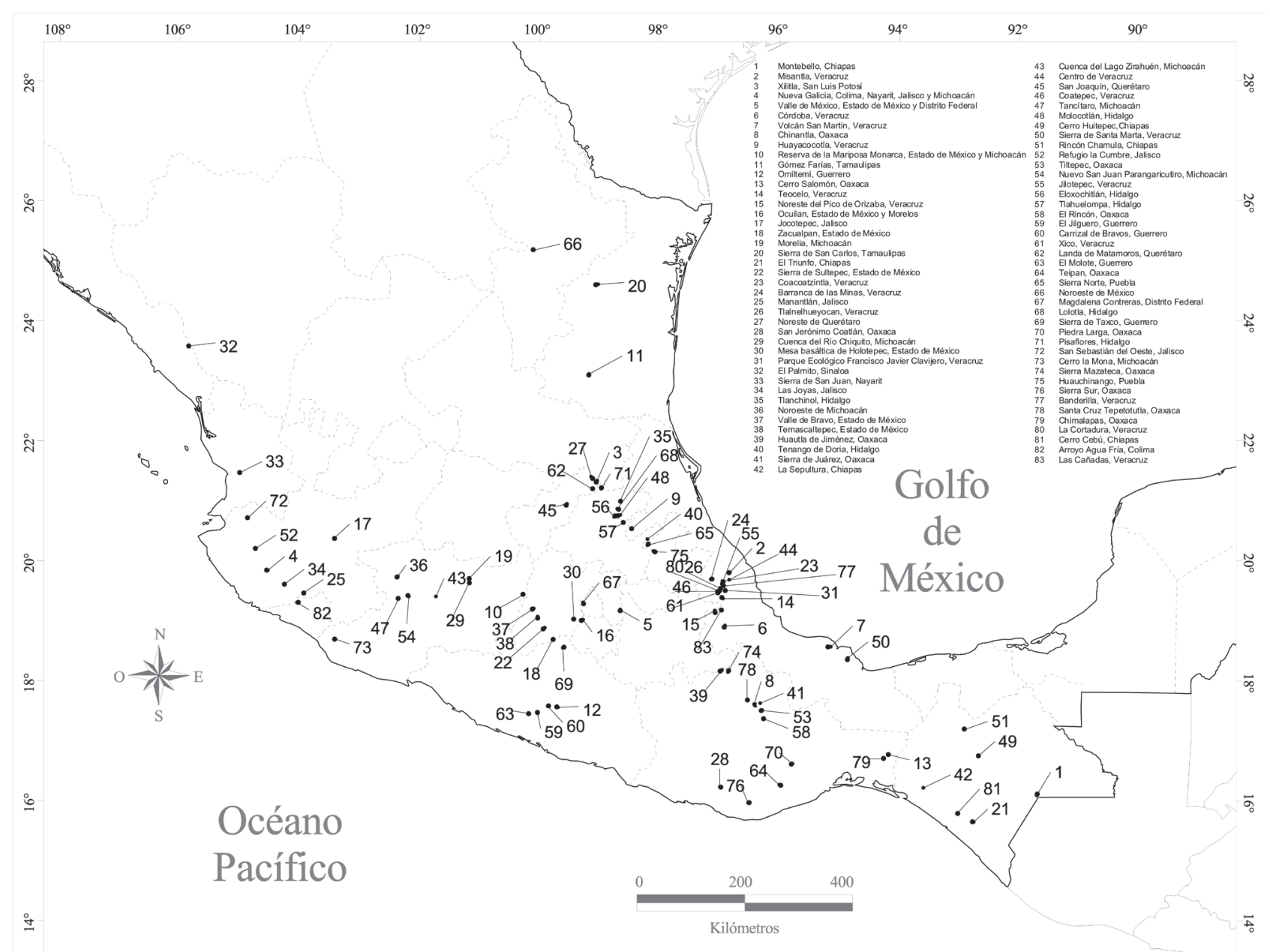

Figura 1. Ubicación geográfica de diferentes localidades del BMM en México.

mendable para analizar matrices binarias (J. L.Villaseñor, com. pers.). Los valores de semejanza obtenidos se utilizaron para construir un dendrograma mediante el método de promedio de grupo no ponderado, utilizando la media aritmética (UPGMA; McCune y Mefford, 2006). Con el programa ANUCLIM (Houlder et al., 2000) se generó el perfil bioclimático de los grupos identificados en el dendrograma, mediante el algoritmo BIOCLIM (Cuadro 2). Posteriormente, se elaboró una matriz de los grupos y se obtuvo el promedio de las variables bioclimáticas. Con el programa PC-ORD versión 5 (McCune y Mefford, 2006) se realizó una clasificación (cluster analysis) empleando la distancia euclideana y como método de unión de grupo, el del promedio de grupo (UPGMA; McCune y Mefford, 2006). Los valores de semejanza obtenidos se utilizaron para construir un dendrograma. Finalmente, se realizó un análisis de componentes principales (ACP) basado en la matriz de varianza/covarianza para obtener la ordenación de los grupos y subgrupos e interpretar la importancia de las variables bioclimáticas.

\section{Resultados}

En la figura 1 se indica la ubicación geográfica de las 83 UGO de BMM consideradas en el estudio. El análisis de agrupamiento permitió identificar 13 grupos y subgrupos en los dendrogramas (Fig. 2). Los 13 grupos (A-M) se delimitaron considerando un valor de corte mínimo de $44.3 \%$ de la información remanente. Estos grupos corresponden, de manera general, a las provincias florísticas de México (sensu Rzedowski, 1978; Rzedowski y Trujillo, 1990) y a las subprovincias geológicas de Ferrusquía-Villafranca (1998) (Cuadro 1).

El dendrograma generado con los índices de similitud muestra una topología general similar, las principales diferencias se presentan en la estructura interna de asociación 
Información remanente $(\%)$

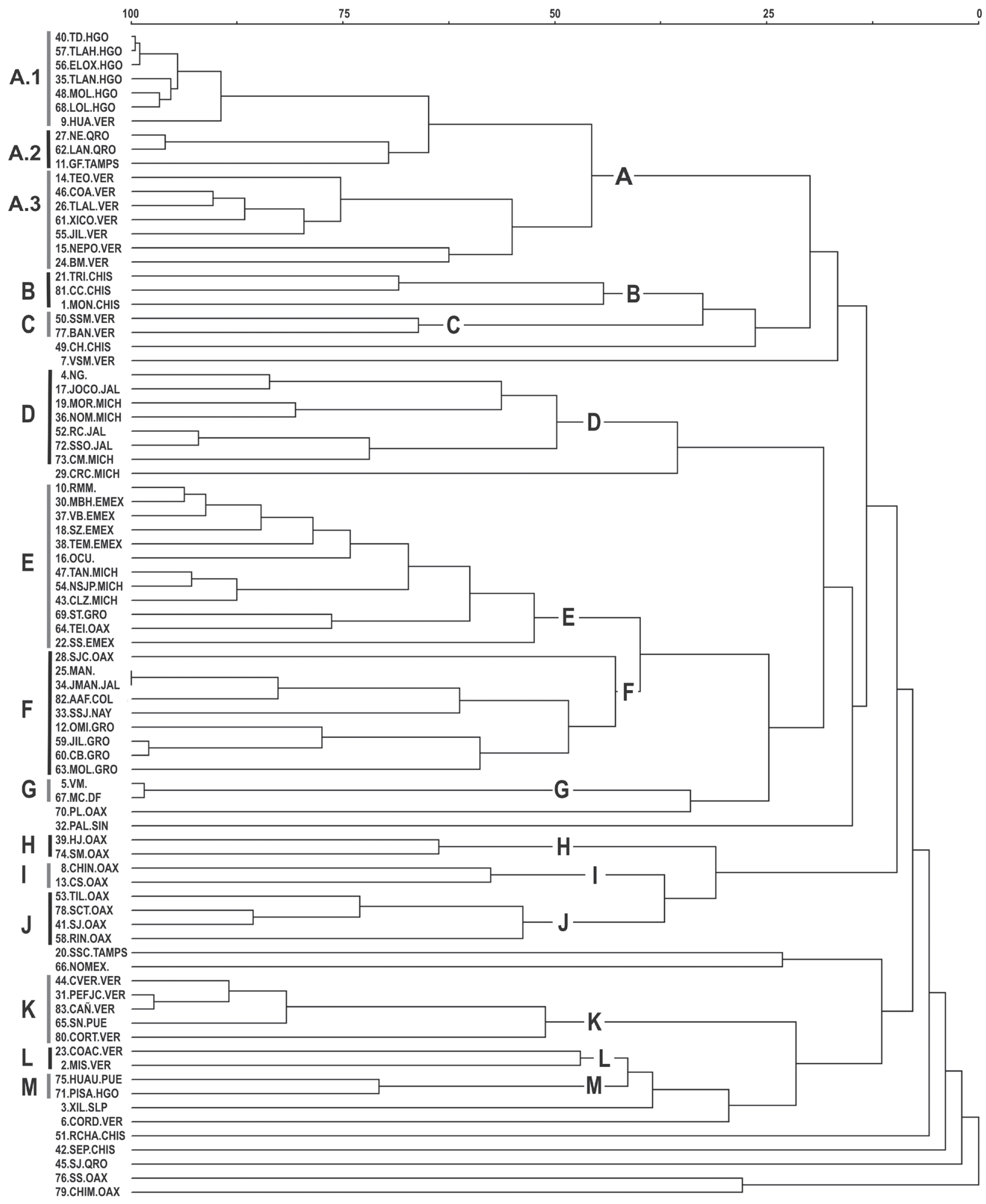

Figura 2. Dendrograma de la similitud florística de las 83 UGO de BMM mediante el índice de similitud de Sorensen (Bray-Curtis). 
del grupo D y en que el dendrograma creado con el índice de Sorensen (Bray-Curtis; Fig.2) presenta mayores porcentajes de similitud entre los grupos, que el obtenido con el índice de Jaccard.

El grupo A incluye los BMM de 2 provincias florísticas sensu Rzedowski (1978) y Rzedowski y Reyna-Trujillo (1990): la Sierra Madre Oriental (en lo sucesivo SMO) y las Serranías Meridionales (SM) del centro de Veracruz. El grupo se subdividió en 3 subgrupos. El A1 (Fig. 3a), al centro de la SMO, incluye 6 BMM de Hidalgo y el de Hauyacocotla, Veracruz (con 90\% de similitud florística); el A2 (Fig. 3a), al norte de la SMO, incluye los BMM de Querétaro y el de Gómez Farías, Tamaulipas (70\% de similitud) y el subgrupo A3 (Fig. 3a), al sur de la SMO, que incluye 7 BMM del centro de Veracruz (55\% de similitud) (Fig. 2).

Para cada grupo se seleccionaron las especies arbóreas representativas (Apéndice) con base en el índice de frecuencia (Braun-Blanquet, 1932); se consideraron exclusivamente las presentes en más del $60 \%$ de las UGO del grupo (clase IV, 61 a 80\%; clase V, 81 a 100\%).

El grupo A posee una alta diversidad florística en la sinusia arbórea, las especies representativas del grupo son: Carpinus caroliniana, Liquidambar styraciflua, Sambucus nigra var. canadensis y Xylosma flexuosa. Las especies diagnósticas del estrato arbóreo del subgrupo A1 se presentan en el Apéndice; de ellas, las inscritas en alguna categoría de riesgo para su conservación son: $C$. caroliniana y Magnolia schiedeana (amenazadas - A) y Acer negundo var. mexicanum, Cyathea fulva, Ostrya virginiana y Podocarpus matudae (sujetas a protección especial - Pr). Los bosques se distribuyen en áreas con temperatura promedio anual de $17.1^{\circ} \mathrm{C}$, precipitación anual de $2385 \mathrm{~mm}$, en un intervalo altitudinal de 730 a $2500 \mathrm{~m} \mathrm{snm}$. (Cuadro 3).

En el subgrupo A2, dentro del estrato arbóreo representativo (Apéndice) se presentan las siguientes especies en categorías de riesgo: C. caroliniana y M. schiedeana (A), Litsea glaucescens y M.dealbata (en peligro de extinciónP), Alsophila firma, O. virginiana y Taxus globosa (sujetas a protección especial - Pr). Los bosques se distribuyen en áreas con temperatura promedio anual de $20.7^{\circ} \mathrm{C}$, precipitación anual de $1048 \mathrm{~mm}$, en un intervalo altitudinal de 600 a $2650 \mathrm{~m}$ snm (Cuadro 3).

El subgrupo A3 presenta un estrato arbóreo variado (Apéndice), en él se encuentran las siguientes especies en alguna categoría de riesgo: C. caroliniana (A) y $L$. glaucescens $(\mathrm{P})$. Los bosques se distribuyen en áreas con temperatura promedio anual de $16.2^{\circ} \mathrm{C}$, precipitación anual de $1541 \mathrm{~mm}$, en un intervalo altitudinal de 895 a 2 $690 \mathrm{~m} \mathrm{snm}$ (Cuadro 3).

El grupo B (Fig. 3b) está integrado por 3 bosques ubicados en el Soconusco y las Serranías Transístmicas de Chiapas (Rzedowski, 1978; Rzedowski y Reyna-Trujillo, 1990), con 45\% de similitud florística. Las especies representativas del estrato arbóreo (Apéndice) incluidas en alguna categoría de riesgo son: C. fulva y P. matudae (Pr). Los bosques se distribuyen en áreas con temperatura promedio anual de $17.9^{\circ} \mathrm{C}$, precipitación anual de 1861 $\mathrm{mm}$, en un intervalo altitudinal de 1000 a $2980 \mathrm{~m} \mathrm{snm}$ (Cuadro 3).

El grupo C (Fig. 3b) conjunta los BMM ubicados en Golfo de México, Sierra de Santa Martha y una localidad de la SMO, Banderilla, Veracruz (Rzedowski, 1978; Rzedowski y Reyna-Trujillo, 1990; Fig. 1), con 66\% de similitud florística. Los árboles dominantes son: C. caroliniana (A), A. firma, Cyathea bicrenata y Cyathea divergens var. tuerckheimii (Pr). Los bosques se distribuyen en áreas con temperatura promedio anual de $20.3^{\circ} \mathrm{C}$, precipitación anual de $2405 \mathrm{~mm}$, en un intervalo altitudinal de 1040 a 1 $610 \mathrm{~m} \mathrm{snm}$ (Cuadro 3).

El grupo D (Fig. 3d) incluye los bosques de Serranías Meridionales de Jalisco y Michoacán (Rzedowski, 1978; Rzedowski y Reyna-Trujillo, 1990), con 50\% de similitud florística. Los árboles más notables son C. caroliniana (A) y Tilia americana var. mexicana (P). Los bosques se distribuyen en áreas con temperatura promedio anual de $18.9^{\circ} \mathrm{C}$, precipitación anual de $1102 \mathrm{~mm}$, en un intervalo altitudinal que va de los 780 a $2625 \mathrm{~m} \mathrm{snm}$ (Cuadro 3).

El grupo E (Fig. 3c) integra los bosques de Serranías Meridionales en los estados de México, Guerrero, Michoacán, Morelos (Rzedowski, 1978; Rzedowski y Reyna-Trujillo, 1990) y una localidad de la Sierra Madre del Sur de Oaxaca (Fig. 2), con 53\% de similitud florística. La especie arbórea predominante es C. caroliniana (A). Los bosques se distribuyen en áreas con temperatura promedio anual de $13.6^{\circ} \mathrm{C}$, precipitación anual de $999 \mathrm{~mm}$, en un intervalo altitudinal que va de 1000 a $2950 \mathrm{~m} \mathrm{snm}$ (Cuadro 3).

El grupo F (Fig. 3d) conjunta los bosques de Serranías Meridionales de Guerrero, Colima, Jalisco, Oaxaca y Nayarit (Rzedowski, 1978; Rzedowski y Reyna-Trujillo, 1990), con $43 \%$ de similitud florística. Los árboles representativos son C. caroliniana (A), O. virginiana (Pr), Saurauia serrata $(\mathrm{Pr})$ y Zinowiewia concinna $(\mathrm{P})$. Los bosques se distribuyen en áreas con temperatura promedio anual de $22.3^{\circ} \mathrm{C}$, precipitación anual de $1318 \mathrm{~mm}$, en un intervalo altitudinal de 775 a $2900 \mathrm{~m} \mathrm{snm}$ (Cuadro 3).

El grupo G (Fig. 3a) integra 2 bosques ubicados en Serranías Meridionales dentro de los límites del Valle de México (Iztaccíhuatl y Magdalena Contreras), con 99\% de similitud florística. El árbol representativo del grupo, que está incluido en la NOM-059-SEMARNAT-2010 (SEMARNAT, 2010), es A. negundo var. mexicanum (Pr). Los bosques se distribuyen en áreas con temperatura 
Cuadro 3. Perfiles bioclimáticos de los grupos de árboles encontrados en este estudio. El número de la izquierda corresponde al parámetro enunciado en el Cuadro 1. Se ofrecen valores máximos y mínimos; entre paréntesis el promedio y la desviación estándar

\begin{tabular}{|c|c|c|c|c|}
\hline & A1 & $\mathrm{A} 2$ & A3 & $\mathrm{B}$ \\
\hline 1 & $13.5-21.8(17.1 \pm 1.93)$ & $15.1-23.4(20.70 \pm 1.12)$ & $10.9-20.6(16.20 \pm 2.22)$ & $10.9-21.9(17.90 \pm 1.9)$ \\
\hline 2 & $9.6-13(11.5 \pm 0.79)$ & $10.3-16.3(14.10 \pm 0.74)$ & $8.7-12.6(10.70 \pm 0.77)$ & $8.4-15(11.80 \pm 1.66)$ \\
\hline 3 & $0.55-0.63(0.59 \pm 0.02)$ & $0.55-0.62(0.59 \pm 0.01)$ & $0.57-0.68(0.62 \pm 0.03)$ & $0.61-0.76(0.70 \pm 0.05)$ \\
\hline 4 & $0.57-1.11(0.76 \pm 0.09)$ & $0.79-1.23(1.06 \pm 0.1)$ & $0.49-0.84(0.65 \pm 0.06)$ & $0.27-0.55(0.38 \pm 0.06)$ \\
\hline 5 & $22.8-32.6(26.8 \pm 2.08)$ & $25-35.4(32.10 \pm 1.28)$ & $19.6-29.3(24.70 \pm 2.14)$ & $20-30.7(26 \pm 1.81)$ \\
\hline 6 & $4.6-10(7.2 \pm 1.43)$ & $5.1-10.6(8.10 \pm 1.24)$ & $2.1-11.3(7.50 \pm 2.19)$ & $-0.3-12.6(9.30 \pm 2.55)$ \\
\hline 7 & $17.4-22.6(19.6 \pm 1.1)$ & $18.7-26.4(23.90 \pm 0.96)$ & $15.3-18.9(17.30 \pm 0.71)$ & $13.8-20.3(16.80 \pm 1.44)$ \\
\hline 8 & $14-24.3(18.4 \pm 2.25)$ & $16.1-25.8(23.10 \pm 1.12)$ & $11.5-22.2(17.30 \pm 2.49)$ & $11.8-22.6(18.50 \pm 1.86)$ \\
\hline 9 & $11.8-17.6(14.7 \pm 1.42)$ & $12-20.8(17 \pm 1.68)$ & $9.4-17.7(14.20 \pm 1.81)$ & $9.6-20.2(16.90 \pm 1.92)$ \\
\hline 10 & $15.6-25.2(19.5 \pm 2.07)$ & $17.8-27.1(23.90 \pm 1.22)$ & $12.6-23(18.20 \pm 2.35)$ & $11.8-23.7(19.10 \pm 2.06)$ \\
\hline 11 & $11.2-17.1(14 \pm 1.53)$ & $12-18.5(16.20 \pm 1.12)$ & $9-17.3(13.50 \pm 1.95)$ & $9.6-19.7(16.30 \pm 1.75)$ \\
\hline 12 & $940-2385(1569.4 \pm 317.1)$ & $570-1589(1048 \pm 188)$ & $821-2110(1541 \pm 205.61)$ & $1089-2697(1861 \pm 376.41)$ \\
\hline 13 & $48-143(87.8 \pm 19.0)$ & $30-104(57 \pm 12.4)$ & $43-102(74 \pm 8.83)$ & $53-117(86 \pm 14.89)$ \\
\hline 14 & $0-12(1.8 \pm 4.14)$ & $(0)$ & $0-16(5 \pm 5.52)$ & $(0)$ \\
\hline 15 & $68-85(80.1 \pm 1.86)$ & $76-97(84 \pm 2.93)$ & $62-80(69 \pm 3.12)$ & $66-96(83 \pm 8.4)$ \\
\hline 16 & $469-1201(798.2 \pm 159.72)$ & $286-819(543 \pm 83.93)$ & $404-1060(715 \pm 96.76)$ & $521-1340(922 \pm 195.69)$ \\
\hline 17 & $48-175(109.0 \pm 28.7)$ & $27-117(64 \pm 13.52)$ & $70-225(148 \pm 21.8)$ & $0-188(65 \pm 51.66)$ \\
\hline 18 & $240-689(426.3 \pm 102.09)$ & $193-537(401 \pm 50.05)$ & $225-650(440 \pm 78.52)$ & $433-683(549 \pm 41.85)$ \\
\hline \multirow[t]{2}{*}{19} & $52-196(123.4 \pm 33.43)$ & $31-136(70 \pm 17.37)$ & $72-246(159 \pm 23.8)$ & $17-367(99 \pm 99.18)$ \\
\hline & $\mathrm{C}$ & $\mathrm{D}$ & $\mathrm{E}$ & $\mathrm{F}$ \\
\hline 1 & $17.1-22(20.30 \pm 1.18)$ & $14.5-23.9(18.90 \pm 2.91)$ & $13-14.5(13.6 \pm 0.48)$ & $14.6-26.9(22.30 \pm 1.72)$ \\
\hline 2 & $7.7-9.9(8 \pm 0.61)$ & $11.8-19.9(15.90 \pm 2.47)$ & $13.2-16.1(14.4 \pm 0.83)$ & $10.6-16.8(14 \pm 1.49)$ \\
\hline 3 & $0.52-0.6(0.54 \pm 0.02)$ & $0.59-0.7(0.67 \pm 0.03)$ & $0.66-0.69(0.68 \pm 0.01)$ & $0.63-0.75(0.67 \pm 0.02)$ \\
\hline 4 & $0.6-0.67(0.64 \pm 0.02)$ & $0.36-0.81(0.67 \pm 0.13)$ & $0.52-0.63(0.58 \pm 0.03)$ & $0.25-0.85(0.52 \pm 0.11)$ \\
\hline 5 & $25.1-30.3(28.20 \pm 1.19)$ & $26.1-33.8(30.70 \pm 1.94)$ & $22.7-25.6(23.8 \pm 0.91)$ & $21.8-39.3(32.60 \pm 2.3)$ \\
\hline 6 & $9-14.9(13.40 \pm 1.58)$ & $2.3-14.7(6.80 \pm 4.03)$ & $2.1-3.1(2.5 \pm 0.25)$ & $7.5-14.9(11.60 \pm 1.97)$ \\
\hline 7 & $14.1-16.6(14.90 \pm 0.58)$ & $17.2-28.4(23.90 \pm 3.33)$ & $19.9-23.5(21.3 \pm 1.08)$ & $14.3-26.1(21.10 \pm 2.5)$ \\
\hline 8 & $18.3-23.2(21.50 \pm 1.18)$ & $16.2-24.9(20.30 \pm 2.89)$ & $13.7-15.7(14.6 \pm 0.61)$ & $14.6-28.3(23.10 \pm 1.87)$ \\
\hline 9 & $15-22.8(20.80 \pm 2.1)$ & $13.6-23(18.30 \pm 3.02)$ & $10.7-12(11.3 \pm 0.41)$ & $13.8-26.9(21.90 \pm 2.02)$ \\
\hline 10 & $19.2-24.1(22.30 \pm 1.18)$ & $17.3-25.3(21.10 \pm 2.54)$ & $14.8-16.4(15.5 \pm 0.52)$ & $15.6-29.3(24.10 \pm 1.85)$ \\
\hline 11 & $14.4-19.1(17.60 \pm 1.17)$ & $11.4-22.1(16.20 \pm 3.26)$ & $10.7-11.9(11.2 \pm 0.36)$ & $13.7-23.8(20.20 \pm 1.66)$ \\
\hline 12 & $1530-2743(2405 \pm 323.48)$ & $800-1296(1102 \pm 160.1)$ & $847-1085(999 \pm 85.06)$ & $720-1693(1318 \pm 168.8)$ \\
\hline 13 & $71-115(98 \pm 10.81)$ & $47-84(67 \pm 11.76)$ & $42-60(53 \pm 7.26)$ & $44-100(75 \pm 10.4)$ \\
\hline 14 & $0-11(1 \pm 3.46)$ & $(0)$ & $(0)$ & $(0)$ \\
\hline 15 & $66-70(68 \pm 1.67)$ & $99-115(106 \pm 4.14)$ & $90-99(95 \pm 3.55)$ & $95-120(105 \pm 5.1)$ \\
\hline 16 & $691-1305(1115 \pm 159.99)$ & $506-866(714 \pm 118.14)$ & $480-663(592 \pm 69.86)$ & $469-1056(820 \pm 104.56)$ \\
\hline 17 & $138-170(156 \pm 6.88)$ & $0-30(7 \pm 12.15)$ & $27-38(33 \pm 3.04)$ & $0-38(11 \pm 14.74)$ \\
\hline 18 & $460-655(577 \pm 52.74)$ & $240-700(429 \pm 171.67)$ & $260-311(297 \pm 13.81)$ & $191-801(419 \pm 127.22)$ \\
\hline 19 & $164-350(306 \pm 52.46)$ & $32-65(47 \pm 12.59)$ & $27-38(33 \pm 3.1)$ & $12-104(51 \pm 14.58)$ \\
\hline
\end{tabular}


Cuadro 3. Continúa

\begin{tabular}{|c|c|c|c|c|}
\hline & G & $\mathrm{H}$ & I & $\mathrm{J}$ \\
\hline 1 & $13-14.5(13.6 \pm 0.48)$ & $13.3-21.9(15.80 \pm 2.33)$ & $15.1-20.7(18.20 \pm 1.36)$ & $12.2-20(17.60 \pm 2.28)$ \\
\hline 2 & $13.2-16.1(14.4 \pm 0.83)$ & $10.6-13.3(11.50 \pm 0.56)$ & $10.6-13.2(12.20 \pm 0.68)$ & $9.2-13.3(12.10 \pm 0.84)$ \\
\hline 3 & $0.66-0.69(0.68 \pm 0.01)$ & $0.61-0.69(0.65 \pm 0.03)$ & $0.61-0.66(0.63 \pm 0.01)$ & $0.57-0.68(0.63 \pm 0.02)$ \\
\hline 4 & $0.52-0.63(0.58 \pm 0.03)$ & $0.39-0.71(0.52 \pm 0.09)$ & $0.48-0.65(0.58 \pm 0.05)$ & $0.41-0.69(0.58 \pm 0.07)$ \\
\hline 5 & $22.7-25.6(23.8 \pm 0.91)$ & $21.8-32.6(25.10 \pm 2.58)$ & $25.1-29.7(28.20 \pm 1.32)$ & $21.2-30.4(27.50 \pm 2.54)$ \\
\hline 6 & $2.1-3.1(2.5 \pm 0.25)$ & $6-11.7(7.40 \pm 1.82)$ & $6.3-12.5(8.90 \pm 1.45)$ & $5.2-11.1(8.40 \pm 1.68)$ \\
\hline 7 & $19.9-23.5(21.3 \pm 1.08)$ & $15.9-20.9(17.70 \pm 0.97)$ & $16.3-21(19.30 \pm 1.29)$ & $16-21(19.10 \pm 1.32)$ \\
\hline 8 & $13.7-15.7(14.6 \pm 0.61)$ & $13.4-23(16.20 \pm 2.63)$ & $15.2-22(18.80 \pm 1.66)$ & $12-21.1(18 \pm 2.61)$ \\
\hline 9 & $10.7-12(11.3 \pm 0.41)$ & $13.3-21(15.60 \pm 2.13)$ & $15-19.9(17.50 \pm 1.14)$ & $12.4-19.1(16.90 \pm 1.89)$ \\
\hline 10 & $14.8-16.4(15.5 \pm 0.52)$ & $14.9-24.4(17.80 \pm 2.55)$ & $17.2-22.3(20.30 \pm 1.35)$ & $14-22.4(19.80 \pm 2.41)$ \\
\hline 11 & $10.7-11.9(11.2 \pm 0.36)$ & $12-19(13.80 \pm 1.9)$ & $13.5-18.5(16 \pm 1.15)$ & $11-17.6(15.40 \pm 1.87)$ \\
\hline 12 & $847-1085(999 \pm 85.06)$ & $1290-2653(1639 \pm 399.74)$ & $1329-2127(1692 \pm 179.64)$ & $1266-2732(1661 \pm 329.55)$ \\
\hline 13 & $42-60(53 \pm 7.26)$ & $69-139(87 \pm 21.34)$ & $62-99(80 \pm 8.88)$ & $60-120(78 \pm 13.97)$ \\
\hline 14 & $(0)$ & $(0)$ & $(0)$ & $0-10(0 \pm 1.17)$ \\
\hline 15 & $90-99(95 \pm 3.55)$ & $84-93(88 \pm 1.94)$ & $78-87(84 \pm 2.49)$ & $75-88(84 \pm 3.14)$ \\
\hline 16 & $480-663(592 \pm 69.86)$ & $732-1476(923 \pm 225.08)$ & $682-1110(902 \pm 101.44)$ & $682-1355(883 \pm 153.43)$ \\
\hline 17 & $27-38(33 \pm 3.04)$ & $55-131(73 \pm 19.67)$ & $60-108(75 \pm 11.3)$ & $50-172(77 \pm 27.57)$ \\
\hline 18 & $260-311(297 \pm 13.81)$ & $204-580(288 \pm 103.82)$ & $181-512(314 \pm 95.8)$ & $148-621(288 \pm 120.61)$ \\
\hline \multirow[t]{2}{*}{19} & $27-38(33 \pm 3.1)$ & $85-219(123 \pm 35.36)$ & $96-186(133 \pm 18.05)$ & $88-262(134 \pm 40.61)$ \\
\hline & $\mathrm{K}$ & $\mathrm{L}$ & M & \\
\hline 1 & $13-19.3(17.50 \pm 1.62)$ & $13.4-23.1(18.50 \pm 2.14)$ & $14.1-22.3(16.10 \pm 2.7)$ & \\
\hline 2 & 8.4-13.6 (11.40土1.1) & $8.1-10(9.10 \pm 0.52)$ & $11-14(12.20 \pm 0.82)$ & \\
\hline 3 & $0.57-0.66(0.61 \pm 0.02)$ & $0.55-0.59(0.57 \pm 0.01)$ & $0.57-0.64(0.60 \pm 0.02)$ & \\
\hline 4 & $0.59-0.92(0.70 \pm 0.08)$ & $0.61-0.94(0.74 \pm 0.09)$ & $0.64-1.15(0.76 \pm 0.15)$ & \\
\hline 5 & $22.6-28.2(26.60 \pm 1.55)$ & $21.7-31.4(26.20 \pm 2.23)$ & $23.7-34(25.90 \pm 3.32)$ & \\
\hline 6 & $2.4-10.1(8 \pm 2.06)$ & $6.2-13.7(10.30 \pm 1.54)$ & $3.7-9.7(5.60 \pm 2.12)$ & \\
\hline 7 & $14.6-20.9(18.60 \pm 1.6)$ & $14.5-17.7(15.90 \pm 0.84)$ & $19.2-24.3(20.30 \pm 1.44)$ & \\
\hline 8 & $13.8-20.7(18.90 \pm 1.78)$ & $14.1-25.3(20 \pm 2.53)$ & $15-24.8(17.50 \pm 3.17)$ & \\
\hline 9 & $10.9-16.7(15.30 \pm 1.25)$ & $14.5-23.4(16.80 \pm 1.37)$ & $12.2-18.6(14 \pm 2.25)$ & \\
\hline 10 & $15-21.4(19.70 \pm 1.63)$ & $15.4-25.8(20.70 \pm 2.31)$ & $16.4-25.8(18.60 \pm 3.07)$ & \\
\hline 11 & $10.6-16.4(14.60 \pm 1.53)$ & $11-19.1(15.40 \pm 1.77)$ & $11.6-17.5(13 \pm 2.02)$ & \\
\hline 12 & $602-1982(1705 \pm 297.5)$ & $1389-1787(1659 \pm 83)$ & $1292-2156(1679 \pm 260.37)$ & \\
\hline 13 & $33-93(81 \pm 12.57)$ & $58-86(80 \pm 5.22)$ & $69-98(82 \pm 9.57)$ & \\
\hline 14 & $0-11(6 \pm 5.37)$ & $0-15(11 \pm 4.21)$ & $(0)$ & \\
\hline 15 & $67-100(76 \pm 7.37)$ & $49-69(62 \pm 4.17)$ & $79-82(80 \pm 0.93)$ & \\
\hline 16 & $265-1059(852 \pm 166.81)$ & $557-788(733 \pm 44.37)$ & $657-1145(874 \pm 146.79)$ & \\
\hline 17 & $26-172(136 \pm 31.29)$ & $152-208(180 \pm 12.2)$ & $84-150(115 \pm 20.09)$ & \\
\hline 18 & $183-640(507 \pm 109.9)$ & $367-521(456 \pm 40.68)$ & $326-644(440 \pm 99.36)$ & \\
\hline 19 & $39-208(147 \pm 32.22)$ & $176-234(204 \pm 12.87)$ & $97-163(130 \pm 20.98)$ & \\
\hline
\end{tabular}


A

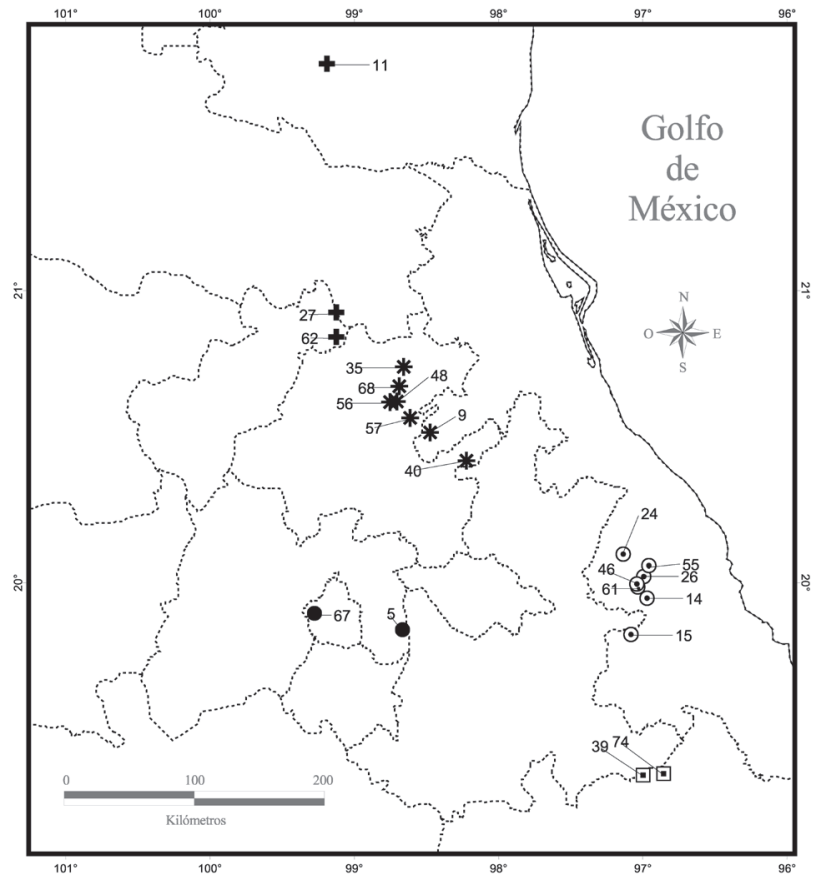

C

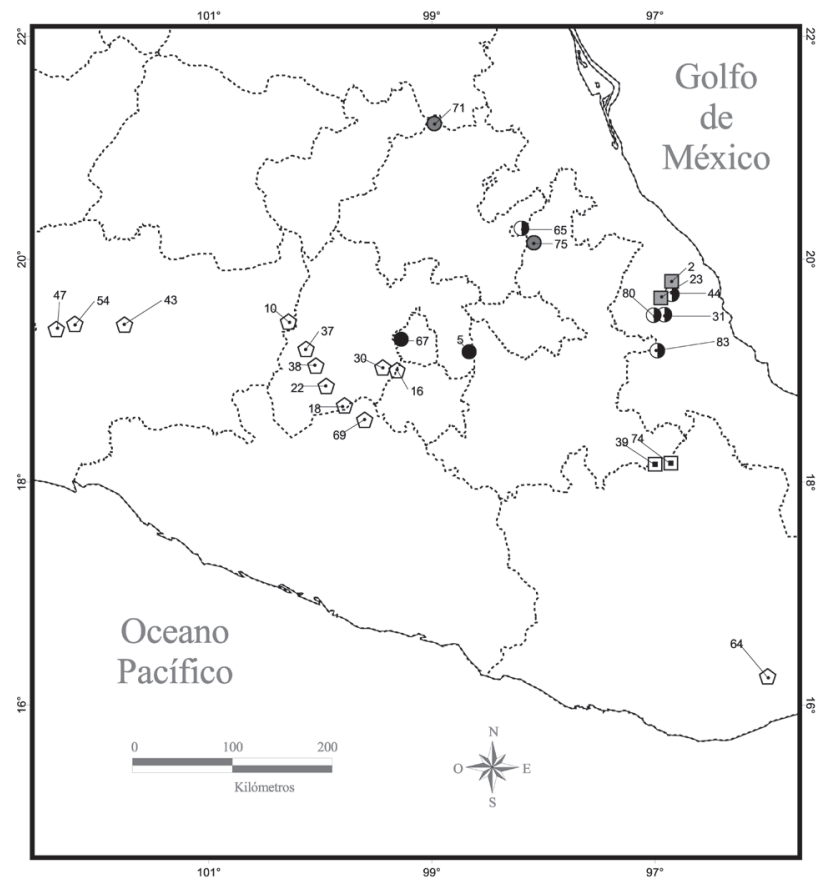

B

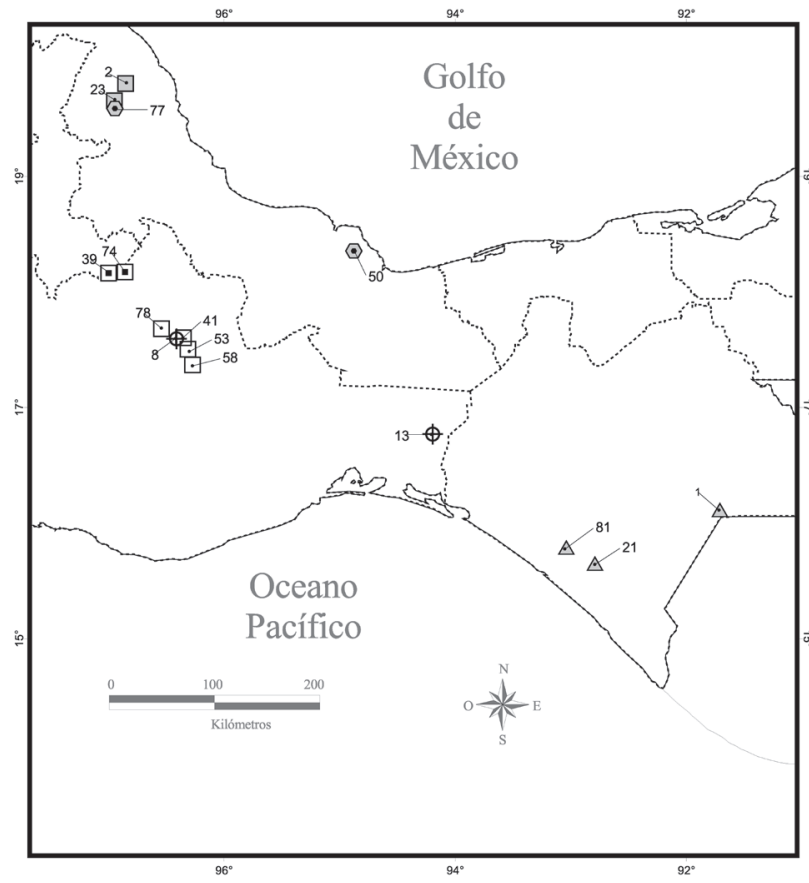

D

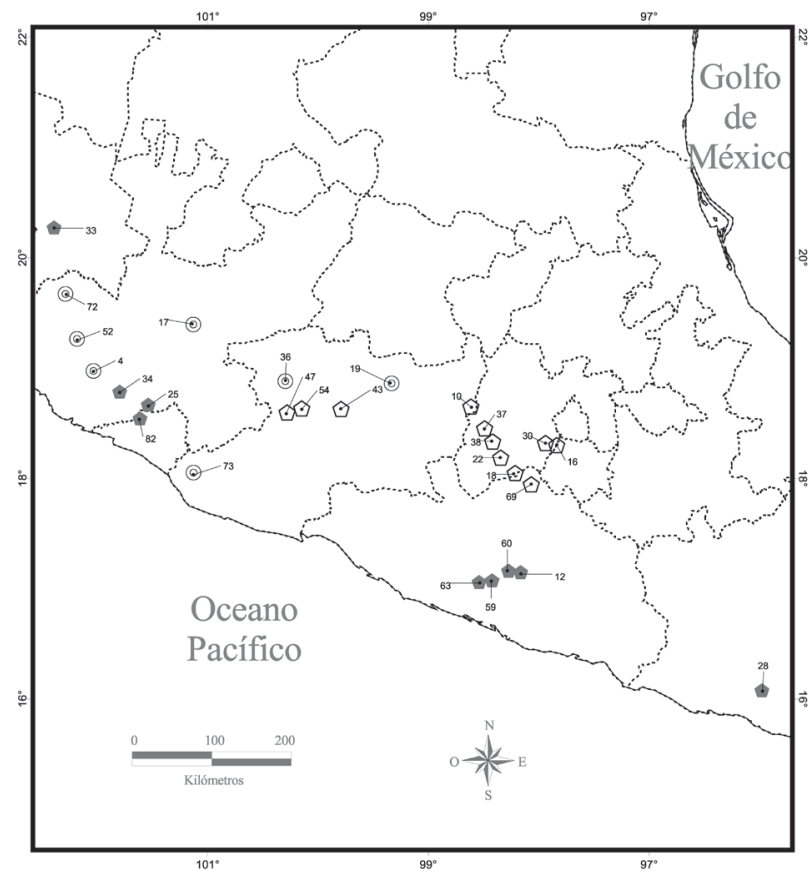

Figura 3. Ubicación geográfica de los grupos y subgrupos florísticos del BMM. a) Grupos: A1, *; A2, +; A3, $\odot$; G, •; H, —. b) Grupos: B, $\triangle ; \mathrm{C}, \triangle ; \mathrm{H}, \square ; \mathrm{I}, \oplus ; \mathrm{J}, \square ; \mathrm{L}, \square$. c) Grupos: E, $\triangle$; G, •; H, $\square$; K, \; L, $\square ; \mathrm{M}, \bigcirc$. d) Grupos: D, ๑; E, $\triangle ; \mathrm{F}, \triangle$. 
promedio anual de $13.6^{\circ} \mathrm{C}$, precipitación anual de 999 $\mathrm{mm}$, en un intervalo altitudinal de 2500 a $3135 \mathrm{~m} \mathrm{snm}$ (Cuadro 3).

Los grupos H, I y J reúnen los bosques de Serranías Meridionales de Oaxaca y de Valle de Tehuacán (Rzedowski, 1978; Rzedowski y Reyna-Trujillo, 1990); el grupo H (Fig. 3b) conjunta los de Sierra Mazateca, con $64 \%$ de similitud florística; el grupo I (Fig. 3b), agrupa los bosques de la Chinantla y del Cerro Salomón en los Chimalapas, con 58\% de similitud florística; el grupo J (Fig. $3 \mathrm{~b}$ ) incluye los bosques de la parte norte de Oaxaca, con $54 \%$ de similitud florística. Los árboles representativos en categorías de riesgo del grupo $\mathrm{H}$ son $M$. schiedeana (A), C. fulva y P. matudae ( $\mathrm{Pr}$ ). Los bosques se distribuyen en áreas con temperatura promedio anual de $15.8^{\circ} \mathrm{C}$, precipitación anual de $1639 \mathrm{~mm}$, en un intervalo altitudinal que va de los 1090 a $2690 \mathrm{~m} \mathrm{snm}$ (Cuadro 3).

El árbol representativo para los grupos I y J, que está en las listas de la NOM-059-SEMARNAT-2010 (SEMARNAT, 2010) es C. caroliniana (A). Los bosques del grupo I, se distribuyen en áreas con temperatura promedio anual de $18.2^{\circ} \mathrm{C}$, precipitación anual de $1692 \mathrm{~mm}$ y un intervalo altitudinal que va de 1420 a $2240 \mathrm{~m} \mathrm{snm}$ (Cuadro 3). Los bosques del grupo $\mathrm{J}$ se ubican en áreas con temperatura promedio anual de $17.6^{\circ} \mathrm{C}$, precipitación anual de $1661 \mathrm{~mm}$, en un intervalo altitudinal de 985 a $2590 \mathrm{~m}$ snm (Cuadro 3).

El grupo K (Fig. 3c) lo integran 4 bosques ubicados en la SMO, en el centro de Veracruz, y 1 en la Sierra Norte de Puebla, con 51\% de similitud florística. El árbol representativo de este grupo está en las listas de la NOM059-SEMARNAT-2010 (SEMARNAT, 2010) y es $M$. schiedeana (A). Estos bosques se distribuyen en áreas con temperatura promedio anual de $17.5^{\circ} \mathrm{C}$, precipitación anual de $1705 \mathrm{~mm}$, en un intervalo altitudinal de 1 100 a $2340 \mathrm{~m}$ snm (Cuadro 3).

El grupo L (Fig. 3b) incluye 2 bosques ubicados en la SMO de Veracruz, con $47 \%$ de similitud florística. Los árboles representativos son Alchornea latifolia y Trichilia havanensis (Apéndice). Estos bosques se distribuyen en áreas con temperatura promedio anual de $18.5^{\circ} \mathrm{C}$, precipitación anual de $1659 \mathrm{~mm}$, en un intervalo altitudinal de 700 a $2100 \mathrm{~m}$ snm (Cuadro 3).

Finalmente, el grupo M (Fig. 3c) une 2 BMM de la SMO, Huauchinango, Puebla y el de Pisaflores, Hidalgo, con $71 \%$ de similitud florística. Los árboles representativos son Clethra mexicana, C. pringlei y Prunus brachybotrya (Apéndice). Los bosques se distribuyen en áreas con una temperatura promedio anual $16.1^{\circ} \mathrm{C}$, precipitación anual de $1679 \mathrm{~mm}$, en un intervalo altitudinal de 850 a $2100 \mathrm{~m}$ snm (Cuadro 3).
Los perfiles bioclimáticos de cada grupo (Cuadro 3) indican los valores máximos, mínimos, promedio y desviación estándar de los 19 parámetros bioclimáticos obtenidos con el programa BIOCLIM.

El dendrograma de similitud bioclimática entre los grupos y subgrupos (Fig. 4), resultado del análisis de agrupamiento (cluster analysis), muestra 3 conjuntos bioclimáticos.

En el conjunto 1 se unen 9 grupos y subgrupos, que se distribuyen desde la parte central y sur de la SMO, este de la Faja Volcánica Transmexicana (en lo sucesivo FVT), la Sierra Norte de Oaxaca y hasta los bosques de la Sierra Madre y meseta central de Chiapas. Figs. 1, 3).

El conjunto 2 se integra con 6 grupos y subgrupos, distribuidos al norte de la SMO, centro y oeste de la FVT, la Planicie Costera del Noroeste y los bosques de la Sierra Madre del Sur; Figs. 1, 3).

El conjunto C (Fig. 4) corresponde al grupo C que incluye 2 bosques ubicados en la planicie costera del Golfo de México y en la parte este de la FVT (Figs. 1, 3).

La ordenación por componentes principales (Fig. 5) explica el $42.07 \%$ de la varianza acumulada entre los 2 primeros ejes $(1=27.66,2=14.41)$. El análisis indica que la estacionalidad de la temperatura (4.ET) es el factor más importante, explica la variación a lo largo del eje de ordenación $1(\mathrm{r}=-0.794)$, seguido por la temperatura máxima promedio del periodo más cálido (5.TMPPC, $\mathrm{r}=$ -0.475) y la temperatura promedio del cuatrimestre más lluvioso (8.TPCLL, $r=-0.471$ ). Para el eje 2, las principales variables bioclimáticas fueron la precipitación del periodo más lluvioso (13.PPLL, $r=-0.465)$, la estacionalidad de la temperatura (4.ET, $\mathrm{r}=0.332$ ) y la precipitación del cuatrimestre más lluvioso (16.PCLL, $\mathrm{r}=-0.282$ ).

En el lado izquierdo del eje 1 del espacio de ordenación se separa el subgrupo A2 que se ubica al norte de la $\mathrm{SMO}$; en la parte inferior del eje 2 se separa el subgrupo A1 y el grupo B ubicados al centro de la SMO y en Chiapas, respectivamente. Finalmente, de forma general los vectores obtenidos muestran gradientes de temperatura y de precipitación hacia la parte izquierda y derecha del espacio de ordenación.

\section{Discusión}

En los últimos 25 años, se han realizado estudios para establecer la similitud florística y generar hipótesis de la relación entre fragmentos de BMM que están ubicados en las provincias florísticas de México. Estos trabajos han empleado índices de similitud (Puig, 1983; Luna-Vega et al., 1988; Luna-Vega et al., 1989; Puig, 1989; Fragoso, 1990; López, 1995; Acosta, 1997; Alcántara y Luna- 


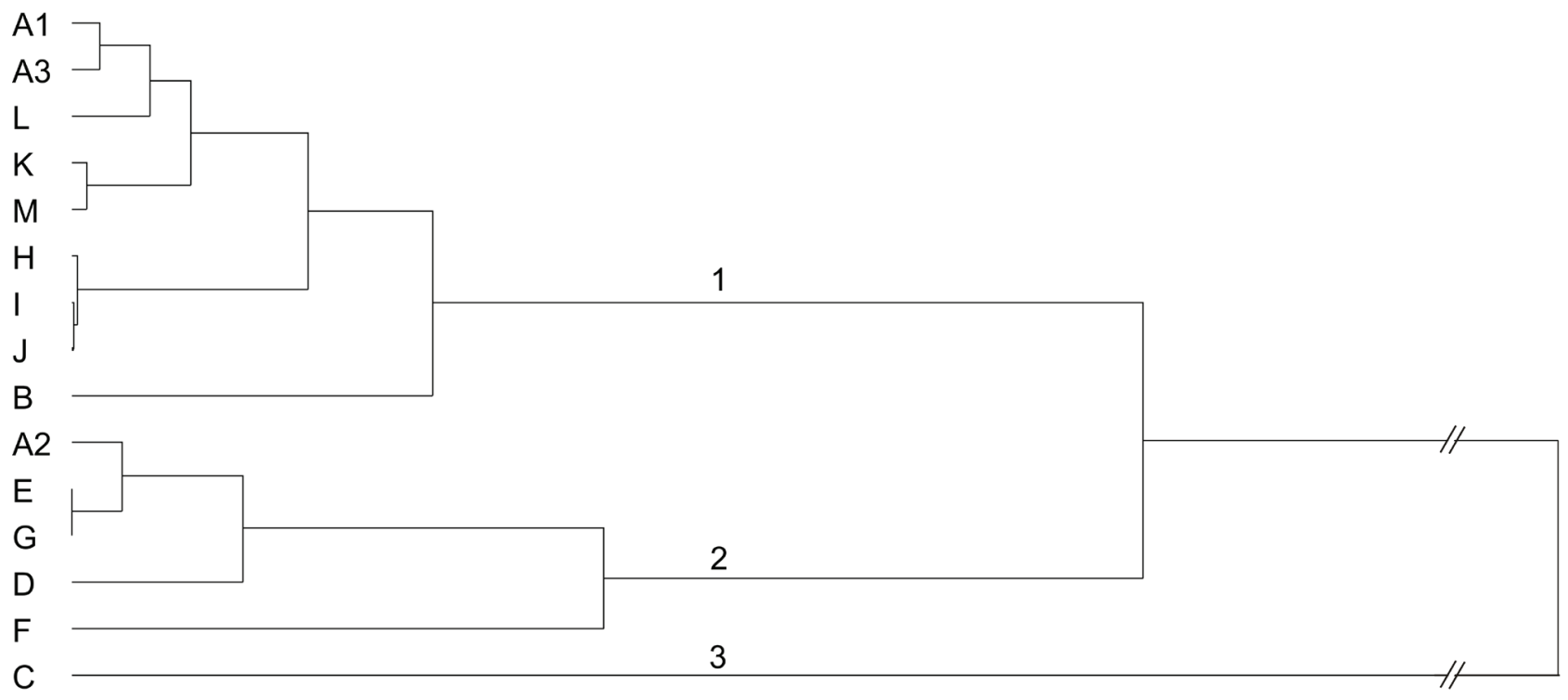

Figura 4. Dendrograma de la similitud bioclimática de los grupos y subgrupos de BMM mediante la distancia euclideana.

Vega, 1997), análisis numéricos (Vázquez-García, 1993; Ramírez-Marcial, 2001 y Acosta, 2004) y análisis biogeográficos (Luna-Vega et al., 1999; Luna-Vega et al., 2000 y Luna-Vega et al., 2001).

La información que se tiene de este tipo de vegetación es difícil de interpretar y generalizar, debido a la variabilidad fisonómica y estructural del BMM en las provincias florísticas del país. Esta heterogeneidad se atribuye a que las zonas de México donde se desarrolla constituyen una compleja matriz de variables ambientales como la altitud, suelo y clima; aunando a ello, su historia biogeográfica, que a su vez interactúa con las particularidades locales, como la orientación, la pendiente, la altitud, la latitud, la nubosidad y la humedad del aire y del suelo, para constituir un tipo de vegetación complejo (Ruiz-Jiménez, 1995; Ruiz-Jiménez et al., 2000). Aun en la misma localidad se pueden presentar diferencias espaciales en la distribución de las especies que incrementan la heterogeneidad florística, fisonómica y estructural del bosque (Miranda y Sharp, 1950; Puig, 1974; Rzedowski, 1978).

En este estudio se consideraron 83 localidades con BMM que incluyen 2856 especies de plantas vasculares; las cuales se compararon mediante técnicas estadísticas de análisis multivariado de clasificación y ordenación, para simplificar y reducir conjuntos complejos de datos de la vegetación a través de la generación de modelos sobre las relaciones entre las especies, la vegetación y el ambiente (McCune y Grace, 2002; Sánchez-González y López-Mata, 2003).
La clasificación de los BMM de México mediante el análisis de agrupamiento permitió determinar grupos y subgrupos en el dendrograma; el nivel de corte tomó en cuenta un compromiso entre la pérdida de información y la simplificación de un número de unidades de vegetación interpretables desde el punto de vista natural (McCune y Grace, 2002).

De manera general, el dendrograma presenta un arreglo de las localidades del BMM de acuerdo con su similitud florística, que corresponde con la ubicación geográfica conforme a las provincias florísticas (Rzedowski, 1978; Rzedowski y Trujillo, 1990) o las subprovincias geológicas (Ferrusquía-Villafranca, 1998) a las que pertenecen. Asimismo, el dendrograma muestra grupos conformados por localidades de BMM cercanas entre sí y otros conjuntos formados por bosques de diferentes provincias florísticas (Fig. 2).

Normalmente, las localidades más cercanas entre sí presentan mayor semejanza en su composición florística y conforme se incrementa la distancia entre ellas, disminuye el número de especies compartidas (Puig et al., 1983; Puig, 1989). En este estudio se corroboró que las localidades de BMM muestran mayor similitud florística con áreas fisiográficas contiguas sólo si se ubican en zonas que tienen condiciones climáticas similares (LunaVega et al., 1988).

Sin embargo, existen localidades cercanas que pueden presentar diferencias en su composición florística y tener 


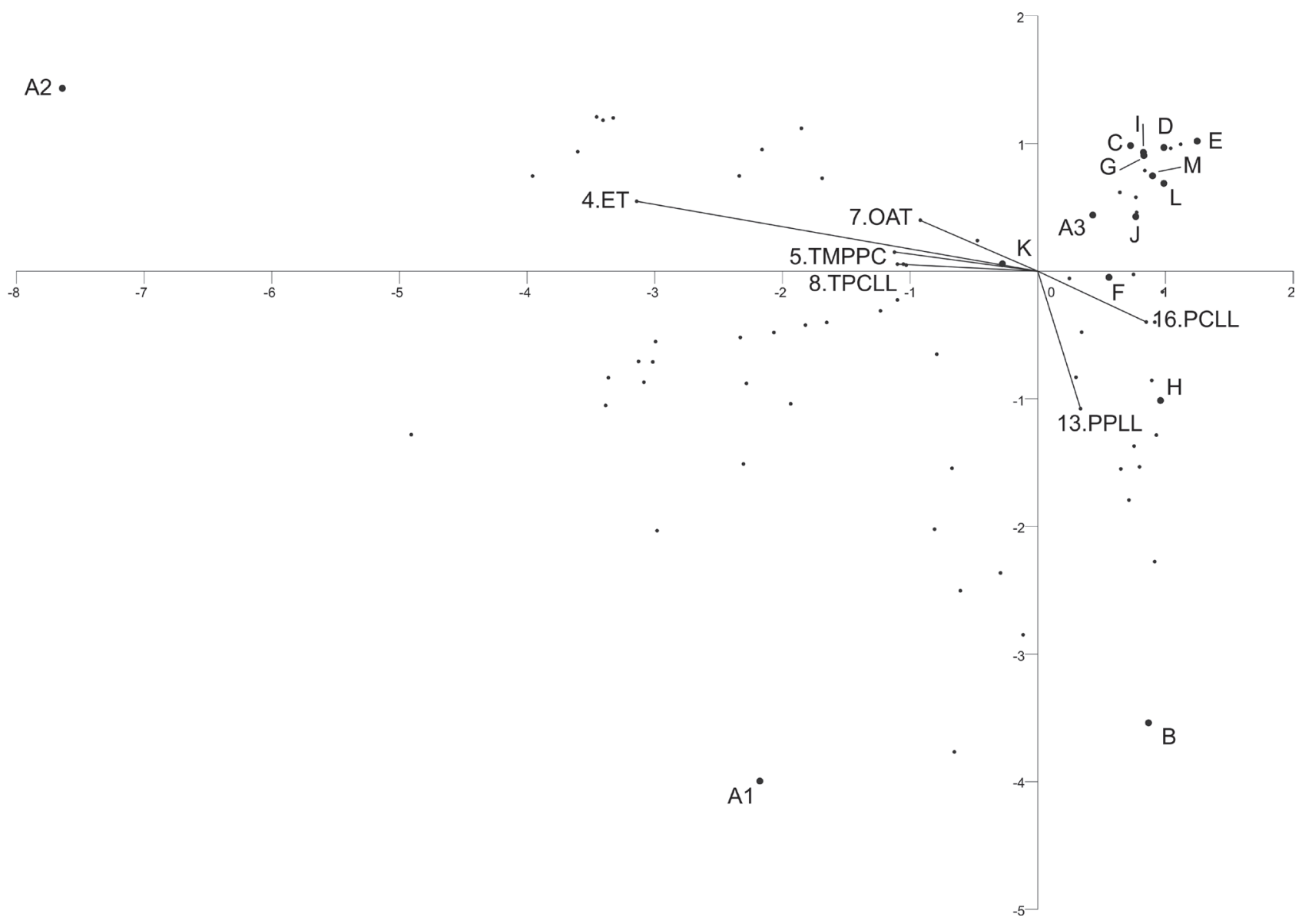

Figura 5. Ordenación mediante análisis de componentes principales de los BMM de México. Se explica el 42.07\% de varianza acumulada. a) Grupos y subgrupos de A-M; vectores, sólo las variables bioclimáticas más importantes.

valores de similitud bajos, de manera que en los dendrogramas forman grupos con bosques de diferentes provincias florísticas. Debe considerarse que las diferencias en la riqueza específica para cada una de las localidades analizadas puede estar influida por factores, ambientales, históricos, de disturbio antropogénico y metodológicos.

Las diferencias bioclimáticas de precipitación y temperatura entre localidades pueden dar, como consecuencia, baja semejanza florística entre ellas; las diferencias bioclimáticas significativas entre las localidades son suficientes para que exista una diferenciación biogeográfica que aumente las tasas de especiación por vicarianza. Entre los aspectos metodológicos se pueden considerar el tipo de muestreo empleado, los criterios de delimitación de la zona de estudio, los esfuerzos de recolección y muestreo, y el tamaño del área (Sánchez, 2004).

La composición florística de una zona se debe a los procesos que ocurren a escala local y regional (Ohmann y Spies, 1988), mientras que la diversidad biológica de una región es el resultado de la interacción entre los factores que favorecen la aparición de nuevos fenotipos y facilitan su acumulación durante un tiempo geológico amplio.

El análisis comparativo con otros estudios en los que se han empleado índices de similitud muestra que el grupo A incluye la mayoría de los bosques de la SMO considerados en este estudio (Fig. 2). El grupo se dividió en 3 subgrupos de acuerdo con su ubicación geográfica dentro de la sierra (centro, norte y Veracruz, A1, A2 y A3, respectivamente). El agrupamiento coincide con los resultados de otros estudios florísticos y estructurales realizados en la SMO. Puig y Bracho (1983) y Puig (1989) indican que los valores de similitud florística en genéros y especies del BMM de Gómez Farías, Tamaulipas son mayores que los de otros bosques del centro y norte de la SMO (Huayacocotla, Tlanchinol y Xilitla). Alcántara y Luna-Vega (1997) comparan la composición florística del BMM de Tenango de Doria (Hidalgo) y encuentran la mayor similitud florística con los bosques del centro de la SMO (Tlanchinol, Helechales y Hayacocotla). La similitud disminuye con los bosques más lejanos y los de otras provincias florísticas (Sierra de San Carlos y Montebe- 


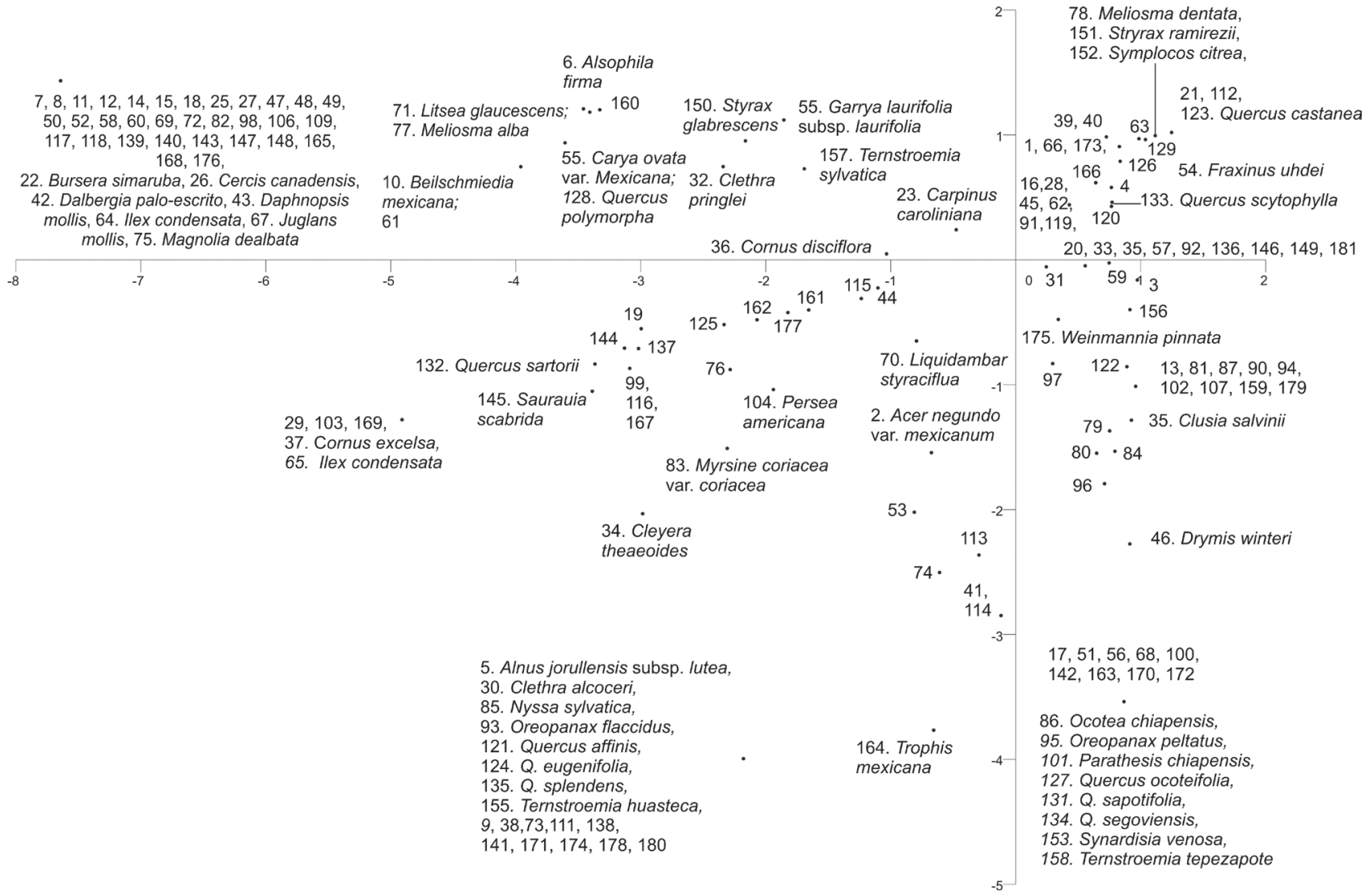

Figura 5. b) Especies + .

1lo, Chiapas). El subgrupo A1 coincide con los resultados de Acosta (2004), en el que compara la composición florística en el nivel de género de varios BMM del nordeste, centro y sur de México y encuentra que los bosques de Hidalgo son más afines entre sí.

En el subgrupo A3, que está formado por la mayoría de los BMM de Veracruz que se incluyen en este estudio, se agrupa el bosque de Teocelo donde Luna-Vega et al. (1988) estudiaron la composición florística y realizaron la comparación de ésta con la de otras localidades del país mediante el índice de Sorensen; encontraron que la mayor similitud la presenta en el nivel de géneros con un BMM del centro de Veracruz, seguido por un bosque de Chiapas. Los resultados de este estudio coinciden de manera general con los de Luna-Vega et al. (1988) y con la relación de los grupos B y C constituidos por BMM de los estados de Chiapas y de Veracruz, respectivamente (Fig. 2). La topología general de los subgrupos A1, A2 y A3 es similar a la que encontró Acosta (2004) para los BMM de la SMO.

El grupo E, que forman los BMM de la FVT, se divide de manera general en 2 subgrupos, el del centro y el del oeste (Figs. 2, 3), división que coincide con los resultados de López (1995), que compara diversas localidades de
BMM de la FVT del Estado de México mediante el índice de similitud de Sorensen y elabora un dendrograma que evidencia la similitud del bosque de Valle de Bravo y el de la mesa de Holotepec, esta similitud disminuye con los bosques de la Sierra de Zacualpan, las Cañadas de Ocuilan y la Sierra de Sultepec. Es necesario destacar que a pesar de que en este grupo se consideran localidades de la misma provincia florística (Rzedowski, 1978), la cercanía geográfica no asegura la mayor similitud entre los bosques, ya que existe una gran influencia climática tropical de provincias cercanas que influyen en la composición florística y las condiciones ecológicas relacionan estas localidades con la cuenca del Balsas (López, 1995). Así también, el grupo E concuerda con los resultados del estudio de Fragoso (1990) en el que el BMM de la Sierra de Zacualpan presenta la mayor similitud florística con el bosque de Ocuilan.

La división del grupo E en subgrupos con mayor similitud florística y geográficamente distribuidos dentro de la FVT (Figs. 2, 3), se apoya con los resultados de Luna-Vega et al. (1989), quienes comparan el bosque de Ocuilan con otras localidades y encuentran la mayor semejanza en su composición florística con bosques cercanos de la misma 
provincia y ésta disminuye conforme aumenta la distancia entre ellos (Tepoztlán, Tancítaro y la vertiente oeste del Iztaccíhuatl, respectivamente). En el estudio de los BMM del noreste, centro y sur de México, Acosta (2004) muestra un conjunto de bosques de la FVT que presentan este comportamiento (Sultepec, Ocuilan y Valle de México).

De manera general para la FVT, es claro que las localidades más cercanas tienen mayor similitud florística; sin embargo, las contiguas con condiciones ecológicas diferentes o que presentan influencia climática de otras provincias florísticas colindantes pueden presentar altos valores en el índice de similitud (Luna-Vega et al., 1988; Luna-Vega et al., 1989; López, 1995).

El grupo F conjunta los BMM de las Serranías Meridionales del oeste de la FVT, de la Sierra Madre del Sur (en lo sucesivo SMS) y la Planicie Costera del Noroeste (PCN); en el dendrograma (Fig. 2) se observa que los BMM de la SMS de Oaxaca dentro de los grupos E y F se agrupan con los bosques de la FVT y posteriormente con los de la SMO. Esta relación coincide parcialmente con el estudio de Acosta (1997), quien comparó la afinidad genérica del BMM de Pluma Hidalgo, Oaxaca con otros bosques del país mediante el índice de similitud de Sorensen. La mayor similitud la encontró con el bosque de Teocelo (Luna-Vega et al., 1988), seguido por el bosque de la Sierra Madre del Sur de Guerrero (Lorenzo et al., 1983) y el de Gómez Farías, Tamaulipas (Puig, 1989). Acosta (2004) también encontró la misma relación al analizar los BMM del noreste, centro y sur del país.

El grupo I conjunta Bosques de la Chinantla y Cerro Salomón, dos sitios de las serranías meridionales de Oaxaca pero de diferentes vertientes y provincias geológicas; el primero se considera un relicto del Terciario, el otro como bosque del tipo elfin forest. Ambos se desarrollan en condiciones ambientales similares de humedad y en condiciones ecológicas particulares. Este grupo también lo obtiene Acosta (2004) en su estudio de los BMM del nordeste, centro y sur del país.

Los grupos D, J, K, L y M no presentan coincidencias con la mayoría de los estudios donde se han empleado índices de similitud, análisis numéricos y biogeográficos, debido a que la mayoría de las localidades que aquí se consideran no se incluyeron en análisis previos.

En los trabajos de Vázquez-García (1993) y RamírezMarcial (2001) se utilizaron análisis de ordenación para comparar la relación de los BMM de México con los bosques de Centroamérica y de manera general obtuvieron resultados similares; agrupaciones de bosques de acuerdo con la vertiente en la que se ubican (del golfo o del Pacífico), bosques relacionados florísticamente con Centroamérica y otros aislados por su diversidad y altitud particulares. Comparando tales resultados con los del presente estudio, se observa que existen coincidencias en las agrupaciones por vertiente y por provincias florísticas (Figs. 2, 3).

Al comparar los resultados del presente estudio con los de Luna-Vega et al. (1999), quienes analizan las relaciones históricas del BMM de México mediante un análisis de parsimonia de endemismos, se presentan coincidencias generales entre los grupos y los clados (subgrupo A1 y clado $\mathrm{E}$ que incluye Huautla de Jiménez) y parciales (subgrupo A2 y clado B, grupo B y C con el clado A). Además, las UGO comprendidas en algunos grupos $(\mathrm{E}$ y $\mathrm{F}$ ) están incluidas en ciertos clados (D y C). De este modo existen coincidencias en la constitución de los grupos o clados que conforman las provincias florísticas.

Es posible aseverar que conforme se genera más información acerca del BMM de México, los estudios de similitud refuerzan las hipótesis de relación entre los manchones de este bosque en las provincias florísticas; si se considera un mayor número de localidades en los análisis, se corrobora la semejanza de la composición florística en las localidades geográficamente más cercanas entre sí; no obstante, las diferencias en los resultados para ciertas regiones dependen del progreso en las listas de las áreas que se comparan, por lo que sólo cuando se cuente con listas florísticas terminadas se podrán dar interpretaciones suficientes (Puig y Bracho, 1983; Puig, 1989; Luna-Vega et al., 1988).

En todos los estudios que se han realizado es evidente la presencia de grupos naturales y grupos heterogéneos cuyas relaciones de afinidad contradictoria ponen de manifiesto la necesidad de seguir realizando estudios dentro de esta comunidad vegetal particular, de gran importancia y vulnerabilidad (Puig et al., 1983; Luna-Vega et al., 1988; Acosta, 1997, 2004).

Los valores altos de similitud en la composición florística y en los parámetros bioclimáticos, y las condiciones fisiográficas entre las localidades cercanas, sugieren la posibilidad de que en la antigüedad los bosques formaban parte de uno solo (Puig y Bracho, 1983; Puig, 1989; LunaVega et al., 1988). Además, la semejanza puede deberse a que todos han pasado por los mismos acontecimientos históricos y climáticos, constituyendo floras similares en origen y evolución (Luna-Vega et al., 1988).

Las fluctuaciones climáticas y los cambios fisiográficos del Pleistoceno, pudieron haber contribuido a la diversificación de la flora de México, aunque ésta ya estaba establecida desde el Terciario medio (Rzedowski, 1991); los cambios climáticos del Neogeno y del Pleistoceno provocaron extinciones locales y nuevas invasiones de taxa, principalmente en el sur del país a partir de refugios florísticos (Toledo, 1982).

El clima y la ubicación geográfica de México son los factores que determinan la composición florística regio- 
nal y la distribución general de los BMM. El cambio en la composición florística entre las localidades se presenta conforme aumenta la distancia entre ellas, debido a las condiciones ambientales locales (Vázquez-García, 1993). Estos patrones deben tomarse en cuenta cuando se establecen áreas naturales protegidas, y es importante que en su delimitación se incluya una área representativa de este tipo de vegetación en la zona.

Asimismo, la composición florística de los BMM cercanos puede modificarse debido al disturbio antropogénico de bajo y alto impacto; los primeros consideran la extracción selectiva de especies comerciales, leña, productos no maderables (helechos, orquídeas y palmas) y el pastoreo; los del segundo rubro implican el cambio de uso de suelo para establecer áreas agrícolas, ganaderas, urbanas que provocan la fragmentación y destrucción del BMM (Challenger, 1998). Sin embargo, los disturbios antropogénicos pueden tener efectos positivos en la composición florística de una región al ocasionar la hibridación de especies silvestres y domesticadas o efectos negativos que determinan su desaparición (Bye, 1993).

En lo que se refiere al análisis de clasificación bioclimática de los grupos y subgrupos, se conformaron conjuntos que en general presentan una distribución en la vertiente del Golfo y la parte sur de la vertiente del Pacífico (conjunto 1, Fig. 4) y en la parte norte de la vertiente del Golfo, la FVT y la vertiente del Pacífico (conjunto 2, Fig. 4).

Es probable que la similitud bioclimática del conjunto 1 se deba a la influencia que reciben las provincias florísticas o las subprovincias geológicas donde se ubican las localidades de BMM que conforman estos grupos y subgrupos, de los sistemas meteorológicos estacionales que a continuación se describen.

En verano o temporada de lluvias (mayo a octubre) dominan los sistemas tropicales y de vientos que incluyen los alisios del hemisferio norte con dirección noreste o suroeste, que toman la humedad de las aguas cálidas del Golfo de México y se cargan de humedad causando lluvias torrenciales (Soto y Gama, 1997; Soto, 2004; Trejo, 2004). La cantidad de humedad que se vierte en las sierras depende del grado de exposición, la profundidad de los vientos y las dimensiones de dichas cadenas montañosas.

En esta misma época o a finales del verano y principios del otoño se presentan perturbaciones tropicales, los denominados ciclones, que se forman en aguas tropicales cálidas y avanzan hacia ambas vertientes del territorio mexicano (Soto y Gama, 1997; Hernández-Cerda y Carrasco-Anaya, 2004; Soto, 2004; Trejo, 2004).

De noviembre a febrero (o hasta abril), en la época seca, se presentan los "nortes" que son masas de aire frío continental provenientes del sur de Canadá y del norte de Estados Unidos de América, que al pasar sobre el golfo de México se llenan de humedad y ocasionan el aumento de la precipitación, descensos rápidos en la temperatura $\mathrm{y}$ vientos fríos y húmedos dominantes del norte y noreste de hasta 100 kh/h (Rzedowski, 1978; Soto y Gama, 1997; Hernández-Cerda y Carrasco-Anaya, 2004; Soto, 2004; Trejo, 2004).

La distribución del BMM de México es la más septentrional en el mundo, debido a lo cual las condiciones climáticas son marcadamente estacionales (Challenger, 1998), la disminución estacional de las lluvias se compensa en la vegetación por la presencia de niebla (Stadtmuller, 1987); sin embargo, la temperatura muestra estacionalidad, se pueden presentar heladas en los meses más fríos y de manera esporádica en zonas de menor altitud (Rzedowski, 1978).

En el análisis de ordenación, el factor más importante para explicar la distribución de los grupos y subgrupos fue la estacionalidad de la temperatura; presentó los valores más heterogéneos para los subgrupos A1 y A2, y los más homogéneos para el grupo $\mathrm{B}$, haciendo evidente su separación en el espacio de ordenación. Esta separación refuerza la hipótesis biogeográfica que considera que algunas de las provincias florísticas de México no constituyen unidades naturales (Luna et al., 1999), particularmente para la SMO (subgrupos A1 y A2), las Serranías transístmicas y el Soconusco (grupo B).

Los resultados de esta investigación muestran que conforme se incrementa el conocimiento de este tipo de vegetación se apoyan las hipótesis sobre la relación entre las provincias florísticas, y se confirma que el BMM de México es el tipo de vegetación con mayor riqueza florística del país. Su distribución fragmentaria en una superficie menor al $1 \%$ del territorio nacional, su situación de vulnerabilidad ante el cambio de uso de suelo para establecer áreas agrícolas y ganaderas, y el cambio climático hacen urgente la promoción de estrategias de conservación encaminadas a la protección y restauración ecológica de esta comunidad vegetal orientadas a su manejo sustentable.

\section{Agradecimientos}

Este trabajo forma parte del proyecto de tesis doctoral del primer autor y fue posible realizarlo gracias al apoyo económico de la beca otorgada por el CONACYT (Reg. 186230). Agradezco al posgrado en Ciencias Biológicas de la UNAM por haberme dado la oportunidad de cursar mis estudios de Doctorado en esta institución. Agradecemos el apoyo financiero del proyecto DGAPAPAPIIT IN221711. Agradecemos a Dafne Saavedra Millán, Martha Martínez Gordillo, Hugo López Rosas y José de Jesús Saavedra Romero, por sus valiosas críticas 
y sugerencias que enriquecieron este trabajo; a Enrique Valente Sánchez-Rodríguez y a Jorge Martínez Meléndez, por proporcionarnos información acerca de sus investigaciones del BMM, y a los revisores anónimos, quienes con sus acertadas observaciones contribuyeron a mejorar este trabajo.

\section{Literatura citada}

Acosta, S. 1997. Afinidades fitogeográficas del bosque mesófilo de montaña de la zona de Pluma Hidalgo, Oaxaca, México. Polibotánica 6:25-39.

Acosta, I. 2002. Vegetación y flora del municipio de Xico, Veracruz, México. Tesis de licenciatura. Facultad de Biología, Universidad Veracruzana, Xalapa, Veracruz. 150 p.

Acosta, S. 2004. Afinidades de la flora genérica de algunos bosques mesófilos de montaña del noreste, centro y sur de México: un enfoque fenético. Anales del Instituto de Biología, Universidad Nacional Autónoma de México, Serie Botánica 75:61-72.

Ahumada, C. B. 1994. Distribución y biodiversidad del bosque mesófilo de montaña en El Palmito, municipio de Condordia, Sinaloa. Seminario de Investigación II, 1994. Universidad Autónoma de Sinaloa, Culiacán. 90 p.

Alcántara, O. 1996. Estudio florístico y biogeografía del bosque mesófilo de montaña del Municipio de Tenango de Doria, Hidalgo, México. Tesis, Facultad de Ciencias, Universidad Nacional Autónoma de México, México, D. F. 83 p.

Alcántara, O. e I. Luna-Vega. 1997. Florística y análisis biogeográfico del bosque mesófilo de montaña de Tenango de Doria, Hidalgo, México. Anales del Instituto de Biología, Universidad Nacional Autónoma de México, Serie Botánica 68:57-106.

Alcántara, O. e I. Luna-Vega. 2001. Análisis florístico de dos áreas con bosque mesófilo de montaña en el estado de Hidalgo, México: Eloxochitlán y Tlahuelompa. Anales del Instituto de Biología, Universidad Nacional Autónoma de México, Serie Botánica 54:51-87.

Álvarez del Castillo, C. 1977. Estudio ecológico y florístico del cráter del volcán San Martín Tuxtla, Veracruz, México. Biotica 2:3-54.

Arellanes, Y. 2000. Análisis estructural de un bosque mesófilo de montaña de Ticodendron incognitum en la Sierra Norte de Oaxaca, México. Tesis, Facultad de Ciencias, Universidad Nacional Autónoma de México, México, D. F. 86 p.

Arriaga, L. 1994. Dinámica de claros y procesos de regeneración en un bosque mesófilo de montaña. Tesis, Doctorado Facultad de Ciencias, Universidad Nacional Autónoma de México, México, D. F. 279 p.

Ávila, V. 2004. La vegetación de la cuenca alta del río Magdalena: un enfoque florístico, fitosociológico y estructural. Tesis, Facultad de Ciencias, Universidad Nacional Autónoma de
México, México, D. F. 112 p.

Ávila, V. 2006. Autenticidad de los bosques en la cuenca alta del río Magdalena: diagnostico hacia la restauración ecológica. Tesis, Maestría Facultad de Ciencias, Universidad Nacional Autónoma de México, México, D. F. 83 p.

Ávila, V., B. González-Hidalgo, M. Nava-López y L. AlmeidaLeñero. 2008. Refugio de fitodiversidad en la ciudad de México, el caso de la cuenca del río Magdalena. Journal of the Botanical Research Institute of Texas 2:605-619.

Ballesteros, M. 1986. Estudio de la flora y la vegetación de Helechales en el municipio de Huayacocotla, Veracruz. Tesis, Facultad de Ciencias, Universidad Nacional Autónoma de México, México, D. F. 66 p.

Blanco, J. 1994. La vegetación de la sierra de San Juan, Nayarit, México. Tesis, Facultad de Ciencias, Universidad Nacional Autónoma de México, México, D. F. 87 p.

Blanco, A. 2001. Análisis sucesional del bosque mesófilo de montaña en El Rincón, sierra Norte de Oaxaca. Tesis, Escuela Nacional de Estudios Profesionales Iztacala, Universidad Nacional Autónoma de México, Los Reyes Ixtacala, Estado de México. 60 p.

Boyle, B. 1996. Changes on altitudinal and latitudinal gradients in neotropical montane forests. Tesis, Doctorado.School of Arts and Sciences, Washington University, Saint Louis, Missouri. 260 p.

Braun-Blanquet, J. 1932. Plant Sociology, the study of plant communities. Hafner, New York. 439 p.

Briones, O. 1991. Sobre la flora, vegetación y fitogeografía de la sierra de San Carlos, Tamaulipas. Acta Botánica Mexicana 16:15-43.

Bye, R. 1998. La intervención del hombre en la diversificación de las plantas en México. In Diversidad biológica de México: orígenes y distribución, T. Ramamoorthy, R. Bye, A. Lot y J. Fa. (eds.). Instituto de Biología, UNAM, México, D. F. p 689-713.

Campos-Villanueva, A. 1993. Estudio florístico de la porción central del municipio de San Jerónimo Coatlán (Oaxaca). Tesis, Facultad de Ciencias, Universidad Nacional Autónoma de México, México, D. F. 97 p.

Campos-Villanueva, A. y J. L. Villaseñor. 1995. Estudio florístico de la porción central del municipio de San Jerónimo Coatlán, distrito de Miahuatlán (Oaxaca). Boletín de la Sociedad Botánica de México 56:95-120.

Carlson, M. 1954. Floral elements of the pine-oak-liquidambar forest of Montebello, Chiapas, México. Bulletin of the Torrey Botanical Club 8:387-399.

Cartujano, S., S. Zamudio, O. Alcántara e I. Luna-Vega. 2002. El bosque mesófilo de montaña en el municipio de Landa de Matamoros, Querétaro, México. Boletín de la Sociedad Botánica de México 70:13-43.

Castillo, J. 1996. Vegetación de la Reserva de la Biosfera La Sepultura, Chiapas. Tesis, Facultad de Ciencias, Universidad 
Nacional Autónoma de México, México, D. F. 58 p.

Castillo-Campos, G. y V. E. Luna. 2009. Flora y vegetación del municipio de Coatepec, Veracruz, Flora de Veracruz, fascículo complementario I, $281 \mathrm{p}$.

Catalán, C. 2004. Estructura, composición florística y diversidad de especies leñosas de un bosque mesófilo de montaña de Guerrero, México. Tesis, Doctorado Instituto de Recursos Naturales, Colegio de Postgraduados, Texcoco, Estado de México. 96 p.

Chiang, F. 1970. La vegetación de Córdoba, Ver. Tesis, Facultad de Ciencias, Universidad Nacional Autónoma de México, México, D. F. 37 p.

Challenger, A. 1998. Utilización y conservación de los ecosistemas terrestres de México. Pasado, presente y futuro. Comisión Nacional para el Conocimiento y Uso de la Biodiversidad/ Instituto de Biología, UNAM/ Agrupación Sierra Madre, México, D. F. 847 p.

Cornejo-Tenorio, G., A. Casas, B. Farfán, J. L. Villaseñor y G. Ibarra. 2003. Flora y vegetación de las zonas núcleo de la Reserva de la Biosfera Mariposa Monarca, México. Boletín de la Sociedad Botánica de México 73:43-62.

Croda, G. 1992. Efecto de borde sobre las densidades absoluta y relativa (categorías diamétricas y alturas) y el área basal de los árboles en fragmentos de bosque mesófilo de Coacoatzintla, Veracruz. Tesis, Facultad de Biología, Universidad Veracruzana, Xalapa, Veracruz. 77 p.

Crovello, T.J. 1981. Quantitative biogeography: an overview. Taxon 30:563-575.

Cuevas, R. 1994. Flora de la estación científica Las Joyas, municipio de Autlán, Jalisco, México. Tesis, Maestría Colegio de Postgraduados, Texcoco, Estado de México. 133 p.

Cuevas, R. 2002. Análisis de gradientes de la vegetación de la cañada El Tecolote, en la sierra de Manantlán, Jalisco, México. Tesis, Doctorado del Instituto de Recursos Naturales, Colegio de Postgraduados, Texcoco, Estado de México. 140 p.

Cuevas, R. y E. Jardel. 2004. Flora y vegetación de la estación científica Las Joyas. Universidad de Guadalajara, Jalisco.

Díaz-Barriga, H. y M. Palacios-Ríos. 1992. Lista preliminar de especies de pteridofitas de los estados de Guanajuato, Michoacán y Querétaro (México). Flora del Bajío y de Regiones Adyacentes, Fascículo complementario III, Centro Regional del Bajío, INECOL, Pátzcuaro, Michoacán.

Diego-Pérez, N., S. Peralta-Gómez y B. Ludlow-Wiechers. 2001. Estudios florísticos en Guerrero 11. El Jilguero, bosque mesófilo de montaña. Las Prensas de Ciencias, Facultad de Ciencias, Universidad Nacional Autónoma de México, México, D. F. 42 p.

Durán, C. 1992. La vegetación de la barranca de las Minas, Veracruz, México. Tesis, Facultad de Biología, Universidad Veracruzana, Xalapa, Veracruz. $61 \mathrm{p}$.
Escutia, J. 2004. Análisis estructural del bosque mesófilo de montaña de Monte Grande de Lolotla, Hidalgo, México. Tesis, Facultad de Ciencias. Universidad Nacional Autónoma de México, México, D. F. 98 p.

Fernández, R. y J. Colmenero. 1997. San Joaquín. Notas sobre la vegetación y flora del municipio de San Joaquín, Querétaro, México. Polibotánica 4:10-36.

Ferrusquía-Villafranca, I. 1998. Geología de México: una sinopsis. In Diversidad biológica de México: orígenes y distribución, T. Ramamoorty, R. Bye, A. Lot y J. Fa. (eds.). Instituto de Biología, UNAM, México, D. F. p. 689-713.

Fonseca, R., E. Velázquez y E. Domínguez. 2001. Estudios Florísticos en Guerrero 12. Carrizal de Bravos, Bosque mesófilo de montaña. Las Prensas de Ciencias, Facultad de Ciencias, UNAM, México, D. F. 41 p.

Fragoso, R. 1990. Estudio florístico en la parte alta de la sierra de Zacualpan, estado de México. Tesis, Escuela Nacional de Estudios Profesionales Iztacala, Universidad Nacional Autónoma de México, Los Reyes Ixtacala, Estado de México. 79 p.

Gallardo-Hernández, C., N. Velázquez y H. Asbjornsen. 2008. Composición florística y estructura de dos comunidades de bosque mesófilo afectadas por los incendios de 1998, en los Chimalapas, Oaxaca, México. In Ecología, manejo y conservación de los ecosistemas de montaña en México, L. Sánchez-Velázquez, J. Galindo-González y F. Díaz-Fleischer (eds.). Mundi-Prensa, México D. F. p 167-183.

García, M. 1988. Distribución y estructura de las comunidades arbóreas del Parque Estatal Omiltemi, Gro. Una contribución a su planificación. Tesis, Facultad de Ciencias, Universidad Nacional Autónoma de México, México, D. F. 105 p.

García, I., J. Nava, R. Flores, M. Cházaro, A. Machuca y E. del Río. 1998. Flora del Parque Nacional Pico de Tancítaro, Michoacán. Informe técnico final. CIIDIR-IPN/ CONABIO. $99 \mathrm{p}$.

García-Franco, J., G. Castillo-Campos, K. Mehltreter, M. Martínez y G. Vázquez. 2008. Composición florística de un bosque mesófilo del centro de Veracruz, México. Boletín de la Sociedad Botánica de México 83:37-52.

García-Franco, J. y T. Toledo. 2008. Epífitas vasculares: bromelias y orquídeas. In Agroecosistemas cafetaleros de Veracruz. Biodiversidad manejo y conservación, R. Manson, V. Hernández-Ortiz, S. Gallina y K. Mehltreter (eds.). Instituto de Ecología/ Instituto Nacional de Ecología, México, D. F. p. 69-82.

Gómez-Pompa, A. 1966. Estudios botánicos en la Región de Misantla, Veracruz. Instituto Mexicano de Recursos Naturales Renovables, México, D. F. 173 p.

Graham, A. 1998. Factores históricos de la diversidad biológica de México. In Diversidad biológica de México: orígenes y distribución, T. Ramamoorthy, R. Bye, A. Lot y J. Fa (eds.). Instituto de Biología, UNAM. México, D. F. p. 689-713. 
Hernández, V. 2001. Influencia del suelo en el crecimiento de cuatro especies arbóreas a lo largo de un gradiente sucesional del bosque mesófilo de montaña, Sierra Norte, Oaxaca. Tesis, Facultad de Estudios Superiores Iztacala, Universidad Nacional Autónoma de México, Los Reyes, Ixtacala, Tlalnepantla, Estado de México. 81 p.

Hernández-Cerda, M. y G. Carrasco-Anaya. 2004. Climatología. In Biodiversidad de la sierra Madre Oriental, I. Luna-Vega, J. Morrone y D. Espinosa (eds.). UNAM/ CONABIO, México, D. F. p 63-108.

Houlder, D., M. Hutchinson, H. Nix y J. McMahon. 2000. ANUCLIM user's guide. CRES. Canberra.

Ibarra, G. 1983. Comunidades vegetales del cerro El Cacique, ubicado en el Eje Neovolcánico; Zitácuaro, Michoacán. Tesis Facultad de Ciencias, Universidad Nacional Autónoma de México, México D. F. 105 p.

Ishiki, M. 1988. Las selvas bajas perennifolias del Cerro Salomón, región de Chimalapa, Oaxaca: flora, comunidades y relaciones fitogeográficas. Tesis, Maestría.Colegio de Postgraduados. Texcoco, Estado de México. 201 p.

Jiménez, J., J. Contreras, R. González, R. Ocampo, G. Lozano y S. Torres. 1993. Plantas vasculares. In Historia natural del Parque Ecológico Estatal Omiltemi, Chilpancingo, Guerrero, México, I. Luna-Vega, y J. Llorente-Bousquets (eds.). Facultad de Ciencias, Universidad Nacional Autónoma de México, México, D. F. p. 127-250.

Juárez, K. 2008. Biodiversidad de la flora del bosque mesófilo de montaña del municipio de Huayacocotla, Veracruz, México. Tesis, Facultad de Ciencias, UNAM, México, D. F. 72 p.

Labat, J. 1995. Végétation du nord-ouest du Michoacán Mexique. Flora del Bajío y Regiones Adyacentes, Fascículo complementario VIII, Centro Regional del Bajío, INECOL, Pátzcuaro, Michoacán. 401 p.

Long, A. y M. Heath. 1991. Flora of the El Triunfo Biosphere Reserve, Chiapas, México: a preliminary floristic inventory and the plant communities of Polygon I. Anales del Instituto de Biología, Universidad Nacional Autónoma de México, Serie Botánica 62:133-172.

López, Y. 1995. Inventario florístico y conocimiento estructural del bosque mesófilo en el municipio de Valle de Bravo, Estado de México, México. Tesis, Escuela Nacional de Estudios Profesionales Iztacala, Universidad Nacional Autónoma de México, Los Reyes Ixtacala, Estado de México. 92 p.

López, M. 1997. Tendencias ecológicas en la estructura de la madera de árboles de un bosque mesófilo de montaña, de Michoacán. Tesis, Escuela Nacional de Estudios Profesionales Iztacala, Universidad Nacional Autónoma de México. Los Reyes Ixtacala, Estado de México. 80 p.

Lorea, F. 2005. Estudio florístico de los bosques mesófilos de la sierra Mazateca de Oaxaca, México. Informe técnico final. Instituto de Ecología, Xalapa, Veracruz/ CONABIO, México, D. F. 32 p.
Lorenzo, S., A. Ramírez, M. Soto, A. Breceda, M. Calderón, H. Cortéz, C. Puchet, M. Ramírez, R. Villalón y E. Zapata. 1983. Nota sobre la fitogeografía del bosque mesófilo de montaña en la sierra Madre del Sur, México. Boletín de la Sociedad Botánica de México 44:97-102.

Lozada, L., M. León, J. Rojas y R. de Santiago. 2003. Bosque mesófilo de montaña en el Molote. Estudios Florísticos en Guerrero 13. Las Prensas de Ciencias, Facultad de Ciencias, UNAM, México, D. F. 35 p.

Luna-Vega, I., L. Almeida-Leñero, L. Villers y L. Lorenzo. 1988. Reconocimiento florístico y consideraciones fitogeográficas del bosque mesófilo de montaña de Teocelo, Veracruz. Boletín de la Sociedad Botánica de México 48:35-63.

Luna-Vega, I., L. Almeida-Leñero y J. Llorente-Bousquets. 1989. Florística y aspectos fitogeográficos del bosque mesófilo de montaña de las cañadas de Ocuilan, estados de Morelos y México. Anales del Instituto de Biología, Universidad Nacional Autónoma de México, Serie Botánica 59:63-87.

Luna-Vega, I., S. Ocegueda y O. Alcántara. 1994. Florística y notas biogeográficas del bosque mesófilo de montaña del municipio de Tlanchinol, Hidalgo, México. Anales del Instituto de Biología, Universidad Nacional Autónoma de México, Serie Botánica 65:31-62.

Luna, V. 1997. Estudio de vegetación y flora del municipio de Coatepec, Veracruz. Tesis, Facultad de Biología, Universidad Veracruzana, Xalapa, Veracruz. 163 p.

Luna-Vega, I., O. Alcántara, D. Espinosa-Organista y J. Morrone. 1999. Historical relationships of the Mexican cloud forests: a preliminary vicariance model applying parsimony analysis of endemicity to vascular plant taxa. Journal of Biogeography 26:1299-1305.

Luna-Vega, I., O. Alcántara, J. Morrone y D. Espinosa-Organista. 2000. Track analysis and conservation priorities in the cloud forests of Hidalgo, Mexico. Diversity and Distributions 6:137-143.

Luna-Vega, I., J. Morrone, O. Alcántara y D. Espinosa-Organista. 2001. Biogeographical affinities among Neotropical cloud forests. Plant Systematics and Evolution 228:229-239.

Machuca, J. 1989. Florística y ecología de la vegetación fanerogámica de la región septentrional de Jocotepec, Jalisco (México). Tesis, Facultad de Agronomía, Universidad de Guadalajara, Jalisco. 221 p.

McCune, B. y J. Grace. 2002. Analysis of ecological communities. MjM software design, Gleneden Beach, Oregon.

McCune, B. y M. Mefford. 2006. PC-ORD. Multivariate analysis of ecological data, version 5. MjM Software, Gleneden Beach, Oregon.

Madrigal, X. 1990. Ensayo metodológico para la determinación del estado natural forestal en la región oriental del estado de Michoacán, México. Tesis, Maestría Facultad de Ciencias, Universidad Nacional Autónoma de México, México, D. F. 80 p. 
Martínez, J. 1988. La vegetación de la zona noreste del Pico de Orizaba, Veracruz, México. Facultad de Biología, Universidad Veracruzana, Xalapa, Veracruz. 96 p.

Martínez, M., R. Cruz, J. Castrejón, S. Valencia, J. Jiménez y C. A. Ruiz-Jiménez. 2004. Flora vascular de la porción guerrerense de la sierra de Taxco, Guerrero, México. Anales del Instituto de Biología, Universidad Nacional Autónoma de México, Serie Botánica 75:105-189.

Martínez-Meléndez, J., M. Pérez-Farrera y O. Farrera-Sarmiento. 2008. Inventario florístico del cerro el Cebú y zonas adyacentes en la Reserva de la Biosfera El Triunfo (polígono V), Chiapas, México. Boletín de la Sociedad Botánica de México 82:21-40.

Mascarúa, L. 2000. Reintroducción de plántulas de dos especies arbóreas en sitios degradadosd del bosque mesófilo en el norte de Chiapas, México. Tesis, Facultad de Ciencias, Universidad Nacional Autónoma de México, México D. F. $92 \mathrm{p}$.

Mayorga, R., I. Luna-Vega y O. Alcántara. 1998. Florística del bosque mesófilo de montaña de Molocotlán, MolangoXochicoatlán, Hidalgo, México. Boletín de la Sociedad Botánica de México 63:101-119.

Meave, J., M. Soto, L. Calvo, H. Paz y S. Valencia. 1992. Análisis sinecológico del bosque mesófilo de montaña, Omiltemi, Guerrero. Boletín de la Sociedad Botánica de México 52: 31-77.

Medina, C. y S. Rodríguez. 1993. Estudio florístico de la cuenca del río Chiquito de Morelia, Michoacán, México. Flora del Bajío y de Regiones Adyacentes. Fascículo complementario IV. Centro Regional del Bajío, INECOL, Pátzcuaro, Michoacán. 71 p.

Medina, C., F. Guevara-Fefer, M. Martínez P. Silvia-Sáenz, M. Chávez-Carvajal e I. García. 2000. Estudio florístico en el área de la comunidad indígena de Nuevo San Juan Parangaricutiro, Michoacán, México. Acta Botanica Mexicana 52:5-41.

Mehltreter, K. 2008. Helechos. In Agroecosistemas cafetaleros de Veracruz. Biodiversidad manejo y conservación, R. Manson, V. Hernández-Ortiz, S. Gallina y K. Mehltreter (eds.). Instituto de Ecología, Xalapa, Veracruz/ Instituto Nacional de Ecología, México, D. F. p. 83-94.

Mejía-Domínguez, N. 2003. Análisis estructural en una parcela de una hectárea de bosque mesófilo de montaña en el extremo oriental de la sierra Madre del Sur (Oaxaca), México. Tesis, Facultad de Ciencias, Universidad Nacional Autónoma de México, México, D. F. 72 p.

Mejía-Domínguez, N., J. Meave y C. A. Ruiz-Jiménez. 2004. Análisis estructural de un bosque mesófilo de montaña en el extremo oriental de la sierra Madre del Sur (Oaxaca) México. Boletín de la Sociedad Botánica de México 74:13-29.

Mendoza, P., C. A. Ruiz-Jiménez, J. Escutia y N. MejíaDomínguez. 2005. Propuesta metodológica para la restauración de un tramo carretero: reintroducción selectiva de especies clave. Memorias del I Simposio, Ecología, manejo y conservación de los ecosistemas de montaña en México, 17-18 de noviembre, 2005, Instituto de Ecología, Xalapa, Veracruz.

Miranda, F. y A. Sharp. 1950. Characteristics of the vegetation in certain temperate regions of Eastern Mexico. Ecology 31:313-333

Miranda, M. y M. González. 1993. Estudio de la vegetación y florística de la mesa basáltica de Holotepec, distrito de Tenango del Valle, Estado de México. Tesis, Escuela Nacional de Estudios Profesionales Iztacala, Universidad Nacional Autónoma de México, Los Reyes Ixtacala, Estado de México. 96 p.

Montalvo, L. 2006. Composición florística y manejo de la vegetación leñosa de los cafetales en la sierra Madre del Sur, Oaxaca. Tesis, Maestría Colegio de Postgraduados, Texcoco, Estado de México. 105 p.

Muñoz, M. 1992. Distribución de especies arbóreas del bosque mesófilo de montaña en la Reserva de la Biosfera Sierra de Manantlán. Tesis, Facultad de Ciencias Biológicas, Universidad de Guadalajara, Jalisco. 102 p.

Ohmann, J. y T. Spies. 1988. Regional gradient analysis and spatial pattern of woody plant communities of Oregon forests. Ecological Monographs 68:151-182.

Orozco, M. 1995. Vegetación del municipio de Temascaltepec, Estado de México. Tesis, Escuela Nacional de Estudios Profesionales Iztacala, Universidad Nacional Autónoma de México. Los Reyes Ixtacala, Estado de México.100 p.

Osorio, A. 2003. Estudio comparativo de dos sitios de regeneración (natural y artificial) en potreros abandonados con vegetación anterior de bosque mesófilo de montaña en el Municipio de San Andrés Tlalnelhuayocan, Veracruz, México. Tesis, Facultad de Biología, Universidad Veracruzana, Xalapa, Veracruz. $60 \mathrm{p}$.

Padilla, E., R. Cuevas y S. Koch. 2008. Plantas vasculares y vegetación de la parte alta del Arroyo Agua Fría, municipio de Minatitlán, Colima, México. Acta Botanica Mexicana $84: 25-72$.

Palacio-Prieto, J., G. Bocco, A. Velázquez, J. Mas, F. TakakiTakaki, A. Victoria, L. Luna-González, G. Gómez-Rodríguez, J. López-García, M. Palma, I. Trejo-Vázquez, A. Peralta, J. Prado-Molina, A. Rodríguez-Aguilar, R. Mayorga-Saucedo y F. González-Medrano. 2000. La condición actual de los recursos forestales en México: resultados del Inventario Forestal Nacional 2000. Investigaciones Geográficas, Boletín del Instituto de Geografía, Universidad Nacional Autónoma de México 43: 183-202.

Pérez-Cálix, E. 1996. Flora y vegetación de la cuenca del lago Zirahuén, Michoacán, México. Flora del Bajío y de Regiones Adyacentes, fascículo complementario XIII. 73 p.

Peterson, T., L. Canseco, J. Contreras, G. Escalona-Segura, 
O. Flores-Villela, J. García, B. Hernández-Baños, C. A. Ruiz-Jiménez, L. León-Paniagua, S. Mendoza, A. NavarroSigüenza, V. Sánchez-Cordero y D. Willard. 2004. A preliminary biological survey of cerro Piedra Larga, Oaxaca, México: birds, mammals, reptiles, amphibians, and plants. Anales del Instituto de Biología, Universidad Nacional Autónoma de México, Serie Zoológica 75: 439-466.

Ponce-Vargas, A., I. Luna-Vega, O. Alcántara y C.A. RuizJiménez. 2006. Florística del bosque mesófilo de montaña de Monte Grande, Lolotla, Hidalgo, México. Revista Mexicana de Biodiversidad 77:177-190.

Puig, H., R. Bracho y V. Sosa. 1983. Composición florística y estructura del bosque mesófilo en Gómez Farías, Tamaulipas, México. Biotica 8:339-359.

Puig, H. y R. Bracho (eds.). 1987. El bosque mesófilo de montaña de Tamaulipas. Instituto de Ecología, Xalapa, Veracruz, 186 p.

Puig, H. 1989. Análisis fitogeográfico del bosque mesófilo de Gómez Farías. Biotam 1: 34-53.

Quintos, A., I. Luna-Vega, O. Alcántara y C. A. Ruiz-Jiménez. 2004. Síndrome de dispersión de plantas representativas del bosque mesófilo de montaña del estado de Hidalgo, México. Memorias del XVI Congreso Mexicano de Botánica, 17-22 octubre, Oaxaca, Oaxaca.

Ramírez, F. 1999. Flora y vegetación de la sierra de Santa Marta, Veracruz. Tesis, Facultad de Ciencias, Universidad Nacional Autónoma de México, México, D. F. 409 p.

Ramírez-Marcial, N., S. Ochoa-Gaona, M. González-Espinosa y P. Quintana-Ascencio. 1998. Análisis florístico y sucesional en la estación biológica Cerro Huitepec, Chiapas, México. Acta Botanica Mexicana 44: 59-85.

Ramírez-Marcial, N. 2001. Diversidad florística del bosque mesófilo de montaña en el norte de Chiapas y su relación con México y Centroamérica. Boletín de la Sociedad Botánica de México 69:63-76.

Reyes, G. y A. Breceda. 1985. Análisis de la composición florística y estructura de la vegetación secundaria derivada de un bosque mesófilo de montaña en Gómez Farías, Tamaulipas (México). Tesis, Facultad de Ciencias, Universidad Nacional Autónoma de México, México, D. F. 168 p. Centro Regional del Bajío, Pátzcuaro, Michoacán. 168 p.

Reyes, M. 2003. Estudio de la vegetación en los municipios de Honey y Pahuatlán de la sierra Norte de Puebla, Puebla. Tesis. Facultad de Ciencias, Universidad Nacional Autónoma de México, México, D. F. 81 p.

Reynoso, J. 2004. Florística y fitogeografía de la flora arbórea del bosque mesófilo de montaña en San Sebastián del Oeste, Jalisco, México. Tesis, Maestría, Centro Universitario de Ciencias Biológicas y Agropecuarias. Departamento de Botánica y Zoología, Universidad de Guadalajara, Jalisco. $97 \mathrm{p}$.

Rincón, A. 2007. Estructura y composición florística de los bosques tropicales húmedos de montaña de Santa Cruz Tepetotutla,
Oaxaca, México. Tesis, Facultad de Ciencias, Universidad Nacional Autónoma de México, México, D. F. 105 p.

Ruiz-Jiménez, C.A. 1995. Análisis estructural del bosque mesófilo de la región de Huautla de Jiménez (Oaxaca), México. Tesis, Facultad de Ciencias, Universidad Nacional Autónoma de México, México, D. F. 103 p.

Ruiz-Jiménez, C. A., J. Meave y J. L. Contreras. 2000. El bosque mesófilo de la región de Huautla de Jiménez (Oaxaca), México: análisis estructural. Boletín de la Sociedad Botánica de México 65:23-37.

Ruiz-Jiménez, C. A., J. Escutia, N. Mejía-Domínguez y P. Mendoza.2005. Estructura y composición de la vegetación sobre un trazo carretero: un estudio en un bosque amenazado. Memorias del I Simposio Ecología, manejo y conservación de los ecosistemas de montaña en México, 17-18.XI.2005, Instituto de Ecología, Xalapa, Veracruz.

Rzedowski, J. 1966. Vegetación del estado de San Luis Potosí. Acta Científica Potosina 5:5-291.

Rzedowski, J. y R. McVaugh. 1966. Bosque mesófilo de montaña. In La vegetación de Nueva Galicia. Contributions of the University of Michigan Herbarium 9:1-123.

Rzedowski, J. 1970. Nota sobre el bosque mesófilo de montaña en el Valle de México. Anales de la Escuela Nacional de Ciencias Biológicas, México 18:91-106.

Rzedowski, J. y R. Palacios-Chávez. 1977. El bosque de Engelhardtia (Oreomunnea) mexicana en la región de la Chinantla (Oaxaca, México). Una reliquia del Cenozoico. Boletín de la Sociedad Botánica de México 36:93-123.

Rzedowski, J. 1978. Vegetación de México. Limusa, México, D. F. 432 p.

Rzedowski, J. y T. Reyna-Trujillo. 1990. Divisiones florísticas. Tópicos fitogeográficos (provincias, matorral xerófilo y cactáceas). IV. 8.3. In Atlas Nacional de México, vol. II. Escala 1:8000000. Instituto de Geografía, UNAM, México, D. F.

Rzedowski, J. 1991. Diversidad y orígenes de la flora fanerogámica de México. Acta Botanica Mexicana 14 3-21.

Saavedra-Millán, F. 2009. Estudio de la vegetación del Parque Estatal Francisco Torres Moreno, Cerro del Huixteco, Taxco, Guerrero, México. Tesis, Facultad de Ciencias, Universidad Nacional Autónoma de México, México, D. F. 161 p.

Sahagún, E. 2004. Ordenación del bosque mesófilo en el cerro La Mona, sierra de Coalcomán, México, en el contexto del cambio climático. Tesis, Doctorado Centro Universitario de Ciencias Biológicas y Agropecuarias. Universidad de Guadalajara. Zapopan, Jalisco. 115 p.

Sánchez, G. 2001. Estudio de la interacción planta-herbívoro en el bosque mesófilo de la Reserva de la Biosfera El Cielo, Tamaulipas, México. Tesis, Doctorado Facultad de Ciencias, Universidad Nacional Autónoma de México. México, D. F. 157 p.

Sánchez-González, A. y L. López-Mata. 2003. Clasificación y 
ordenación de la vegetación del norte de la sierra Nevada a lo largo de un gradiente altitudinal. Anales del Instituto de Biología, Universidad Nacional Autónoma de México, Serie Botánica 74: 47-71.

Sánchez-González, A. 2004. Análisis sinecológico, florístico y biogeográfico de la vegetación del norte de la sierra Nevada. Tesis, Doctorado Colegio de Postgraduados, Texcoco, Estado de México. 153 p.

Sánchez-Rodríguez, E. 2002. Estructura, composición florística y diversidad de especies arbóreas de un bosque mesófilo de montaña en Cuzalapa, Sierra de Manantlán, Jalisco, México. Tesis, Maestría Colegio de Postgraduados, Texcoco, Estado de México.133 p.

Sánchez-Rodríguez, E., L. López-Mata, E. García-Moya y R. Cuevas-Guzmán. 2003. Estructura, composición florística y diversidad de especies leñosas de un bosque mesófilo de montaña en la sierra de Manantlán, Jalisco. Boletín de la Sociedad Botánica de México 73:17-34.

Santiago, A. 1992. Estudio fitosociológico del bosque mesófilo de montaña de la sierra de Manantlán. Tesis, Facultad de Ciencias Biológicas, Universidad de Guadalajara, Jalisco. 111 p.

Santiago, A. y E. Jardel. 1993. Composición y estructura del bosque mesófilo de montaña en la sierra de Manantlán, Jalisco-Colima. Biotam 5:13-26.

Santiago, A. 2006. Efecto de la fragmentación en la diversidad del bosque mesófilo de montaña, Sierra de Manantlán, México. Tesis, Maestría.Centro Universitario de Ciencias Biológicas y Agropecuarias, Universidad de Guadalajara, Zapopan, Jalisco. 79 p.

SEMARNAT (Secretaría del Medio Ambiente y Recursos Naturales). 2010. Norma Oficial Mexicana NOM-059SEMARNAT-2010, protección ambiental-especies nativas de México de flora y fauna silvestres-categorías de riesgo y especificaciones para su inclusión, exclusión o cambio-lista de especies en riesgo. Diario Oficial de la Federación, 30 de diciembre, México, D. F.

Smith, M. 1995. La riqueza y diversidad de la flora arbórea de un bosque mesófilo de montaña del centro de Veracruz, bajo dos condiciones distintas de exposición. Tesis Facultad de Biología, Universidad Veracruzana, Xalapa, Veracruz. 377 p.

Soto, M. y L. Gama. 1997. Climas. In Historia natural de Los Tuxtlas, E. González-Soriano, R. Dirzo y R. Vogt (eds.). UNAM/ CONABIO, México, D. F. p 7-23.

Soto, M. 2004. El clima. In Los Tuxtlas, el paisaje de la sierra, S. Guevara, J. Laborde y G. Sánchez-Ríos (eds.). Instituto de Ecología, Xalapa, Veracruz. p 196-198.

Stadtmuller, T. 1987. Los bosques nublados en el trópico húmedo. Universidad de las Naciones Unidas, Turrialba. 85 p.

Téllez-Valdés, O. 1995. Flora, vegetación y fitogeografía de Nayarit, México. Tesis, Maestría Facultad de Ciencias, Universidad Nacional Autónoma de México, México, D. F. $166 \mathrm{p}$.
Toledo, V. 1982. Pleistocene changes of vegetation in tropical Mexico. In Biological diversification in tropics, G. T. Prance (ed.). Columbia University Press. Nueva York. p 93-111.

Tolomé, J. 1993. Caída de hojarasca y comportamiento fenológico de las especies arbóreas del bosque mesófilo de montaña del Parque Ecológico Francisco Javier Clavijero (Xalapa, Ver.). Tesis, Facultad de Biología, Universidad Veracruzana, Xalapa, Veracruz. 74 p.

Torres, M. 1991. Estudio florístico de la sierra de Sultepec, Estado de México. Tesis, Escuela Nacional de Estudios Profesionales Iztacala, Universidad Nacional Autónoma de México. Los Reyes Ixtacala, Estado de México. 49 p.

Trejo, I. 2004. Clima. In Biodiversidad de Oaxaca, A. GarcíaMendoza, M. Ordóñez y M. Briones-Salas (eds.). UNAM/ Fondo Oaxaqueño para la Conservación de la Naturaleza/ WWF, México, D. F. p 67-85.

Valdez, V., R. Foroughbakhch y G. Alanís. 2003. Distribución relictual del bosque mesófilo de montaña en el noroeste de México. Ciencia, Universidad Autónoma de Nuevo León 6:360-365.

Vargas, Y. 1982. Análisis florístico y fitogeográfico de un bosque mesófilo de montaña en Huayacocotla, Ver. Tesis, Facultad de Ciencias, Universidad Nacional Autónoma de México, México, D. F. 105 p.

Vargas, Y. 2005. Ecology of disjunct cloud forest sugar maple populations (Acer saccharum subsp. skutchii) in north and central America. Master in Sciences Thesis, Louisiana State University and Agricultural and Mechanical College, Baton Rouge. $122 \mathrm{p}$.

Vázquez-García, J. 1993. Cloud forest archipelagos: Preservation of fragmented montane ecosystems in tropical America. In Tropical montane cloud forests. Ecological Studies 110. L. S. Hamilton, J. O. Juvik y F. N. Scatena (eds.). Springer, New York, p 315-332.

Vázquez, J., R. Cuevas, T. Cochrane, H. Iltis, F. Santana y L. Guzmán. 1995. Flora de Manantlán. Sida, Botanical Miscellany 13 -IMECBIO-Universidad de Guadalajara/ Universidad de Wisconsin-Madison- Botanical Research Institute of Texas, Fort Worth. 316 p.

Vázquez, J., Y. Vargas y F. Aragón. 1999. Descubrimiento de un bosque de Acer-Podocarpus-Abies en el municipio de Talpa de Allende, Jalisco, México. Boletín del Instituto de Botánica de la Universidad de Guadalajara 7:159-183.

Vázquez, M., J. Campos y A. Cruz. 2006. Los helechos y plantas afines del bosque mesófilo de montaña de Banderilla, Veracruz, México. Polibotánica 22:63-77.

Vázquez, V. 2000. Riqueza fanerogámica del municipio de Jilotepec, Veracruz, México. Tesis, Maestría Instituto de Genética Forestal,Universidad Veracruzana. Xalapa, Veracruz. 232 p.

Williams-Linera, G. 1991. Nota sobre la estructura del estrato arbóreo del bosque mesófilo de montaña en los alrededores 
del campamento "El Triunfo", Chiapas. Acta Botanica Mexicana 13:1-7.

Williams-Linera, G., I. Pérez-García y J. Tolomé. 1996. El bosque mesófilo de montaña y un gradiente altitudinal del centro de Veracruz, México. La Ciencia y El Hombre. Universidad Veracruzana 23:149-161

Williams-Linera, G. y A. López-Gómez. 2008. Estructura y diversidad de la vegetación leñosa. In Agroecosistemas cafetaleros de Veracruz. Biodiversidad manejo y conservación, R. Manson, V. Hernández-Ortiz, S. Gallina y K. Mehltreter (eds.). Instituto de Ecología, Xalapa, Veracruz/ Instituto Nacional de Ecología, México, D. F. p 55-68.

Villaseñor, J. L. 2010. El bosque húmedo de montaña de México y sus plantas vasculares: catálogo florístico-taxonómico. UNAM/ CONABIO. México, D. F. 38 p.

Zamora, P. 1992. Flora vascular del municipio de Tlalnelhueyocan, Veracruz. Tesis, Facultad de Biología, Universidad Veracruzana, Xalapa, Veracruz. 104 p.

Zamudio, S., J. Rzedowski, E. Carranza y G. Calderón-de Rzedowski. 1992. La vegetación del estado de Querétaro. Panorama preliminar. Centro Regional del Bajío, INECOL, Querétaro, Querétaro. 92 p. Pátzcuaro, Michoacán. 92 p.

Zarco, P. 2000. Análisis de la vegetación y fauna asociada en bosques templados del Parque Nacional Lagunas de Montebello, Chiapas. Tesis, Escuela Nacional de Estudios Profesionales Iztacala, Universidad Nacional Autónoma de México, Los Reyes Ixtacala, Estado de México. 61 p. 
Cuadro 1. Ubicación de localidades con BMM en la República Mexicana

\begin{tabular}{|c|c|c|c|c|c|}
\hline Núm.. & Localidad & Estado (s) & Coordenadas extremas & $\begin{array}{c}\text { Provincia florística } \\
\text { sensu Rzedowski (1978) } \\
\text { y Rzedowski y Trujillo } \\
\text { (1990); entre paréntesis las } \\
\text { subprovincias geológicas } \\
\text { de Ferrusquía-Villafranca } \\
\text { (1993) }\end{array}$ & Autor (es) \\
\hline 1 & Montebello & Chiapas & $\begin{array}{l}16^{\circ} 04^{\prime} 40^{\prime \prime}-16^{\circ} 10^{\prime} 20^{\prime \prime} \mathrm{N} / \\
91^{\circ} 37^{\prime} 40^{\prime \prime}-91^{\circ} 47^{\prime} 40^{\prime \prime} \mathrm{O}\end{array}$ & $\begin{array}{c}\text { Serranías Transístmicas } \\
\text { (Meseta central de } \\
\text { Chiapas) }\end{array}$ & $\begin{array}{l}\text { Carlson (1954), } \\
\text { Zarco (2000) }\end{array}$ \\
\hline 2 & Misantla & Veracruz & $\begin{array}{l}19^{\circ} 44^{\prime} 58^{\prime \prime}-19^{\circ} 52^{\prime} 09^{\prime \prime} \mathrm{N} / \\
96^{\circ} 48^{\prime} 34^{\prime \prime}-96^{\circ} 55^{\prime} 23^{\prime \prime} \mathrm{O}\end{array}$ & $\begin{array}{l}\text { Sierra Madre Oriental (Faja } \\
\text { Volcánica Transmexicana) }\end{array}$ & $\begin{array}{l}\text { Gómez-Pompa } \\
\text { (1966) }\end{array}$ \\
\hline 3 & Xilitla & San Luis Potosí & $\begin{array}{l}21^{\circ} 16^{\prime} 18^{\prime \prime}-21^{\circ} 24^{\prime} 18^{\prime \prime} \mathrm{N} / \\
99^{\circ} 01^{\prime} 55^{\prime \prime}-99^{\circ} 06^{\prime} 00^{\prime \prime} \mathrm{O}\end{array}$ & $\begin{array}{l}\text { Sierra Madre Oriental } \\
\text { (Sierra Madre Oriental) }\end{array}$ & Rzedowski (1966) \\
\hline 4 & Nueva Galicia & $\begin{array}{l}\text { Colima, Nayarit, } \\
\text { Jalisco y Michoacán }\end{array}$ & $\begin{array}{l}18^{\circ} 45^{\prime} 10^{\prime \prime}-22^{\circ} 54^{\prime} 14^{\prime \prime} \mathrm{N} / \\
100^{\circ} 44^{\prime} 16^{\prime \prime}-105^{\circ} 13^{\prime} 12^{\prime \prime} \mathrm{O}\end{array}$ & $\begin{array}{l}\text { Serranías Meridionales } \\
\text { (Sierra Madre Oriental, } \\
\text { Faja Volcánica } \\
\text { Transmexicana, Sierra } \\
\text { Madre del Sur ) }\end{array}$ & $\begin{array}{c}\text { Rzedowski y } \\
\text { McVaugh (1966) }\end{array}$ \\
\hline 5 & Valle de México & $\begin{array}{l}\text { Distrito Federal y } \\
\text { Estado de México }\end{array}$ & $\begin{array}{l}18^{\circ} 45^{\prime} 10^{\prime \prime}-19^{\circ} 34^{\prime} 08^{\prime \prime} \mathrm{N} / \\
98^{\circ} 42^{\prime} 40^{\prime \prime}-99^{\circ} 24^{\prime} 35^{\prime \prime} \mathrm{O}\end{array}$ & $\begin{array}{c}\text { Serranías Meridionales } \\
\text { (Faja Volcánica } \\
\text { Transmexicana) }\end{array}$ & Rzedowski (1969) \\
\hline 6 & Córdoba & Veracruz & $\begin{array}{l}18^{\circ} 20^{\prime} 00^{\prime \prime}-19^{\circ} 12^{\prime} 00^{\prime \prime} \mathrm{N} / \\
96^{\circ} 36^{\prime} 00^{\prime \prime}-97^{\circ} 08^{\prime} 00^{\prime \prime} \mathrm{O}\end{array}$ & $\begin{array}{l}\text { Serranías Meridionales } \\
\text { (Sierra Norte de Oaxaca) }\end{array}$ & Chiang (1970) \\
\hline 7 & $\begin{array}{l}\text { Volcán San } \\
\text { Martín }\end{array}$ & Veracruz & $\begin{array}{l}18^{\circ} 33^{\prime} 06^{\prime \prime}-18^{\circ} 34^{\prime} 03^{\prime \prime} \mathrm{N} / \\
95^{\circ} 10^{\prime} 49^{\prime \prime}-95^{\circ} 12^{\prime} 41^{\prime \prime} \mathrm{O}\end{array}$ & $\begin{array}{c}\text { Costa del Golfo de México } \\
\text { (Planicie Costera del Golfo } \\
\text { de México) }\end{array}$ & $\begin{array}{c}\text { Álvarez del Castillo } \\
\text { (1977) }\end{array}$ \\
\hline 8 & Chinantla & Oaxaca & $\begin{array}{l}17^{\circ} 35^{\prime} 03 ”-17^{\circ} 37^{\prime} 05^{\prime \prime} \mathrm{N} / \\
96^{\circ} 22^{\prime} 10^{\prime \prime}-96^{\circ} 28^{\prime} 09^{\prime \prime} \mathrm{O}\end{array}$ & $\begin{array}{l}\text { Serranías Meridionales } \\
\text { (sierra Norte de Oaxaca) }\end{array}$ & $\begin{array}{c}\text { Rzedowski y } \\
\text { Palacios-Chávez } \\
\text { (1977) }\end{array}$ \\
\hline 9 & Huayacocotla & Veracruz & $\begin{array}{l}20^{\circ} 32^{\prime} 29^{\prime \prime}-20^{\circ} 38^{\prime} 48^{\prime \prime} \mathrm{N} / \\
98^{\circ} 25^{\prime} 36^{\prime \prime}-98^{\circ} 29^{\prime} 32^{\prime \prime} \mathrm{O}\end{array}$ & $\begin{array}{l}\text { Sierra Madre Oriental } \\
\text { (Sierra Madre Oriental) }\end{array}$ & $\begin{array}{l}\text { Vargas (1982), } \\
\text { Ballesteros (1986), } \\
\text { Juárez (2008) }\end{array}$ \\
\hline 10 & $\begin{array}{l}\text { Reserva de } \\
\text { la Mariposa } \\
\text { Monarca }\end{array}$ & $\begin{array}{l}\text { Estado de México y } \\
\text { Michoacán }\end{array}$ & $\begin{array}{l}19^{\circ} 57^{\prime} 07^{\prime \prime}-19^{\circ} 59^{\prime} 42^{\prime \prime} \mathrm{N} / \\
100^{\circ} 06^{\prime} 39^{\prime} "-100^{\circ} 09^{\prime} 54^{\prime \prime} \mathrm{O} \text { y } \\
19^{\circ} 18^{\prime} 32^{\prime \prime}-19^{\circ} 44^{\prime} 27^{\prime \prime} \mathrm{N} / \\
100^{\circ} 09^{\prime} 07^{\prime} \text { - } 100^{\circ} 22^{\prime} 26^{\prime \prime} \mathrm{O}\end{array}$ & $\begin{array}{l}\text { Serranías Meridionales } \\
\text { (Faja Volcánica } \\
\text { Transmexicana) }\end{array}$ & $\begin{array}{c}\text { Ibarra (1983), } \\
\text { Cornejo-Tenorio et } \\
\text { al. }(2003)\end{array}$ \\
\hline 11 & Gómez Farías & Tamaulipas & $\begin{array}{l}23^{\circ} 03^{\prime} 53^{\prime \prime}-23^{\circ} 07^{\prime} 06^{\prime \prime} \mathrm{N} / \\
99^{\circ} 10^{\prime} 53^{\prime \prime}-99^{\circ} 12^{\prime} 36^{\prime \prime} \mathrm{O}\end{array}$ & $\begin{array}{l}\text { Sierra Madre Oriental } \\
\text { (Sierra Madre Oriental) }\end{array}$ & $\begin{array}{c}\text { Puig y Bracho } \\
\text { (1983), Reyes } \\
\text { y Breceda } \\
\text { (1985),Puig y } \\
\text { Bracho (1987), } \\
\text { Puig (1989), } \\
\text { Arriaga (1994), } \\
\text { Sánchez (2001) }\end{array}$ \\
\hline
\end{tabular}


Cuadro 1. Continúa

\begin{tabular}{|c|c|c|c|c|c|}
\hline Núm.. & Localidad & Estado (s) & Coordenadas extremas & $\begin{array}{c}\text { Provincia florística } \\
\text { sensu Rzedowski (1978) } \\
\text { y Rzedowski y Trujillo } \\
\text { (1990); entre paréntesis las } \\
\text { subprovincias geológicas } \\
\text { de Ferrusquía-Villafranca } \\
\text { (1993) }\end{array}$ & Autor (es) \\
\hline 12 & Omiltemi & Guerrero & $\begin{array}{l}17^{\circ} 30^{\prime} 33^{\prime \prime}-17^{\circ} 35^{\prime} 11^{\prime \prime} \mathrm{N} / \\
99^{\circ} 39^{\prime} 27^{\prime \prime}-99^{\circ} 44^{\prime} 04^{\prime \prime} \mathrm{O}\end{array}$ & $\begin{array}{l}\text { Serranías Meridionales } \\
\text { (Sierra Madre del Sur) }\end{array}$ & $\begin{array}{l}\text { García (1988), } \\
\text { Meave et al. } \\
\text { (1992), Jiménez et } \\
\text { al. (1993) }\end{array}$ \\
\hline 13 & Cerro Salomón & Oaxaca & $\begin{array}{l}16^{\circ} 30^{\prime} 00^{\prime \prime}-16^{\circ} 46^{\prime} 15^{\prime \prime} \mathrm{N} / \\
94^{\circ} 00^{\prime} 00^{\prime \prime}-94^{\circ} 15^{\prime} 00^{\prime \prime} \mathrm{O}\end{array}$ & $\begin{array}{c}\text { Serranías Meridionales } \\
\text { (Sierra Madre de Chiapas) }\end{array}$ & Ishiki (1988) \\
\hline 14 & Teocelo & Veracruz & $\begin{array}{l}19^{\circ} 18^{\prime} 59^{\prime \prime}-19^{\circ} 23^{\prime} 23^{\prime \prime} \mathrm{N} / \\
96^{\circ} 57^{\prime} 58^{\prime \prime}-97^{\circ} 05^{\prime} 46^{\prime \prime} \mathrm{O}\end{array}$ & $\begin{array}{l}\text { Sierra Madre Oriental (Faja } \\
\text { Volcánica Transmexicana) }\end{array}$ & $\begin{array}{l}\text { Luna-Vega et al. } \\
\qquad(1988)\end{array}$ \\
\hline 15 & $\begin{array}{c}\text { Noreste del Pico } \\
\text { de Orizaba }\end{array}$ & Veracruz & $\begin{array}{l}19^{\circ} 07^{\prime} 03 ”-19^{\circ} 10^{\prime} 03 ” \mathrm{~N} / \\
97^{\circ} 02^{\prime} 39^{\prime \prime}-97^{\circ} 06^{\prime} 23^{\prime \prime} \mathrm{O}\end{array}$ & $\begin{array}{c}\text { Serranías Meridionales } \\
\text { (Faja Volcánica } \\
\text { Transmexicana) }\end{array}$ & Martínez (1988) \\
\hline 16 & Ocuilan & $\begin{array}{l}\text { Estado de México, } \\
\text { Morelos }\end{array}$ & $\begin{array}{l}18^{\circ} 58^{\prime} 12^{\prime \prime}-19^{\circ} 02^{\prime} 07^{\prime \prime} \mathrm{N} / \\
99^{\circ} 16^{\prime} 32^{\prime \prime}-99^{\circ} 21^{\prime} 37^{\prime \prime} \mathrm{O}\end{array}$ & $\begin{array}{c}\text { Serranías Meridionales } \\
\text { (Faja Volcánica } \\
\text { Transmexicana) }\end{array}$ & $\begin{array}{l}\text { Luna-Vega et al. } \\
\qquad(1989)\end{array}$ \\
\hline 17 & Jocotepec & Jalisco & $\begin{array}{l}20^{\circ} 20^{\prime} 40^{\prime \prime}-20^{\circ} 23^{\prime} 16^{\prime \prime} \mathrm{N} / \\
103^{\circ} 22^{\prime} 50^{\prime \prime}-103^{\circ} 26^{\prime} 47^{\prime \prime} \mathrm{O}\end{array}$ & $\begin{array}{c}\text { Serranías Meridionales } \\
\text { (Faja Volcánica } \\
\text { Transmexicana) }\end{array}$ & Machuca (1989) \\
\hline 18 & Zacualpan & Estado de México & $\begin{array}{l}18^{\circ} 38^{\prime} 50^{\prime \prime}-18^{\circ} 43^{\prime} 37^{\prime \prime} \mathrm{N} / \\
99^{\circ} 46^{\prime} 06^{\prime \prime}-99^{\circ} 51^{\prime} 21^{\prime \prime} \mathrm{O}\end{array}$ & $\begin{array}{l}\text { Serranías Meridionales } \\
\text { (Depresión del Balsas) }\end{array}$ & Fragoso (1990) \\
\hline 19 & Morelia & Michoacán & $\begin{array}{l}19^{\circ} 40^{\prime} 15^{\prime \prime}-19^{\circ} 48^{\prime} 31^{\prime \prime} \mathrm{N} / \\
101^{\circ} 08^{\prime} 40^{\prime \prime}-101^{\circ} 14^{\prime} 53^{\prime \prime} \mathrm{O}\end{array}$ & $\begin{array}{c}\text { Serranías Meridionales } \\
\text { (Faja Volcánica } \\
\text { Transmexicana) }\end{array}$ & $\begin{array}{l}\text { Madrigal (1990), } \\
\text { Madrigal y Guridi } \\
\text { (inédito), López } \\
\text { (1997) }\end{array}$ \\
\hline 20 & $\begin{array}{l}\text { Sierra de San } \\
\quad \text { Carlos }\end{array}$ & Tamaulipas & $\begin{array}{l}24^{\circ} 31^{\prime} 21^{\prime \prime}-24^{\circ} 38^{\prime} 33^{\prime \prime} \mathrm{N} / \\
98^{\circ} 57^{\prime} 15^{\prime \prime}-99^{\circ} 05^{\prime} 41^{\prime \prime} \mathrm{O}\end{array}$ & $\begin{array}{l}\text { Sierra Madre Oriental } \\
\text { (Sierra Madre Oriental) }\end{array}$ & Briones (1991) \\
\hline 21 & El Triunfo & Chiapas & $\begin{array}{l}15^{\circ} 35^{\prime} 36^{\prime \prime}-15^{\circ} 43^{\prime} 17^{\prime \prime} \mathrm{N} / \\
92^{\circ} 41^{\prime} 57^{\prime \prime}-92^{\circ} 52^{\prime} 38^{\prime \prime} \mathrm{O}\end{array}$ & $\begin{array}{c}\text { Soconusco (Sierra Madre } \\
\text { de Chiapas) }\end{array}$ & $\begin{array}{l}\text { Long y Heath } \\
\qquad(1991)\end{array}$ \\
\hline 22 & $\begin{array}{l}\text { Sierra de } \\
\text { Sultepec }\end{array}$ & Estado de México & $\begin{array}{l}18^{\circ} 41^{\prime} 36^{\prime \prime}-18^{\circ} 53^{\prime} 11^{\prime \prime} \mathrm{N} / \\
99^{\circ} 51^{\prime} 32^{\prime \prime}-100^{\circ} 07^{\prime} 37^{\prime \prime} \mathrm{O}\end{array}$ & $\begin{array}{l}\text { Serranías Meridionales } \\
\text { (Depresión del Balsas) }\end{array}$ & Torres (1991) \\
\hline 23 & Coacoatzintla & Veracruz & $\begin{array}{l}19^{\circ} 38^{\prime} 55^{\prime \prime}-19^{\circ} 39^{\prime} 15^{\prime \prime} \mathrm{N} / \\
96^{\circ} 56^{\prime} 45^{\prime \prime}-96^{\circ} 57^{\prime} 12^{\prime \prime} \mathrm{O}\end{array}$ & $\begin{array}{l}\text { Sierra Madre Oriental (Faja } \\
\text { Volcánica Transmexicana) }\end{array}$ & $\begin{array}{l}\text { Croda (1992), } \\
\text { Smith (1995) }\end{array}$ \\
\hline 24 & $\begin{array}{l}\text { Barranca de las } \\
\text { Minas }\end{array}$ & Veracruz & $\begin{array}{l}19^{\circ} 40^{\prime} 48^{\prime \prime}-19^{\circ} 43^{\prime} 57^{\prime \prime} \mathrm{N} / \\
97^{\circ} 04^{\prime} 07^{\prime \prime}-97^{\circ} 09^{\prime} 09^{\prime \prime} \mathrm{O}\end{array}$ & $\begin{array}{l}\text { Sierra Madre Oriental (Faja } \\
\text { Volcánica Transmexicana) }\end{array}$ & Durán (1992) \\
\hline
\end{tabular}


Cuadro 1. Continúa

\begin{tabular}{|c|c|c|c|c|c|}
\hline Núm.. & Localidad & Estado (s) & Coordenadas extremas & $\begin{array}{c}\text { Provincia florística } \\
\text { sensu Rzedowski (1978) } \\
\text { y Rzedowski y Trujillo } \\
\text { (1990); entre paréntesis las } \\
\text { subprovincias geológicas } \\
\text { de Ferrusquí-Villafranca } \\
\text { (1993) }\end{array}$ & Autor (es) \\
\hline 25 & Manantlán & Jalisco & $\begin{array}{l}19^{\circ} 25^{\prime} 00^{\prime \prime}-19^{\circ} 45^{\prime} 00^{\prime \prime} \mathrm{N} / \\
103^{\circ} 45^{\prime} 00^{\prime \prime}-104^{\circ} 30^{\prime} 00^{\prime \prime} \mathrm{O}\end{array}$ & $\begin{array}{c}\text { Serranías Meridionales } \\
\text { (Faja Volcánica } \\
\text { Transmexicana) }\end{array}$ & $\begin{array}{c}\text { Muñoz (1992), } \\
\text { Santiago (1992), } \\
\text { Santiago y Jardel } \\
\text { (1993), Vázquez et } \\
\text { al. (1995), Cuevas } \\
\text { (2002), Sánchez- } \\
\text { Rodríguez (2002), } \\
\text { Sánchez-Rodríguez } \\
\text { et al. (2003), } \\
\text { Santiago (2006) }\end{array}$ \\
\hline 26 & Tlalnelhueyocan & Veracruz & $\begin{array}{l}19^{\circ} 30^{\prime} 53 ”-19^{\circ} 33^{\prime} 30^{\prime \prime} \mathrm{N} / \\
96^{\circ} 58^{\prime} 34^{\prime \prime}-97^{\circ} 01^{\prime} 08^{\prime \prime} \mathrm{O}\end{array}$ & $\begin{array}{l}\text { Sierra Madre Oriental (Faja } \\
\text { Volcánica Transmexicana) }\end{array}$ & $\begin{array}{c}\text { Zamora (1992), } \\
\text { Osorio (2003) }\end{array}$ \\
\hline 27 & $\begin{array}{l}\text { Noreste de } \\
\text { Querétaro }\end{array}$ & Querétaro & $\begin{array}{l}21^{\circ} 09^{\prime} 28^{\prime \prime}-21^{\circ} 26^{\prime} 23^{\prime \prime} \mathrm{N} / \\
99^{\circ} 04^{\prime} 39^{\prime \prime}-99^{\circ} 10^{\prime} 50^{\prime \prime} \mathrm{O}\end{array}$ & $\begin{array}{l}\text { Sierra Madre Oriental } \\
\text { (Sierra Madre Oriental) }\end{array}$ & $\begin{array}{l}\text { Zamudio et al. } \\
\text { (1992), Díaz- } \\
\text { Barriga et al. } \\
\quad(1992)\end{array}$ \\
\hline 28 & $\begin{array}{l}\text { San Jerónimo } \\
\text { Coatlán }\end{array}$ & Oaxaca & $\begin{array}{l}16^{\circ} 09^{\prime} 00^{\prime \prime}-16^{\circ} 15^{\prime} 00^{\prime \prime} \mathrm{N} / \\
96^{\circ} 52^{\prime} 00^{\prime \prime}-97^{\circ} 01^{\prime} 00^{\prime \prime} \mathrm{O}\end{array}$ & $\begin{array}{l}\text { Serranías Meridionales } \\
\text { (Sierra Madre del Sur) }\end{array}$ & $\begin{array}{l}\text { Campos (1993), } \\
\text { Campos y } \\
\text { Villaseñor (1995) }\end{array}$ \\
\hline 29 & $\begin{array}{l}\text { Cuenca del Río } \\
\text { Chiquito }\end{array}$ & Michoacán & $\begin{array}{l}19^{\circ} 36^{\prime} 36^{\prime}-19^{\circ} 39^{\prime} 39^{\prime \prime} \mathrm{N} / \\
101^{\circ} 03 ’ 32^{\prime \prime}-101^{\circ} 11^{\prime} 22^{\prime \prime} \mathrm{O}\end{array}$ & $\begin{array}{c}\text { Serranías Meridionales } \\
\text { (Faja Volcánica } \\
\text { Transmexicana) }\end{array}$ & $\begin{array}{c}\text { Medina y } \\
\text { Rodríguez (1993) }\end{array}$ \\
\hline 30 & $\begin{array}{l}\text { Mesa basáltica } \\
\text { de Holotepec }\end{array}$ & Estado de México & $\begin{array}{l}18^{\circ} 59^{\prime} 09^{\prime \prime}-19^{\circ} 03^{\prime} 19^{\prime \prime} \mathrm{N} / \\
99^{\circ} 24^{\prime} 15^{\prime \prime}-99^{\circ} 28^{\prime} 03^{\prime \prime} \mathrm{O}\end{array}$ & $\begin{array}{c}\text { Serranías Meridionales } \\
\text { (Faja Volcánica } \\
\text { Transmexicana) }\end{array}$ & $\begin{array}{c}\text { Miranda y } \\
\text { González (1993) }\end{array}$ \\
\hline 31 & $\begin{array}{c}\text { Parque } \\
\text { Ecológico } \\
\text { Francisco Javier } \\
\text { Clavijero }\end{array}$ & Veracruz & $19^{\circ} 30^{\prime} 30^{\prime \prime} \mathrm{N} / 96^{\circ} 55^{\prime} 00^{\prime \prime} \mathrm{O}$ & $\begin{array}{l}\text { Sierra Madre Oriental (Faja } \\
\text { Volcánica Transmexicana) }\end{array}$ & Tolomé (1993) \\
\hline 32 & El Palmito & Sinaloa & $23^{\circ} 33^{\prime} \mathrm{N} / 105^{\circ} 50^{\prime} \mathrm{O}$ & $\begin{array}{c}\text { Sierra Madre Occidental } \\
\text { (Sierra Madre Occidental) }\end{array}$ & Ahumada (1994) \\
\hline 33 & $\begin{array}{l}\text { Sierra de San } \\
\text { Juan }\end{array}$ & Nayarit & $\begin{array}{l}21^{\circ} 22^{\prime} 47^{\prime \prime}-21^{\circ} 32^{\prime} 05^{\prime \prime} \mathrm{N} / \\
104^{\circ} 55^{\prime} 24^{\prime \prime}-105^{\circ} 03^{\prime} 19^{\prime \prime} \mathrm{O}\end{array}$ & $\begin{array}{c}\text { Serranías Meridionales } \\
\text { (Planicie Costera del } \\
\text { Noroeste) }\end{array}$ & $\begin{array}{l}\text { Blanco (1994), } \\
\text { Téllez-Valdés } \\
\quad(1995)\end{array}$ \\
\hline 34 & Las Joyas & Jalisco & $\begin{array}{l}19^{\circ} 35^{\prime} 40^{\prime \prime}-19^{\circ} 36^{\prime} 46^{\prime \prime} \mathrm{N} / \\
104^{\circ} 14^{\prime} 53^{\prime \prime}-104^{\circ} 16^{\prime} 17^{\prime \prime} \mathrm{O}\end{array}$ & $\begin{array}{c}\text { Serranías Meridionales } \\
\text { (Faja Volcánica } \\
\text { Transmexicana) }\end{array}$ & Cuevas (1994) \\
\hline 35 & Tlanchinol & Hidalgo & $\begin{array}{l}20^{\circ} 57^{\prime} 20^{\prime \prime}-21^{\circ} 01^{\prime} 45^{\prime \prime} \mathrm{N} / \\
98^{\circ} 32^{\prime} 56^{\prime \prime}-98^{\circ} 40^{\prime} 00^{\prime \prime} \mathrm{O}\end{array}$ & $\begin{array}{l}\text { Sierra Madre Oriental } \\
\text { (Sierra Madre Oriental) }\end{array}$ & $\begin{array}{l}\text { Luna-Vega et al. } \\
\text { (1994) }\end{array}$ \\
\hline 36 & $\begin{array}{l}\text { Noroeste de } \\
\text { Michoacán }\end{array}$ & Michoacán & $\begin{array}{l}20^{\circ} 35^{\prime} 00^{\prime \prime}-20^{\circ} 25^{\prime} 00^{\prime \prime} \mathrm{N} / \\
101^{\circ} 40^{\prime} 00^{\prime \prime}-102^{\circ} 30^{\prime} 00^{\prime \prime} \mathrm{O}\end{array}$ & $\begin{array}{c}\text { Serranías Meridionales } \\
\text { (Faja Volcánica } \\
\text { Transmexicana) }\end{array}$ & Labat (1995) \\
\hline
\end{tabular}


Cuadro 1. Continúa

\begin{tabular}{|c|c|c|c|c|c|}
\hline Núm.. & Localidad & Estado (s) & Coordenadas extremas & $\begin{array}{c}\text { Provincia florística } \\
\text { sensu Rzedowski (1978) } \\
\text { y Rzedowski y Trujillo } \\
\text { (1990); entre paréntesis las } \\
\text { subprovincias geológicas } \\
\text { de Ferrusquía-Villafranca } \\
\text { (1993) }\end{array}$ & Autor (es) \\
\hline 37 & Valle de Bravo & Estado de México & $\begin{array}{l}19^{\circ} 06^{\prime} 32^{\prime \prime}-19^{\circ} 10^{\prime} 19^{\prime \prime} \mathrm{N} / \\
100^{\circ} 01^{\prime} 00^{\prime \prime}-100^{\circ} 09^{\prime} 38^{\prime \prime} \mathrm{O}\end{array}$ & $\begin{array}{l}\text { Serranías Meridionales } \\
\text { (Depresión del Balsas) }\end{array}$ & López (1995) \\
\hline 38 & Temascaltepec & Estado de México & $\begin{array}{l}19^{\circ} 00^{\prime} 04^{\prime \prime}-19^{\circ} 00^{\prime} 16^{\prime \prime} \mathrm{N} / \\
99^{\circ} 55^{\prime} 00^{\prime \prime}-100^{\circ} 04^{\prime} 30^{\prime \prime} \mathrm{O}\end{array}$ & $\begin{array}{l}\text { Serranías Meridionales } \\
\text { (Depresión del Balsas) }\end{array}$ & Orozco (1995) \\
\hline 39 & $\begin{array}{l}\text { Huautla de } \\
\text { Jiménez }\end{array}$ & Oaxaca & $\begin{array}{l}18^{\circ} 07^{\prime} 00^{\prime \prime}-18^{\circ} 12^{\prime} 00^{\prime \prime} \mathrm{N} / \\
96^{\circ} 57^{\prime} 00^{\prime \prime}-97^{\circ} 02^{\prime} 00^{\prime \prime} \mathrm{O}\end{array}$ & $\begin{array}{l}\text { Serranías Meridionales } \\
\text { (Sierra Norte de Oaxaca) }\end{array}$ & $\begin{array}{c}\text { Ruiz-Jiménez } \\
\text { (1995), Ruiz- } \\
\text { Jiménez et al. } \\
\text { (2000) }\end{array}$ \\
\hline 40 & $\begin{array}{l}\text { Tenango de } \\
\text { Doria }\end{array}$ & Hidalgo & $\begin{array}{l}19^{\circ} 22^{\prime} 00^{\prime \prime}-20^{\circ} 40^{\prime} 00^{\prime \prime} \mathrm{N} / \\
97^{\circ} 59^{\prime} 00^{\prime \prime}-98^{\circ} 44^{\prime} 00^{\prime \prime} \mathrm{O}\end{array}$ & $\begin{array}{l}\text { Sierra Madre Oriental } \\
\text { (Sierra Madre Oriental) }\end{array}$ & $\begin{array}{l}\text { Alcántara (1996), } \\
\text { Alcántara y Luna- } \\
\text { Vega (1997) }\end{array}$ \\
\hline 41 & Sierra de Juárez & Oaxaca & $\begin{array}{l}17^{\circ} 34^{\prime} 16^{\prime \prime}-17^{\circ} 37^{\prime} 15^{\prime \prime} \mathrm{N} / \\
96^{\circ} 20^{\prime} 00^{\prime \prime}-96^{\circ} 28^{\prime} 35^{\prime \prime} \mathrm{O}\end{array}$ & $\begin{array}{l}\text { Serranías Meridionales } \\
\text { (Sierra Norte de Oaxaca) }\end{array}$ & Boyle (1996) \\
\hline 42 & La Sepultura & Chiapas & $\begin{array}{l}16^{\circ} 01^{\prime} 56^{\prime \prime}-16^{\circ} 24^{\prime} 12^{\prime \prime} \mathrm{N} / \\
93^{\circ} 28^{\prime} 58^{\prime \prime}-93^{\circ} 48^{\prime} 58^{\prime \prime} \mathrm{O}\end{array}$ & $\begin{array}{c}\text { Serranías Transistmicas } \\
\text { (Sierra Madre de Chiapas) }\end{array}$ & Castillo (1996) \\
\hline 43 & $\begin{array}{l}\text { Cuenca del Lago } \\
\text { Zirahuén }\end{array}$ & Michoacán & $\begin{array}{l}19^{\circ} 24^{\prime} 16^{\prime \prime}-19^{\circ} 25^{\prime} 11^{\prime \prime} \mathrm{N} / \\
101^{\circ} 45^{\prime} 01^{\prime \prime}-101^{\circ} 46^{\prime} 01^{\prime \prime} \mathrm{O}\end{array}$ & $\begin{array}{c}\text { Serranías Meridionales } \\
\text { (Faja Volcánica } \\
\text { Transmexicana) }\end{array}$ & Pérez-Cálix (1996) \\
\hline 44 & $\begin{array}{l}\text { Centro de } \\
\text { Veracruz }\end{array}$ & Veracruz & $\begin{array}{l}19^{\circ} 30^{\prime} 00^{\prime \prime}-19^{\circ} 43^{\prime} 59^{\prime \prime} \mathrm{N} / \\
91^{\circ} 19^{\prime} 59^{\prime \prime}-97^{\circ} 15^{\prime} 00^{\prime \prime} \mathrm{O}\end{array}$ & $\begin{array}{l}\text { Sierra Madre Oriental (Faja } \\
\text { Volcánica Transmexicana) }\end{array}$ & $\begin{array}{l}\text { Williams-Linera et } \\
\text { al. (1996) }\end{array}$ \\
\hline 45 & San Joaquín & Querétaro & $\begin{array}{l}20^{\circ} 55^{\prime} 25^{\prime \prime}-20^{\circ} 55^{\prime} 37^{\prime \prime} \mathrm{N} / \\
99^{\circ} 34^{\prime} 02^{\prime \prime}-99^{\circ} 34^{\prime} 09^{\prime \prime} \mathrm{O}\end{array}$ & $\begin{array}{c}\text { Altiplanicie (Sierra Madre } \\
\text { Oriental) }\end{array}$ & $\begin{array}{c}\text { Fernández y } \\
\text { Colmenero (1997) }\end{array}$ \\
\hline 46 & Coatepec & Veracruz & $\begin{array}{l}19^{\circ} 28^{\prime} 00^{\prime \prime}-19^{\circ} 31^{\prime} 00^{\prime \prime} \mathrm{N} / \\
96^{\circ} 56^{\prime} 45^{\prime \prime}-97^{\circ} 04^{\prime} 00^{\prime \prime} \mathrm{O}\end{array}$ & $\begin{array}{l}\text { Sierra Madre Oriental (Faja } \\
\text { Volcánica Transmexicana) }\end{array}$ & $\begin{array}{c}\text { Luna (1997), } \\
\text { García-Franco et } \\
\text { al. (2008), Castillo- } \\
\text { Campos y Luna } \\
\text { (2009) }\end{array}$ \\
\hline 47 & Tancítaro & Michoacán & $\begin{array}{l}19^{\circ} 18^{\prime} 33^{\prime \prime}-19^{\circ} 28^{\prime} 24^{\prime \prime} \mathrm{N} / \\
102^{\circ} 14^{\prime} 57^{\prime \prime}-102^{\circ} 30^{\prime} 14^{\prime \prime} \mathrm{O}\end{array}$ & $\begin{array}{c}\text { Serranías Meridionales } \\
\text { (Faja Volcánica } \\
\text { Transmexicana) }\end{array}$ & García et al. (1998) \\
\hline 48 & Molocotlán & Hidalgo & $\begin{array}{l}20^{\circ} 44^{\prime} 28^{\prime \prime}-20^{\circ} 48^{\prime} 03 ” \mathrm{~N} / \\
98^{\circ} 41^{\prime} 09^{\prime \prime}-98^{\circ} 43^{\prime} 19^{\prime \prime} \mathrm{O}\end{array}$ & $\begin{array}{l}\text { Sierra Madre Oriental } \\
\text { (Sierra Madre Oriental) }\end{array}$ & $\begin{array}{l}\text { Mayorga et al. } \\
\quad(1998)\end{array}$ \\
\hline 49 & Cerro Huitepec & Chiapas & $\begin{array}{l}16^{\circ} 44^{\prime} 27^{\prime \prime}-16^{\circ} 44^{\prime} 53^{\prime \prime} \mathrm{N} / \\
92^{\circ} 41^{\prime} 35^{\prime \prime}-92^{\circ} 41^{\prime} 53^{\prime \prime} \mathrm{O}\end{array}$ & $\begin{array}{c}\text { Serranías Transistmicas } \\
\text { (Meseta Central de } \\
\text { Chiapas) }\end{array}$ & $\begin{array}{c}\text { Ramírez-Marcial et } \\
\text { al. (1998) }\end{array}$ \\
\hline 50 & $\begin{array}{l}\text { Sierra de Santa } \\
\text { Marta }\end{array}$ & Veracruz & $\begin{array}{l}18^{\circ} 31^{\prime} 59^{\prime \prime}-18^{\circ} 34^{\prime} 45^{\prime \prime} \mathrm{N} / \\
95^{\circ} 09^{\prime} 13^{\prime \prime}-95^{\circ} 13^{\prime} 03^{\prime \prime} \mathrm{O}\end{array}$ & $\begin{array}{c}\text { Costa del Golfo de México } \\
\text { (Planicie Costera del Golfo } \\
\text { de México) }\end{array}$ & Ramírez (1999) \\
\hline
\end{tabular}


Cuadro 1. Continúa

\begin{tabular}{|c|c|c|c|c|c|}
\hline Núm.. & Localidad & Estado (s) & Coordenadas extremas & $\begin{array}{c}\text { Provincia florística } \\
\text { sensu Rzedowski (1978) } \\
\text { y Rzedowski y Trujillo } \\
\text { (1990); entre paréntesis las } \\
\text { subprovincias geológicas } \\
\text { de Ferrusquía-Villafranca } \\
\text { (1993) }\end{array}$ & Autor (es) \\
\hline 51 & Rincón Chamula & Chiapas & $17^{\circ} 11^{\prime} 32^{\prime \prime} \mathrm{N} / 92^{\circ} 55^{\prime} 42^{\prime \prime} \mathrm{O}$ & $\begin{array}{c}\text { Serranías Transistmicas } \\
\text { (Meseta Central de } \\
\text { Chiapas) }\end{array}$ & $\begin{array}{c}\text { Ramírez-Marcial et } \\
\text { al. (1999),Mascarúa } \\
\text { (2000) }\end{array}$ \\
\hline 52 & $\begin{array}{l}\text { Refugio la } \\
\text { Cumbre }\end{array}$ & Jalisco & $\begin{array}{l}20^{\circ} 11^{\prime} 42^{\prime \prime}-20^{\circ} 12^{\prime} 44^{\prime \prime} \mathrm{N} / \\
104^{\circ} 44^{\prime} 23^{\prime \prime}-104^{\circ} 45^{\prime} 20^{\prime \prime} \mathrm{O}\end{array}$ & $\begin{array}{c}\text { Serranías Meridionales } \\
\text { (Faja Volcánica } \\
\text { Transmexicana) }\end{array}$ & $\begin{array}{c}\text { Vázquez-García et } \\
\text { al. (1999), Vargas } \\
\text { (2005) }\end{array}$ \\
\hline 53 & Tiltepec & Oaxaca & $17^{\circ} 31^{\prime} 30^{\prime \prime} \mathrm{N} / 96^{\circ} 18^{\prime} 14^{\prime \prime} \mathrm{O}$ & $\begin{array}{l}\text { Serranías Meridionales } \\
\text { (Sierra Norte de Oaxaca) }\end{array}$ & Arellanes (2000) \\
\hline 54 & $\begin{array}{l}\text { Nuevo San Juan } \\
\text { Parangaricutiro }\end{array}$ & Michoacán & $\begin{array}{l}19^{\circ} 21^{\prime} 00^{\prime \prime}-19^{\circ} 34^{\prime} 00^{\prime \prime} \mathrm{N} / \\
102^{\circ} 08^{\prime} 00^{\prime \prime}-102^{\circ} 17^{\prime} 00^{\prime \prime} \mathrm{O}\end{array}$ & $\begin{array}{c}\text { Serranías Meridionales } \\
\text { (Faja Volcánica } \\
\text { Transmexicana) }\end{array}$ & $\begin{array}{l}\text { Medina et al. } \\
\qquad(2000)\end{array}$ \\
\hline 55 & Jilotepec & Veracruz & $\begin{array}{l}19^{\circ} 35^{\prime} 27^{\prime \prime}-19^{\circ} 37^{\prime} 29^{\prime \prime} \mathrm{N} / \\
96^{\circ} 52^{\prime} 29^{\prime \prime}-96^{\circ} 58^{\prime} 58^{\prime \prime} \mathrm{O}\end{array}$ & $\begin{array}{l}\text { Sierra Madre Oriental (Faja } \\
\text { Volcánica Transmexicana) }\end{array}$ & Vázquez (2000) \\
\hline 56 & Eloxochitlán & Hidalgo & $\begin{array}{l}20^{\circ} 43^{\prime} 00^{\prime \prime}-20^{\circ} 47^{\prime} 00^{\prime \prime} \mathrm{N} / \\
98^{\circ} 44^{\prime} 00^{\prime \prime}-98^{\circ} 46^{\prime} 30^{\prime \prime} \mathrm{O}\end{array}$ & $\begin{array}{c}\text { Sierra Madre Oriental } \\
\text { (Sierra Madre Oriental) }\end{array}$ & $\begin{array}{l}\text { Alcántara y Luna- } \\
\text { Vega (2001) }\end{array}$ \\
\hline 57 & Tlahuelompa & Hidalgo & $\begin{array}{l}20^{\circ} 36^{\prime} 00^{\prime \prime}-20^{\circ} 38^{\prime} 00^{\prime \prime} \mathrm{N} / \\
98^{\circ} 34^{\prime} 00^{\prime \prime}-98^{\circ} 38^{\prime} 00^{\prime \prime} \mathrm{O}\end{array}$ & $\begin{array}{c}\text { Sierra Madre Oriental } \\
\text { (Sierra Madre Oriental) }\end{array}$ & $\begin{array}{l}\text { Alcántara y Luna- } \\
\text { Vega (2001) }\end{array}$ \\
\hline 58 & El Rincón & Oaxaca & $\begin{array}{l}17^{\circ} 19^{\prime} 43^{\prime \prime}-17^{\circ} 22^{\prime} 28^{\prime \prime} \mathrm{N} / \\
96^{\circ} 15^{\prime} 39^{\prime \prime}-96^{\circ} 21^{\prime} 29^{\prime \prime} \mathrm{O}\end{array}$ & $\begin{array}{l}\text { Serranías Meridionales } \\
\text { (Sierra Norte de Oaxaca) }\end{array}$ & $\begin{array}{l}\text { Blanco (2001), } \\
\text { Hernández (2001) }\end{array}$ \\
\hline 59 & El Jilguero & Guerrero & $\begin{array}{l}17^{\circ} 26^{\prime} 00^{\prime \prime}-17^{\circ} 35^{\prime} 00^{\prime \prime} \mathrm{N} / \\
99^{\circ} 58^{\prime} 00^{\prime \prime}-100^{\circ} 05^{\prime} 00^{\prime \prime} \mathrm{O}\end{array}$ & $\begin{array}{c}\text { Serranías Meridionales } \\
\text { (Sierra Madre del Sur) }\end{array}$ & $\begin{array}{l}\text { Diego-Pérez et al. } \\
\text { (2001) }\end{array}$ \\
\hline 60 & $\begin{array}{l}\text { Carrizal de } \\
\text { Bravos }\end{array}$ & Guerrero & $\begin{array}{l}17^{\circ} 32^{\prime} 30^{\prime \prime}-17^{\circ} 37^{\prime} 16^{\prime \prime} \mathrm{N} / \\
99^{\circ} 47^{\prime} 56^{\prime \prime}-99^{\circ} 54^{\prime} 00^{\prime \prime} \mathrm{O}\end{array}$ & $\begin{array}{l}\text { Serranías Meridionales } \\
\text { (Sierra Madre del Sur) }\end{array}$ & $\begin{array}{l}\text { Fonseca et al. } \\
\text { (2001), Catalán } \\
\text { (2004) }\end{array}$ \\
\hline 61 & Xico & Veracruz & $\begin{array}{l}19^{\circ} 26^{\prime} 48^{\prime \prime}-19^{\circ} 29^{\prime} 52^{\prime \prime} \mathrm{N} / \\
96^{\circ} 59^{\prime} 45^{\prime \prime}-97^{\circ} 04^{\prime} 12^{\prime \prime} \mathrm{O}\end{array}$ & $\begin{array}{l}\text { Sierra Madre Oriental (Faja } \\
\text { Volcánica Transmexicana) }\end{array}$ & Acosta (2002) \\
\hline 62 & $\begin{array}{l}\text { Landa de } \\
\text { Matamoros }\end{array}$ & Querétaro & $\begin{array}{l}21^{\circ} 06^{\prime} 00^{\prime \prime}-21^{\circ} 27^{\prime} 00^{\prime \prime} \mathrm{N} / \\
99^{\circ} 02^{\prime} 00^{\prime \prime}-99^{\circ} 27^{\prime} 00^{\prime \prime} \mathrm{O}\end{array}$ & $\begin{array}{c}\text { Sierra Madre Oriental } \\
\text { (Sierra Madre Oriental) }\end{array}$ & $\begin{array}{l}\text { Cartujano et al. } \\
\qquad(2002)\end{array}$ \\
\hline 63 & El Molote & Guerrero & $\begin{array}{l}17^{\circ} 24^{\prime} 50^{\prime \prime}-17^{\circ} 27^{\prime} 30^{\prime \prime} \mathrm{N} / \\
100^{\circ} 09^{\prime} 40^{\prime \prime}-100^{\circ} 12^{\prime} 20^{\prime \prime} \mathrm{O}\end{array}$ & $\begin{array}{c}\text { Serranías Meridionales } \\
\text { (Sierra Madre del Sur) }\end{array}$ & Lozada et al. (2003) \\
\hline 64 & Teipan & Oaxaca & $\begin{array}{l}16^{\circ} 14^{\prime} 49^{\prime \prime}-16^{\circ} 15^{\prime} 38^{\prime \prime} \mathrm{N} / \\
95^{\circ} 58^{\prime} 55^{\prime \prime}-95^{\circ} 59^{\prime} 41^{\prime \prime} \mathrm{O}\end{array}$ & $\begin{array}{c}\text { Serranías Meridionales } \\
\text { (Sierra Madre del Sur) }\end{array}$ & Mejía (2003) \\
\hline 65 & Sierra Norte & Puebla & $20^{\circ} 13^{\prime} 41^{\prime \prime}-20^{\circ} 17^{\prime} 31^{\prime \prime} \mathrm{N} /$ & $\begin{array}{c}\text { Sierra Madre Oriental } \\
\text { (Sierra Madre Oriental) }\end{array}$ & Reyes (2003) \\
\hline
\end{tabular}


Cuadro 1. Continúa

\begin{tabular}{|c|c|c|c|c|c|}
\hline Núm.. & Localidad & Estado (s) & Coordenadas extremas & $\begin{array}{c}\text { Provincia florística } \\
\text { sensu Rzedowski (1978) } \\
\text { y Rzedowski y Trujillo } \\
\text { (1990); entre paréntesis las } \\
\text { subprovincias geológicas } \\
\text { de Ferrusquía-Villafranca } \\
\text { (1993) }\end{array}$ & Autor (es) \\
\hline 66 & $\begin{array}{l}\text { Noroeste de } \\
\text { México }\end{array}$ & $\begin{array}{l}\text { Nuevo León, San Luis } \\
\text { Potosí, Tamaulipas }\end{array}$ & $\begin{array}{l}22^{\circ} 11^{\prime} 27^{\prime \prime}-22^{\circ} 20^{\prime} 41^{\prime \prime} \mathrm{N} / \\
99^{\circ} 25^{\prime} 32^{\prime \prime}-99^{\circ} 29^{\prime} 43^{\prime \prime} \mathrm{O} \text { y } \\
25^{\circ} 10^{\prime} 41^{\prime \prime}-25^{\circ} 10^{\prime} 533^{\prime \prime} \mathrm{N} / \\
100^{\circ} 07^{\prime} 02^{\prime \prime}-100^{\circ} 07^{\prime} 37^{\prime \prime} \mathrm{O}\end{array}$ & $\begin{array}{l}\text { Sierra Madre Oriental } \\
\text { (Sierra Madre Oriental) }\end{array}$ & Valdez et al. (2003) \\
\hline 67 & $\begin{array}{l}\text { Magdalena } \\
\text { Contreras }\end{array}$ & Distrito Federal & $\begin{array}{l}19^{\circ} 16^{\prime} 25^{\prime \prime}-19^{\circ} 17^{\prime} 18^{\prime \prime} \mathrm{N} / \\
99^{\circ} 15^{\prime} 42^{\prime \prime}-99^{\circ} 17^{\prime} 01^{\prime \prime} \mathrm{O}\end{array}$ & $\begin{array}{c}\text { Serranías Meridionales } \\
\text { (Faja Volcánica } \\
\text { Transmexicana) }\end{array}$ & $\begin{array}{l}\text { Ávila (2004), Ávila } \\
\text { (2006), Ávila et al. } \\
\text { (2008) }\end{array}$ \\
\hline 68 & Lolotla & Hidalgo & $\begin{array}{l}20^{\circ} 50^{\prime} 00^{\prime \prime}-20^{\circ} 54^{\prime} 00^{\prime \prime} \mathrm{N} / \\
98^{\circ} 40^{\prime} 00^{\prime \prime}-98^{\circ} 43^{\prime} 00^{\prime \prime} \mathrm{O}\end{array}$ & $\begin{array}{l}\text { Sierra Madre Oriental } \\
\text { (Sierra Madre Oriental) }\end{array}$ & $\begin{array}{c}\text { Escutia (2004), } \\
\text { Ponce-Vargas et al. } \\
(2006)\end{array}$ \\
\hline 69 & Sierra de Taxco & Guerrero & $\begin{array}{l}18^{\circ} 30^{\prime} 00^{\prime \prime}-18^{\circ} 47^{\prime} 00^{\prime \prime} \mathrm{N} / \\
99^{\circ} 33^{\prime} 00^{\prime \prime}-99^{\circ} 46^{\prime} 00^{\prime \prime} \mathrm{O}\end{array}$ & $\begin{array}{l}\text { Serranías Meridionales } \\
\text { (Depresión del Balsas) }\end{array}$ & $\begin{array}{l}\text { Martínez et al. } \\
\text { (2004), Saavedra- } \\
\text { Millán (2009) }\end{array}$ \\
\hline 70 & Piedra Larga & Oaxaca & $\begin{array}{l}16^{\circ} 31^{\prime} 00^{\prime \prime}-16^{\circ} 37^{\prime} 00^{\prime \prime} \mathrm{N} / \\
95^{\circ} 45^{\prime} 00^{\prime \prime}-95^{\circ} 51^{\prime} 00^{\prime \prime} \mathrm{O}\end{array}$ & $\begin{array}{l}\text { Sierra Madre del Sur } \\
\text { (Sierra Madre del Sur) }\end{array}$ & $\begin{array}{l}\text { Peterson et al. } \\
\text { (2004) }\end{array}$ \\
\hline 71 & Pisaflores & Hidalgo & $\begin{array}{c}21^{\circ} 12^{\prime} 20^{\prime \prime} \mathrm{N} / 98^{\circ} 58^{\prime} 35^{\prime \prime} \mathrm{O} \text { y } \\
21^{\circ} 13^{\prime} 05^{\prime \prime} \mathrm{N} / 98^{\circ} 58^{\prime} 50^{\prime \prime} \mathrm{O}\end{array}$ & $\begin{array}{l}\text { Sierra Madre Oriental } \\
\text { (Sierra Madre Oriental) }\end{array}$ & $\begin{array}{l}\text { Quintos et al. } \\
\qquad(2004)\end{array}$ \\
\hline 72 & $\begin{array}{l}\text { San Sebastián } \\
\text { del Oeste }\end{array}$ & Jalisco & $\begin{array}{l}20^{\circ} 41^{\prime} 40^{\prime \prime}-20^{\circ} 43^{\prime} 36^{\prime \prime} \mathrm{N} / \\
104^{\circ} 52^{\prime} 30^{\prime \prime}-104^{\circ} 53 ’ 10^{\prime \prime} \mathrm{O} \text { y } \\
20^{\circ} 45^{\prime} 57^{\prime \prime}-20^{\circ} 45^{\prime} 40^{\prime \prime} \mathrm{N} / \\
104^{\circ} 56^{\prime} 57^{\prime} \text { - } 104^{\circ} 58^{\prime} 05^{\prime \prime} \mathrm{O}\end{array}$ & $\begin{array}{c}\text { Costa Pacífica (Faja } \\
\text { Volcánica Transmexicana) }\end{array}$ & Reynoso (2004) \\
\hline 73 & Cerro la Mona & Michoacán & $\begin{array}{l}18^{\circ} 40^{\prime} 59^{\prime \prime}-18^{\circ} 41^{\prime} 56^{\prime \prime} \mathrm{N} / \\
103^{\circ} 24^{\prime} 46^{\prime \prime}-103^{\circ} 25^{\prime} 51^{\prime \prime} \mathrm{O}\end{array}$ & $\begin{array}{l}\text { Costa Pacífica (Sierra } \\
\text { Madre del Sur) }\end{array}$ & Sahagún (2004) \\
\hline 74 & Sierra Mazateca & Oaxaca & $\begin{array}{l}18^{\circ} 00^{\prime} 00^{\prime \prime}-18^{\circ} 22^{\prime} 00^{\prime \prime} \mathrm{N} / \\
96^{\circ} 30^{\prime} 00^{\prime \prime}-97^{\circ} 15^{\prime} 00^{\prime \prime} \mathrm{O}\end{array}$ & $\begin{array}{l}\text { Serranías Meridionales } \\
\text { (Sierra Norte de Oaxaca) }\end{array}$ & Lorea (2005) \\
\hline 75 & Huauchinango & Puebla & $\begin{array}{l}20^{\circ} 07^{\prime} 52^{\prime \prime}-20^{\circ} 10^{\prime} 22^{\prime \prime} \mathrm{N} / \\
98^{\circ} 01^{\prime} 11^{\prime \prime}-98^{\circ} 07^{\prime} 01^{\prime \prime} \mathrm{O}\end{array}$ & $\begin{array}{l}\text { Sierra Madre Oriental } \\
\text { (Sierra Madre Oriental) }\end{array}$ & $\begin{array}{l}\text { Ruiz-Jiménez et al. } \\
\text { (2005), Mendoza et } \\
\text { al. (2005) }\end{array}$ \\
\hline 76 & Sierra Sur & Oaxaca & $\begin{array}{l}15^{\circ} 57^{\prime} 00^{\prime \prime}-16^{\circ} 03^{\prime} 00^{\prime \prime} \mathrm{N} / \\
96^{\circ} 20^{\prime} 00^{\prime \prime}-96^{\circ} 38^{\prime} 00^{\prime \prime} \mathrm{O}\end{array}$ & $\begin{array}{l}\text { Sierra Madre del Sur } \\
\text { (Sierra Madre del Sur) }\end{array}$ & Montalvo (2006) \\
\hline 77 & Banderilla & Veracruz & $\begin{array}{l}19^{\circ} 34^{\prime} 36^{\prime \prime}-19^{\circ} 35^{\prime} 10^{\prime \prime} \mathrm{N} / \\
96^{\circ} 56^{\prime} 35^{\prime \prime}-96^{\circ} 56^{\prime} 59^{\prime \prime} \mathrm{O}\end{array}$ & $\begin{array}{l}\text { Sierra Madre Oriental (Faja } \\
\text { Volcánica Transmexicana) }\end{array}$ & $\begin{array}{l}\text { Vázquez et al. } \\
\qquad(2006)\end{array}$ \\
\hline 78 & $\begin{array}{l}\text { Santa Cruz } \\
\text { Tepetotutla }\end{array}$ & Oaxaca & $\begin{array}{l}17^{\circ} 38^{\prime} 54^{\prime \prime}-17^{\circ} 42^{\prime} 15^{\prime \prime} \mathrm{N} / \\
96^{\circ} 31^{\prime} 38^{\prime \prime}-96^{\circ} 33 ’ 36^{\prime \prime} \mathrm{O}\end{array}$ & $\begin{array}{l}\text { Serranías Meridionales } \\
\text { (Sierra Norte de Oaxaca) }\end{array}$ & Rincón (2007) \\
\hline
\end{tabular}


Cuadro 1. Continúa

\begin{tabular}{|c|c|c|c|c|c|}
\hline Núm.. & Localidad & Estado (s) & Coordenadas extremas & $\begin{array}{c}\text { Provincia florística } \\
\text { sensu Rzedowski (1978) } \\
\text { y Rzedowski y Trujillo } \\
\text { (1990); entre paréntesis las } \\
\text { subprovincias geológicas } \\
\text { de Ferrusquía-Villafranca } \\
\text { (1993) }\end{array}$ & Autor (es) \\
\hline 79 & Chimalapas & Oaxaca & $\begin{array}{l}16^{\circ} 42^{\prime} 09^{\prime \prime}-16^{\circ} 44^{\prime} 30.1^{\prime \prime} \mathrm{N} / \\
94^{\circ} 11^{\prime} 30.2^{\prime \prime}-94^{\circ} 16^{\prime} 49^{\prime \prime} \mathrm{O}\end{array}$ & $\begin{array}{c}\text { Serranías meridionales } \\
\text { (Sierra Madre de Chiapas) }\end{array}$ & $\begin{array}{l}\text { Gallardo- } \\
\text { Hernández et al. } \\
\text { (2008) }\end{array}$ \\
\hline 80 & La Cortadura & Veracruz & $\begin{array}{l}19^{\circ} 29^{\prime} 00^{\prime \prime}-19^{\circ} 29^{\prime} 35^{\prime \prime} \mathrm{N} / \\
97^{\circ} 02^{\prime} 00^{\prime \prime}-97^{\circ} 02^{\prime} 45^{\prime \prime} \mathrm{O}\end{array}$ & $\begin{array}{l}\text { Sierra Madre Oriental (Faja } \\
\text { Volcánica Transmexicana) }\end{array}$ & $\begin{array}{l}\text { García-Franco et al. } \\
\qquad(2008)\end{array}$ \\
\hline 81 & Cerro Cebú & Chiapas & $\begin{array}{l}15^{\circ} 49^{\prime} 00^{\prime \prime}-15^{\circ} 50^{\prime} 00^{\prime \prime} \mathrm{N} / \\
93^{\circ} 02^{\prime} 00^{\prime \prime}-93^{\circ} 05^{\prime} 00^{\prime \prime} \mathrm{O}\end{array}$ & $\begin{array}{c}\text { Soconusco (Sierra Madre } \\
\text { de Chiapas) }\end{array}$ & $\begin{array}{l}\text { Martínez-Meléndez } \\
\text { et al. (2008) }\end{array}$ \\
\hline 82 & $\begin{array}{l}\text { Arroyo Agua } \\
\text { Fría }\end{array}$ & Colima & $\begin{array}{l}19^{\circ} 17^{\prime} 34^{\prime \prime}-19^{\circ} 18^{\prime} 52^{\prime} \mathrm{N} / \\
104^{\circ} 01^{\prime} 17^{\prime \prime}-104^{\circ} 02 ’ 54^{\prime \prime} \mathrm{O}\end{array}$ & $\begin{array}{l}\text { Serranías meridionales } \\
\text { (Sierra Madre del Sur) }\end{array}$ & Padilla et al. (2008) \\
\hline 83 & Las Cañadas & Veracruz & $\begin{array}{l}19^{\circ} 09^{\prime} 59^{\prime \prime}-19^{\circ} 11^{\prime} 09^{\prime \prime} \mathrm{N} / \\
96^{\circ} 57^{\prime} 29^{\prime \prime}-96^{\circ} 59^{\prime} 38^{\prime \prime} \mathrm{O}\end{array}$ & $\begin{array}{c}\text { Serranías Meridionales } \\
\text { (Faja Volcánica } \\
\text { Transmexicana) }\end{array}$ & $\begin{array}{l}\text { Williams-Linera } \\
\text { y López-Gómez } \\
\text { (2008), García- } \\
\text { Franco y Toledo } \\
\text { (2008), Mehltreter } \\
\text { (2008) }\end{array}$ \\
\hline
\end{tabular}

Cuadro 2. Parámetros bioclimáticos utilizados por el programa BIOCLIM (Houlder et al., 2000)

\footnotetext{
1. Temperatura promedio anual $\left({ }^{\circ} \mathrm{C}\right)$

2. Oscilación diurna de la temperatura $\left({ }^{\circ} \mathrm{C}\right)$

3. Isotermalidad $\left({ }^{\circ} \mathrm{C}\right)$ (cociente entre parámetros 2 y7)

4. Estacionalidad de la temperatura (coeficiente de variación, en \%)

5. Temperatura máxima promedio del periodo más cálido $\left({ }^{\circ} \mathrm{C}\right)$

6. Temperatura mínima promedio del periodo más frío $\left({ }^{\circ} \mathrm{C}\right)$

7. Oscilación anual de la temperatura $\left({ }^{\circ} \mathrm{C}\right)$ (cociente entre parámetros 5 y 6 )

8. Temperatura promedio del cuatrimestre más lluvioso $\left({ }^{\circ} \mathrm{C}\right)$

9. Temperatura promedio del cuatrimestre más seco $\left({ }^{\circ} \mathrm{C}\right)$

10. Temperatura promedio del cuatrimestre más cálido $\left({ }^{\circ} \mathrm{C}\right)$

11. Temperatura promedio del cuatrimestre más frío $\left({ }^{\circ} \mathrm{C}\right)$

12. Precipitación anual (mm)

13. Precipitación del periodo más lluvioso $(\mathrm{mm})$

14. Precipitación del periodo más seco $(\mathrm{mm})$

15. Estacionalidad de la precipitación (coeficiente de variación, en \%)

16. Precipitación del cuatrimestre más lluvioso ( $\mathrm{mm})$

17. Precipitación del cuatrimestre más seco $(\mathrm{mm})$

18. Precipitación del cuatrimestre más cálido $(\mathrm{mm})$

19. Precipitación del cuatrimestre más frío $(\mathrm{mm})$
} 
Apéndice. Especies arbóreas del BMM para cada grupo identificado.

\begin{tabular}{|c|c|c|c|c|c|c|c|c|c|c|c|c|c|c|c|c|c|}
\hline \multirow[b]{2}{*}{ Familia } & \multirow{2}{*}{\multicolumn{2}{|c|}{ Especie }} & \multicolumn{15}{|c|}{ Grupos } \\
\hline & & & $A 1$ & $A 2$ & $A 3$ & $B$ & $C$ & $D$ & $E$ & $F$ & $G$ & $H$ & $I$ & $J$ & $K$ & $L$ & $M$ \\
\hline Pinaceae & 1 & $\begin{array}{c}\text { Abies religiosa (Kunth) Schltdl } \\
\text { et Cham. }\end{array}$ & & & & & & & & & + & & & & & & \\
\hline Sapindaceae & 2 & $\begin{array}{l}\text { Acer negundo var. mexicanum } \\
\text { (DC.) Standl. et Steyerm. }\end{array}$ & + & & & & & & & & + & & & & & & \\
\hline Euphorbiaceae & 3 & Alchornea latifolia Sw. & & & & & & & & & & + & & & & + & \\
\hline Betulaceae & 4 & $\begin{array}{l}\text { Alnus acuminata Kunth subsp. } \\
\text { arguta (Schltdl.) Furlow }\end{array}$ & & & + & & & & + & + & + & & & & & & \\
\hline Betulaceae & 5 & $\begin{array}{l}\text { Alnus jorullensis Kunth subsp. } \\
\text { lutea Furlow }\end{array}$ & + & & & & & & & & & & & & & & \\
\hline Cyatheaceae & 6 & $\begin{array}{c}\text { Alsophila firma (Baker) D.S. } \\
\text { Conant }\end{array}$ & & + & & & + & & & & & & & & & & \\
\hline Annonaceae & 7 & Annona globiflora Schltdl. & & + & & & & & & & & & & & & & \\
\hline Cannabaceae & 8 & $\begin{array}{c}\text { Aphananthe monoica (Hemsl.) } \\
\text { J.-Leroy }\end{array}$ & & + & & & & & & & & & & & & & \\
\hline Cannabaceae & 9 & Bejaria aestuans Mutis ex L. & + & & & & & & & & & & & & & & \\
\hline Lauraceae & 10 & $\begin{array}{l}\text { Beilschmiedia mexicana }(\mathrm{Mez}) \\
\text { Kosterm. }\end{array}$ & & + & & & & & & & & & & & + & & \\
\hline Berberidaceae & 11 & Berberis gracilis Benth. & & + & & & & & & & & & & & & & \\
\hline Euphorbiaceae & 12 & $\begin{array}{c}\text { Bernardia dodecandra (Sessé } \\
\text { ex Cavagnaro) McVaugh }\end{array}$ & & + & & & & & & & & & & & & & \\
\hline Sapindaceae & 13 & Billia hippocastanum Peyr. & & & & & & & & & & + & & & & & \\
\hline Urticaceae & 14 & Boehmeria ulmifolia Wedd. & & + & & & & & & & & & & & & & \\
\hline Moraceae & 15 & $\begin{array}{l}\text { Brosimum alicastrum Sw. } \\
\text { subsp. alicastrum }\end{array}$ & & + & & & & & & & & & & & & & \\
\hline Brunelliaceae & 16 & Brunellia mexicana Standl. & & & + & & & & & & & & & & & & \\
\hline Malpighiaceae & 17 & Bunchosia lindeniana A. Juss. & & & & + & & & & & & & & & & & \\
\hline Scrophulariaceae & 18 & Buddleja americana $\mathrm{L}$. & & + & & & & & & & & & & & & & \\
\hline Scrophulariaceae & 19 & $\begin{array}{l}\text { Buddleja cordata Kunth subsp. } \\
\text { cordata }\end{array}$ & + & + & & & & & & & + & & & & & & \\
\hline Scrophulariaceae & 20 & Buddleja parviflora Kunth & & & & & & & & + & & & & & & & \\
\hline Scrophulariaceae & 21 & Buddleja sessiliflora Kunth & & & & & & & + & & & & & & & & \\
\hline Burseraceae & 22 & Bursera simaruba (L.) Sarg. & & + & & & & & & & & & & & & & \\
\hline Betulaceae & 23 & Carpinus caroliniana Walt. & + & + & + & & + & + & + & + & & & + & + & & & \\
\hline Juglandaceae & 24 & $\begin{array}{c}\text { Carya ovata (Mill.) K. Koch } \\
\text { var. mexicana (Engelm. Ex } \\
\text { Hemsl.) W.E. Manning }\end{array}$ & & + & & & & & & & & & + & & & & \\
\hline Meliaceae & 25 & Cedrela odorata $\mathrm{L}$ & & + & & & & & & & & & & & & & \\
\hline Fabaceae & 26 & Cercis canadensis L. & & + & & & & & & & & & & & & & \\
\hline Rosaceae & 27 & $\begin{array}{c}\text { Cercocarpus macrophyllus } \\
\text { C.K. Schneid. }\end{array}$ & & + & & & & & & & & & & & & & \\
\hline Solanaceae & 28 & Cestrum tomentosum L.f. & & & + & & & & & & & & & & & & \\
\hline Verbenaceae & 29 & $\begin{array}{c}\text { Citharexylum hidalgense } \\
\text { Moldenke }\end{array}$ & + & + & & & & & & & & & & & & & \\
\hline Clethraceae & 30 & Clethra alcoceri Greenm. & + & & & & & & & & & & & & & & \\
\hline Clethraceae & 31 & Clethra mexicana DC. & + & & + & & & & + & & + & & & + & + & & + \\
\hline
\end{tabular}


Apéndice. Continúa.

\begin{tabular}{|c|c|c|c|c|c|c|c|c|c|c|c|c|c|c|c|c|c|}
\hline & & & \multicolumn{15}{|c|}{ Grupos } \\
\hline Familia & & Especie & $A 1$ & $A 2$ & $A 3$ & $B$ & $C$ & $D$ & $E$ & $F$ & $G$ & $H$ & $I$ & $J$ & $K$ & $L$ & $M$ \\
\hline Clethraceae & 32 & Clethra pringlei S. Watson & & + & & & & & & & & & & & + & & + \\
\hline Pentaphylacaceae & 33 & $\begin{array}{c}\text { Cleyera integrifolia (Benth.) } \\
\text { Choisy }\end{array}$ & & & & & & & & + & & & & & & & \\
\hline Pentaphylacaceae & 34 & $\begin{array}{c}\text { Cleyera theaeoides (Sw.) } \\
\text { Choisy }\end{array}$ & + & + & & + & & & & & & & & & & & \\
\hline Clusiaceae & 35 & Clusia salvinii Donn. Sm. & & & & + & & + & & & & & & & & & \\
\hline Cornaceae & 36 & Cornus disciflora DC. & + & + & & & & + & + & + & + & & & & & & \\
\hline Cornaceae & 37 & Cornus excelsa Kunth & + & + & & & & & & & & & & & & & \\
\hline Rosaceae & 38 & $\begin{array}{c}\text { Crataegus mexicana Moc. et } \\
\text { Sessé ex DC. }\end{array}$ & + & & & & & & & & & & & & & & \\
\hline Cyatheaceae & 39 & Cyathea bicrenata Liebm. & & & & & + & & & & & & & & & & \\
\hline Cyatheaceae & 40 & $\begin{array}{c}\text { Cyathea divergens Kunze var. } \\
\text { tuerckheimii (Maxon) R.M. } \\
\text { Tryon }\end{array}$ & & & & & + & & & & & & & & & & \\
\hline Cyatheaceae & 41 & $\begin{array}{l}\text { Cyathea fulva (M. Martens et } \\
\text { Galeotti) Fée }\end{array}$ & + & & & + & & & & & & + & & & & & \\
\hline Fabaceaea & 42 & $\begin{array}{c}\text { Dalbergia palo-escrito Rzed. et } \\
\text { Guridi-Gómez }\end{array}$ & & + & & & & & & & & & & & & & \\
\hline Thymelaeaceae & 43 & $\begin{array}{c}\text { Daphnopsis mollis (Cham. et } \\
\text { Schltdl.) Standl. }\end{array}$ & & + & & & & & & & & & & & & & \\
\hline Araliaceae & 44 & $\begin{array}{l}\text { Dendropanax arboreus (L.) } \\
\text { Decne. et Planch. }\end{array}$ & & + & & + & & + & & + & & & & & + & & \\
\hline Rubiaceae & 45 & Deppea grandiflora Schltdl. & & & + & & & & & & & & & & & & \\
\hline Winteraceae & 46 & $\begin{array}{l}\text { Drimys winteri J.R. Forst. et G. } \\
\text { Forst. }\end{array}$ & & & & + & & & & & & + & & & & & \\
\hline Putranjivaceae & 47 & $\begin{array}{c}\text { Drypetes lateriflora (Sw.) Krug. } \\
\text { et Urb. }\end{array}$ & & + & & & & & & & & & & & & & \\
\hline Celastraceae & 48 & $\begin{array}{l}\text { Elaeodendron trichotomum } \\
\text { (Turcz.) Lundell }\end{array}$ & & + & & & & & & & & & & & & & \\
\hline Myrtaceae & 49 & $\begin{array}{l}\text { Eugenia capuli (Schltdl. et } \\
\text { Cham.) Hook et Arn. }\end{array}$ & & + & & & & & & & & & & & & & \\
\hline Celastraceae & 50 & Euonymus acuminatus Benth. & & + & & & & & & & & & & & & & \\
\hline Sapindaceae & 51 & $\begin{array}{c}\text { Exothea paniculata (Juss.) } \\
\text { Radlk. }\end{array}$ & & & & + & & & & & & & & & & & \\
\hline Oleaceae & 52 & Forestiera reticulata Torr. & & + & & & & & & & & & & & & & \\
\hline Onagraceae & 53 & $\begin{array}{l}\text { Fuchsia arborescens Sims } \\
\text { subsp. arborescens }\end{array}$ & + & & & & & & & + & & & & & & & \\
\hline Oleaceae & 54 & $\begin{array}{l}\text { Fraxinus uhdei (Wenz.) } \\
\text { Lingelsh. }\end{array}$ & & & & & & + & & + & & & & & & & \\
\hline Garryaceae & 55 & $\begin{array}{l}\text { Garrya laurifolia Hartw. ex } \\
\text { Benth. subsp. laurifolia }\end{array}$ & & + & & & & & + & & + & & & & & & \\
\hline Rubiaceae & 56 & $\begin{array}{l}\text { Glossostipula concinna } \\
\text { (Standl.) Lorence }\end{array}$ & & & & + & & & & & & & & & & & \\
\hline Meliaceae & 57 & Guarea glabra Vahl & & & & & & & & + & & & & & & & \\
\hline Euphorbiaceae & 58 & $\begin{array}{c}\text { Gymnanthes longipes Müll. } \\
\text { Arg. }\end{array}$ & & + & & & & & & & & & & & & & \\
\hline
\end{tabular}


Apéndice. Continúa.

\begin{tabular}{|c|c|c|c|c|c|c|c|c|c|c|c|c|c|c|c|c|}
\hline \multirow[b]{2}{*}{ Familia } & \multirow{2}{*}{\multicolumn{2}{|c|}{ Especie }} & \multicolumn{14}{|c|}{ Grupos } \\
\hline & & & $A 1$ & $A 2$ & $A 3$ & $B$ & $C$ & $D$ & $E$ & $F$ & $G$ & $H$ & $I$ & $J$ & $K$ & $M$ \\
\hline Chloranthaceae & 59 & $\begin{array}{c}\text { Hedyosmum mexicanum } \mathrm{C} \text {. } \\
\text { Cordem. }\end{array}$ & & & & & + & & & + & & + & & & & \\
\hline Malvaceae & 60 & $\begin{array}{l}\text { Heliocarpus americanus L. var. } \\
\text { americanus }\end{array}$ & & + & & & & & & & & & & & & \\
\hline Malvaceae & 61 & $\begin{array}{c}\text { Heliocarpus appendiculatus } \\
\text { Turcz. }\end{array}$ & & + & & & & & & & & & & & + & \\
\hline Fabaceae & 62 & Inga jinicuil Schltdl. & & & + & & & & & & & & & & & \\
\hline Aquifoliaceae & 63 & Ilex brandegeana Loes. & & & & & & + & & & & & & & & \\
\hline Aquifoliaceae & 64 & Ilex condensata Turcz. & & + & & & & & & & & & & & & \\
\hline Aquifoliaceae & 65 & $\begin{array}{l}\text { Ilex discolor Hemsl. var. } \\
\text { discolor }\end{array}$ & + & + & & & & & & & & & & & & \\
\hline Aquifoliaceae & 66 & $\begin{array}{l}\text { Ilex discolor Hemsl. var. } \\
\text { tolucana (Hemsl.) Edwin ex } \\
\text { T.R. Dudley }\end{array}$ & & & & & & & & & + & & & & & \\
\hline Juglandaceae & 67 & Juglans mollis Engelm. & & + & & & & & & & & & & & & \\
\hline Asteraceae & 68 & $\begin{array}{l}\text { Koanophyllon pittieri (Klatt) } \\
\text { R.M. King et Rob. }\end{array}$ & & & & + & & & & & & & & & & \\
\hline Fabaceae & 69 & $\begin{array}{l}\text { Leucaena pulverulenta } \\
\text { (Schltdl.) Benth. }\end{array}$ & & + & & & & & & & & & & & & \\
\hline Hamamelidaceae & 70 & Liquidambar styraciflua $\mathrm{L}$. & + & + & + & + & + & & & & & + & & + & + & \\
\hline Lauraceae & 71 & Litsea glaucescens Kunth & & + & + & & & & & & & & & & & \\
\hline Fabaceae & 72 & $\begin{array}{c}\text { Lonchocarpus rugosus Benth. } \\
\text { var. rugosus }\end{array}$ & & + & & & & & & & & & & & & \\
\hline Cannabaceae & 73 & $\begin{array}{l}\text { Lozanella enantiophylla (Donn. } \\
\text { Sm.) Killip et C.V. Morton }\end{array}$ & + & & & & & & & & & & & & & \\
\hline Ericaceae & 74 & $\begin{array}{c}\text { Lyonia squamulosa } \mathrm{M} \text {. Martens } \\
\text { et Galeotti }\end{array}$ & + & & & & & & & & & + & & & & \\
\hline Magnoliaceae & 75 & Magnolia dealbata Zucc. & & + & & & & & & & & & & & & \\
\hline Magnoliaceae & 76 & Magnolia schiedeana Schltdl. & + & + & & & & & & & & + & & & + & \\
\hline Sabiaceae & 77 & Meliosma alba (Schltdl.) Walp. & & + & + & & & & & & & & & & & \\
\hline Sabiaceae & 78 & $\begin{array}{c}\text { Meliosma dentata (Liebm.) } \\
\text { Urb. }\end{array}$ & & & & & & + & + & & & & & & & \\
\hline Melastomataceae & 79 & $\begin{array}{c}\text { Miconia glaberrima (Schltdl.) } \\
\text { Naudin }\end{array}$ & & & + & + & & & & & & + & & & & \\
\hline Melastomataceae & 80 & $\begin{array}{c}\text { Miconia mexicana (Bonpl.) } \\
\text { Naudin }\end{array}$ & & & + & + & & & & & & & & & & \\
\hline Monimiaceae & 81 & Mollinedia viridiflora tul. & & & & & & & & & & + & & & & \\
\hline Moraceae & 82 & Morus celtidifolia Kunth & & + & & & & & & & & & & & & \\
\hline Myrsinaceae & 83 & $\begin{array}{l}\text { Myrsine coriacea (Sw.) R. Br. } \\
\text { ex Roem et Schult var. coriacea }\end{array}$ & + & + & & + & & & & & & & & & + & \\
\hline Myrsinaceae & 84 & $\begin{array}{c}\text { Myrsine juergensenii (Mez) } \\
\text { Lundell }\end{array}$ & & & & + & & & & + & & + & & & & \\
\hline Nyssaceae & 85 & Nyssa sylvatica Marshall & + & & & & & & & & & & & & & \\
\hline Lauraceae & 86 & $\begin{array}{l}\text { Ocotea chiapensis (Lundell) } \\
\text { standl et Steyerm. }\end{array}$ & & & & + & & & & & & & & & & \\
\hline Lauraceae & 87 & $\begin{array}{c}\text { Ocotea helicterifolia (Meisn.) } \\
\text { Hemsl. }\end{array}$ & & & & & & & & & & + & & & & \\
\hline
\end{tabular}


Apéndice. Continúa.

\begin{tabular}{|c|c|c|c|c|c|c|c|c|c|c|c|c|c|c|c|c|c|}
\hline \multirow[b]{2}{*}{ Familia } & \multirow{2}{*}{\multicolumn{2}{|c|}{ Especie }} & \multicolumn{15}{|c|}{ Grupos } \\
\hline & & & $A 1$ & $A 2$ & $A 3$ & $B$ & $C$ & $D$ & $E$ & $F$ & $G$ & $H$ & $I$ & $J$ & $K$ & $L$ & $M$ \\
\hline Lauraceae & 88 & $\begin{array}{c}\text { Ocotea klotzschiana (Nees) } \\
\text { Hemsl. }\end{array}$ & & + & & & & & & & & & & & & & \\
\hline Lauraceae & 89 & Ocotea salvinii $\mathrm{Mez}$ & & + & & & & & & & & & & & & & \\
\hline Juglandaceae & 90 & $\begin{array}{l}\text { Oreomunnea mexicana } \\
\text { (Standl.) J.-F. Leroy }\end{array}$ & & & & & & & & & & + & & & & & \\
\hline Araliaceae & 91 & $\begin{array}{c}\text { Oreopanax capitatus (Jacq.) } \\
\text { Decne. et Planch. }\end{array}$ & & & + & & & & & & & & & & & & \\
\hline Araliaceae & 92 & $\begin{array}{l}\text { Oreopanax echinops (Schltdl. } \\
\text { et Cham.) Decne. et Planch }\end{array}$ & & & & & & & & + & & & & & & & \\
\hline Araliaceae & 93 & Oreopanax flaccidus Marchal & + & & & & & & & & & & & & & & \\
\hline Araliaceae & 94 & Oreopanax liebmannii Marchal & & & & & & & & & & + & & & & & \\
\hline Araliaceae & 95 & $\begin{array}{c}\text { Oreopanax peltatus Linden ex } \\
\text { Regel }\end{array}$ & & & & + & & & & & & & & & & & \\
\hline Araliaceae & 96 & Oreopanax sanderianus Hemsl. & & & & + & & & & + & & & & & & & \\
\hline Araliaceae & 97 & $\begin{array}{l}\text { Oreopanax xalapensis (Kunth) } \\
\text { Decne. et Planch. }\end{array}$ & + & & + & + & & & + & + & & + & & + & + & & \\
\hline Oleaceae & 98 & $\begin{array}{l}\text { Osmanthus americanus (L.) A. } \\
\text { Gray }\end{array}$ & & + & & & & & & & & & & & & & \\
\hline Betulaceae & 99 & $\begin{array}{l}\text { Ostrya virginiana (Mill.) K. } \\
\text { Koch. }\end{array}$ & + & + & & & & & & + & & & & & & & \\
\hline Rubiaceae & 100 & $\begin{array}{c}\text { Palicourea padifolia (Wild. ex } \\
\text { Roem. et Schult) C.M. Taylor } \\
\text { et Lorence }\end{array}$ & & & & + & & & & & & & & & & & \\
\hline Myrsinaceae & 101 & Parathesis chiapensisFernald & & & & + & & & & & & & & & & & \\
\hline Myrsinaceae & 102 & Parathesis tenuis Standl. & & & & & & & & & & + & & & & & \\
\hline Celastraceae & 103 & Perrottetia ovata Hemsl. & + & + & & & & & & & & & & & & & \\
\hline Lauraceae & 104 & Persea americana Mill. & & + & & + & & & & & & + & & & & & \\
\hline Asteraceae & 105 & Perymenium grande Hemsl. & & & & + & & & & & & & & & & & \\
\hline Rosaceae & 106 & $\begin{array}{c}\text { Photinia mexicana (Baill.) } \\
\text { Hemsl. }\end{array}$ & & + & & & & & & & & & & & & & \\
\hline Phyllonomaceae & 107 & $\begin{array}{c}\text { Phyllonoma laticuspis (Turcz.) } \\
\text { Engl. }\end{array}$ & & & & & & & & & & + & & & & & \\
\hline Picramniaceae & 108 & Picramnia tetramera Turcz. & & & & + & & & & & & & & & & & \\
\hline Pinaceae & 109 & Pinus greggii Engelm. ex Parl. & & + & & & & & & & & & & & & & \\
\hline Pinaceae & 110 & $\begin{array}{l}\text { Pinus oocarpa } \text { Schiede ex } \\
\text { Schltdl. var. oocarpa }\end{array}$ & & & & + & & & & & & & & & & & \\
\hline Pinaceae & 111 & $\begin{array}{c}\text { Pinus patula Schiede ex } \\
\text { Schltdl. et Cham. var. patula }\end{array}$ & + & & & & & & & & & & & & & & \\
\hline Pinaceae & 112 & $\begin{array}{l}\text { Pinus pseudostrobus Lindl. } \\
\text { var. pseudostrobus }\end{array}$ & & & & & & & + & & & & & & & & \\
\hline Platanaceae & 113 & $\begin{array}{l}\text { Platanus mexicana Moric. var. } \\
\text { mexicana }\end{array}$ & + & & + & + & & & & & & & & & & & \\
\hline Podocarpaceae & 114 & Podocarpus matudae Lundell & + & & & + & & & & & & + & & & & & \\
\hline Rosaceae & 115 & Prunus brachybotrya Zucc. & + & + & & & & & & & + & + & & & + & & + \\
\hline Rosaceae & 116 & $\begin{array}{l}\text { Prunus serotina Ehrh. subsp. } \\
\text { capuli (Cav.) McVaugh }\end{array}$ & + & + & & & & & & + & & & & & & & \\
\hline
\end{tabular}


Apéndice. Continúa.

\begin{tabular}{|c|c|c|c|c|c|c|c|c|c|c|c|c|c|c|c|c|}
\hline \multirow[b]{2}{*}{ Familia } & \multirow{2}{*}{\multicolumn{2}{|c|}{ Especie }} & \multicolumn{14}{|c|}{ Grupos } \\
\hline & & & $A 1$ & $A 2$ & $A 3$ & $B$ & $C$ & $D$ & E & $F$ & $G$ & $H$ & $I$ & $J$ & $K$ & $M$ \\
\hline Rosaceae & 117 & $\begin{array}{l}\text { Prunus serotina Ehrh. subsp. } \\
\text { serotina }\end{array}$ & & + & & & & & & & & & & & & \\
\hline Asteraceae & 118 & $\begin{array}{c}\text { Pseudogynoxys chenopodioides } \\
\text { (Kunth) Cabrera var. } \\
\text { chenopodioides }\end{array}$ & & + & & & & & & & & & & & & \\
\hline Rubiaceae & 119 & $\begin{array}{l}\text { Psychotria trichotoma M. } \\
\text { Martens et Galeotti }\end{array}$ & & & + & & & & & & & & & & & \\
\hline Fagaceae & 120 & Quercus acutifolia Née & & & & & & & & & & & & + & & \\
\hline Fagaceae & 121 & Quercus affinis Scheidw. & + & & & & & & & & & & & & & \\
\hline Fagaceae & 122 & Quercus candicans Née & & & & + & & & + & + & & & & & & \\
\hline Fagaceae & 123 & Quercus castanea Née & & & & & & & + & & & & & & & \\
\hline Fagaceae & 124 & Quercus eugeniifolia Liebm. & + & & & & & & & & & & & & & \\
\hline Fagaceae & 125 & $\begin{array}{c}\text { Quercus germana Schltdl. et } \\
\text { cham. }\end{array}$ & + & + & & & & & & & & & & + & + & \\
\hline Fagaceae & 126 & $\begin{array}{l}\text { Quercus laurina Humb. et } \\
\text { Bonpl. }\end{array}$ & & & + & & & & + & & + & & & & & \\
\hline Fagaceae & 127 & Quercus ocoteifolia Liebm. & & & & + & & & & & & & & & & \\
\hline Fagaceae & 128 & $\begin{array}{c}\text { Quercus polymorpha Schltdl. } \\
\text { et Cham. }\end{array}$ & & + & & & & & & & & & + & & & \\
\hline Fagaceae & 129 & Quercus rugosa Née & & & & & & & + & & + & & & & & \\
\hline Fagaceae & 130 & Quercus rysophylla Weath. & & + & & & & & & & & & & & & \\
\hline Fagaceae & 131 & Quercus sapotifolia Liebm. & & & & + & & & & & & & & & & \\
\hline Fagaceae & 132 & Quercus sartorii Liebm. & + & + & & & & & & & & & & & + & \\
\hline Fagaceae & 133 & Quercus scytophylla Liebm. & & & & & & + & & + & & & & & & \\
\hline Fagaceae & 134 & Quercus segoviensis Liebm. & & & & + & & & & & & & & & & \\
\hline Fagaceae & 135 & Quercus splendens Née & + & & & & & & & & & & & & & \\
\hline Fagaceae & 136 & Quercus uxoris McVaugh & & & & & & & & + & & & & & & \\
\hline Fagaceae & 137 & $\begin{array}{l}\text { Quercus xalapensis Humb. et } \\
\text { Bonpl. }\end{array}$ & + & + & & & & & & & & & & + & & \\
\hline Celastraceae & 138 & $\begin{array}{c}\text { Quetzalia schiedeana (Loes.) } \\
\text { Lundell }\end{array}$ & + & & & & & & & & & & & & & \\
\hline Sterculiaceae & 139 & $\begin{array}{l}\text { Reevesia clarkii (Monach.et } \\
\text { Moldenke) Solheim }\end{array}$ & & + & & & & & & & & & & & & \\
\hline Rhamnaceae & 140 & $\begin{array}{c}\text { Rhamnus capreaefolia } \text { Schltdl. } \\
\text { var. capreaefolia }\end{array}$ & & + & & & & & & & & & & & & \\
\hline Rhamnaceae & 141 & Rhamnus longistyla C.B. Wolf & + & & & & & & & & & & & & & \\
\hline Rhamnaceae & 142 & Rhamnus mucronata Schltdl. & & & & + & & & & & & & & & & \\
\hline Proteaceae & 143 & Roupala montana Aubl. & & + & & & & & & & & & & & & \\
\hline Adoxaceae & 144 & $\begin{array}{l}\text { Sambucus nigra L. var. } \\
\text { canadensis (L.) Bolli }\end{array}$ & + & + & + & & & & & & & & & & & \\
\hline Actinidaceae & 145 & Saurauia scabrida Hemsl. & & + & & + & & & & & & & & & & \\
\hline Actinidaceae & 146 & Saurauia serrata DC. & & & & & & & & + & & & & & & \\
\hline Sapindaceae & 147 & Sapindus saponaria L. & & + & & & & & & & & & & & & \\
\hline Solanaceae & 148 & Solanum laurifolium Mill. & & + & & & & & & & & & & & & \\
\hline Styracaceae & 149 & Styrax argenteus C. Presl & & & & & & & & + & & & & & & \\
\hline
\end{tabular}


Apéndice. Continúa.

\begin{tabular}{|c|c|c|c|c|c|c|c|c|c|c|c|c|c|c|c|c|c|}
\hline \multirow[b]{2}{*}{ Familia } & \multirow{2}{*}{\multicolumn{2}{|c|}{ Especie }} & \multicolumn{15}{|c|}{ Grupos } \\
\hline & & & $A 1$ & $A 2$ & $A 3$ & $B$ & $C$ & $D$ & $E$ & $F$ & $G$ & $H$ & $I$ & $J$ & $K$ & $L$ & $M$ \\
\hline Styracaceae & 150 & Styrax glabrescens Benth. & & + & + & & + & & & & & & & & & & \\
\hline Styracaceae & 151 & Styrax ramirezii Greenm. & & & & & & + & + & & & & & & & & \\
\hline Symplocaceae & 152 & $\begin{array}{l}\text { Symplocos citrea Lex. ex La } \\
\text { Llave et Lex. }\end{array}$ & & & & & & + & + & & & & & & & & \\
\hline Myrsinaceae & 153 & $\begin{array}{l}\text { Synardisia venosa (Mast.) } \\
\text { Lundell }\end{array}$ & & & & + & & & & & & & & & & & \\
\hline Taxaceae & 154 & Taxus globosa Schltdl. & & + & & & & & & & & & & & & & \\
\hline Pentaphylacaceae & 155 & $\begin{array}{l}\text { Ternstroemia huasteca B.M. } \\
\text { Barthol. }\end{array}$ & + & & & & & & & & & & & & & & \\
\hline Pentaphylacaceae & 156 & $\begin{array}{l}\text { Ternstroemia lineata subsp. } \\
\text { lineata }\end{array}$ & & & & + & & + & + & + & & & & & & & \\
\hline Pentaphylacaceae & 157 & $\begin{array}{c}\text { Ternstroemia sylvatica Schltdl. } \\
\text { et Cham. }\end{array}$ & & + & + & & + & & & & & & & & + & & \\
\hline Pentaphylacaceae & 158 & $\begin{array}{l}\text { Ternstroemia tepezapote } \\
\text { Schltdl. et Cham. }\end{array}$ & & & & + & & & & & & & & & & & \\
\hline Ticodendraceae & 159 & $\begin{array}{l}\text { Ticodendron incognitum } \\
\text { Gómez Laur. et L.D. Gómez }\end{array}$ & & & & & & & & & & + & & & & & \\
\hline Malvaceae & 160 & $\begin{array}{l}\text { Tilia americana L. var. } \\
\text { mexicana (Schltdl.) Hardin }\end{array}$ & & + & & & & + & & & & & & & & & \\
\hline Cannabaceae & 161 & $\begin{array}{c}\text { Trema micrantha }(\mathrm{L} .) \text { Blume } \\
\text { var. micrantha }\end{array}$ & & + & + & + & & & & & & & & & + & & \\
\hline Meliaceae & 162 & Trichilia havanensis Jacq. & + & + & & & & & & + & & & & & & + & \\
\hline Moraceae & 163 & Trophis chiapensis Brandegee & & & & + & & & & & & & & & & & \\
\hline Moraceae & 164 & $\begin{array}{c}\text { Trophis mexicana (Liebm.) } \\
\text { Bureau }\end{array}$ & + & & & + & & & & & & & & & & & \\
\hline Moraceae & 165 & Trophis racemosa (L.) Urb. & & + & & & & & & & & & & & & & \\
\hline Staphyleaceae & 166 & Turpinia insignis (Kunth) Tul. & & & + & & + & & & & & & & + & & & \\
\hline Staphyleaceae & 167 & $\begin{array}{l}\text { Turpinia occidentalis (Sw.) G. } \\
\text { Don subsp. occidentalis }\end{array}$ & + & + & & & & & & + & & & & & & & \\
\hline Ulmaceae & 168 & $\begin{array}{l}\text { Ulmus mexicana (Liebm.) } \\
\text { Planch. }\end{array}$ & & + & & & & & & & & & & & & & \\
\hline Ericaceae & 169 & Vaccinium leucanthum Schltdl. & + & + & & & & & & & & & & & & & \\
\hline Asteraceae & 170 & Verbesina apleura S.F. Blake & & & & + & & & & & & & & & & & \\
\hline Adoxaceae & 171 & Viburnum ciliatum Greenm. & + & & & & & & & & & & & & & & \\
\hline Adoxaceae & 172 & Viburnum hartwegii Benth. & & & & + & & & & & & & & & & & \\
\hline Adoxaceae & 173 & $\begin{array}{l}\text { Viburnum stenocalyx (Oerst.) } \\
\text { Hemsl. }\end{array}$ & & & & & & & & & + & & & & & & \\
\hline Adoxaceae & 174 & $\begin{array}{l}\text { Viburnum tiliifolium (Oerst.) } \\
\text { Hemsl. }\end{array}$ & + & & & & & & & & & & & & & & \\
\hline Cunoniaceae & 175 & Weinmannia pinnata $\mathrm{L}$. & & & & & & & & & & + & & & + & & \\
\hline Celastraceae & 176 & $\begin{array}{l}\text { Wimmeria concolor Schltdl. et } \\
\text { Cham. }\end{array}$ & & + & & & & & & & & & & & & & \\
\hline Salicaceae & 177 & $\begin{array}{c}\text { Xylosma flexuosa (Kunth) } \\
\text { Hemsl. }\end{array}$ & + & + & + & & & & & + & & & & & + & & \\
\hline Rutaceae & 178 & Zanthoxylum clava-herculis L. & + & & & & & & & & & & & & & & \\
\hline
\end{tabular}


Apéndice. Continúa.

\begin{tabular}{|c|c|c|c|c|c|c|c|c|c|c|c|c|c|c|c|c|}
\hline \multirow[b]{2}{*}{ Familia } & \multirow{2}{*}{\multicolumn{2}{|c|}{ Especie }} & \multicolumn{14}{|c|}{ Grupos } \\
\hline & & & $A 1$ & $A 2$ & $A 3$ & $B$ & $C$ & $D$ & $E$ & $F$ & $G$ & $H$ & $I$ & $J$ & $K$ & $M$ \\
\hline Rutaceae & 179 & $\begin{array}{l}\text { Zanthoxylum melanostictum } \\
\text { Schltdl. et Cham. }\end{array}$ & & & & & & & & & & + & & & & \\
\hline Rutaceae & 180 & Zanthoxylum xicense Miranda & + & & & & & & & & & & & & & \\
\hline Celastraceae & 181 & Zinowiewia concinna Lundell & & & & & & & & + & & & & & & \\
\hline
\end{tabular}

